\title{
LIGHT SCATTERING BY CRYSTALLINE POLYSTYRENE AND POLYPROPYLENE
}

\author{
PROEFSCHRIFT
}

TER VERKRIJGING VAN DE GRAAD VAN DOCTOR IN DE TECHNISCHE WETENSCHAPPEN AAN DE TECHNISCHE HOGESCHOOL DELFT OP GEZAG VAN DE RECTOR MAGNIFICUS DR. IR.C. J.D. M. VERHAGEN, HOOGLERAAR IN DE AFDELING DER TECHNISCHE NATUURKUNDE, VOOR EEN COMMISSIE UIT DE SENAAT TE VERDEDIGEN OP WOENSDAG 22 NOVEMBER 1967 TE 16 UUR

DOOR

\author{
ANTHONY EGIDIUS MARIA KEIJZERS \\ scheikundig ingenieur \\ geboren te Deurne
}

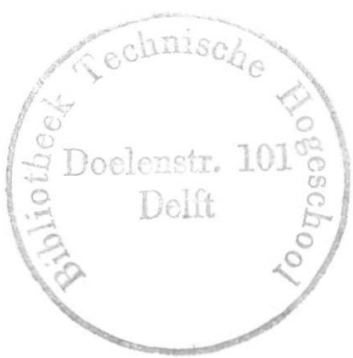

Druk: V.R.B.-Offsetdrukkerij - Groningen 1967 
DIT PROEFSCHRIFT IS GOEDGEKEURD DOOR DE PROMOTOR PROF. DR. W. PRINS 
Aan mijn vrouw 
Het onderzoek, in dit proefschrift beschreven, is verricht in nauwe samenwerking met dr.ir.J.J.van Aartsen, die ik hierbij mijn oprechte dank betuig.

Verder gaat mijn dank uit naar allen die mij in mijn werk behulpzaam zijn geweest, in het bijzonder de heren R.van Donselaar, J.G.Kennedy, H.C. Nieuwpoort en K. Sjoer voor hun steun bij de totstandkoming van de lichtverstrooiingsapparatuur. 
Chapter II THEORETICAL LIGHT SCATTERING CALCULATIONS

II-1 Introduction

II-2 Scattering by the "Random Orientation Model"

II-3 Scattering by Perfect Spherulites

II-4 Scattering by Imperfectly Spherulitic Samples; The Superposition of Random Orientation Crystallites and Perfectly Spherulitic Assemblies

II-5 Dependence of the Spherulitic Scattering on the Distribution of Spherulite Sizes

Chapter III CRYSTALLIZATION FROM THE MELT 26

III-1 The Mechanism of Crystallization 26

III-2 The Crystalline State of Isotactic Polystyrene and Isotactic Polypropylene

Chapter IV EXPERIMENTAL ARRANGEMENTS 30

IV - 1 Sample Preparation 30

IV-2 Light Scattering Instruments 30

Chapter V EVALUATION OF THE LIGHT SCATTERING MEASUREMENTS $\quad 38$

V-1 The Raw Data 38

V-2 Optical Corrections $\quad 39$

V-3 Separation of the Spherulite- and Random Orientation- Scattering

Chapter VI SPHERULITIC CRYSTALLIZATION OF ISOTACTIC POLYSTYRENE 44

VI-1 Results

VI-2 Discussion

Chapter VII LIGHT SCATTERING MEASUREMENTS ON ISOTACTIC POLYSTYRENE AND ISOTACTIC POLYPROPYLENE

VII-1 Results

VII-2 Discussion

Appendix I FRESNEL CORRECTIONS AND THE EXACT DEFINITION OF THE VECTOR $\underline{o}$ IN LIGHT SCATTERING THEORY

Appendix II "ALGOL 60" - PROGRAMS 
References

Summary

Samenvatting 


\section{INTRODUCTION}

The advent of highly crystalline synthetic polymers in the last decade has created a growing interest in the supermolecular ordering, leading to specific morphologic and crystallization behaviour. Obviously these structural characteristics have an important bearing upon the physical, e.g. mechanical, properties of these materials. General techniques which are commonly used in the investigation of the supermolecular ordering are optical microscopy, electron microscopy and diffraction, and low - as well as wide- angle $\mathrm{X}$-ray diffraction. In addition to these techniques, light scattering should in principle also be able to yield information about the supermolecular structure. One would expect this technique to be useful especially in the investigation of aggregates of crystallites of the order of $0.1 \mu$ to a few $\mu$.

Several investigators have already attempted to perform theoretical calculations of the light scattering by solid polymers. Debye and Bueche ${ }^{40}$, describing the scattering by amorphous polymers, introduced a radial density correlation function. Goldstein and Michalik ${ }^{41}$ ) extended the theory of Debye and Bueche for materials containing optically anisotropic regions. Because of their generality, the theoretical expressions obtained by these authors do not lend themselves easily to a confrontation with experimental data. Stein and Wilson ${ }^{6)}$, therefore, made some simplifying assumptions resulting in expressions, which could be handled much easier in connection with experimental data. These latter authors used the so called "random orientation model", which enabled a description of the light scattering by means of spherically symmetric correlation functions for the density and for the orientation of the anisotropic regions. Goldstein ${ }^{11)}$ as well as Stein $c, s_{.}{ }^{7,8}$ ) have also made calculations on a quite different model, the "perfect spherulite model". A perfect spherulite is a spherically symmetric assembly of crystallites with a fixed orientation of optical axes with respect to the radius.

Serious objections can be raised against these models, because they are not representative of the real structure of the polymers. Microscopical investigations have revealed that most polymers crystallize, forming non-perfect spherulites: from a spherulitically disordered centre fibrillar spherulitic crystallites grow in radial directions. At larger distances from the centre branching of these fibrillar crystallites and secondary crystallization in non-spherulitic arrays within the spherulite again may cause deviations from the perfect spherulite model.

Up to the present the quantitative evaluation of light scattering data from solid polymers met with serious difficulties because 
of the lack of a complete description of the scattering. Therefore there was little need for instrumentation specifically designed for highly accurate and quantitativelight scattering measurements on solid polymers.

In this thesis an attempt is made to give a quantitative description of the scattering by means of a combination model, consisting of a superposition of the random orientation model and the perfect spherulite model. In order to ensure accurate measurements of absolute scattering intensities, which are needed to test the applicability of the combination model, a special light scattering photometer is developed. The instrument yields absolute scattering intensities with a high angular resolution down to very small angles $\left(<0.5^{\circ}\right)$. The experimental light scattering data then may be evaluated to yield information regarding the growth rate of the spherulites and the nucleation density in spherulitic crystallization, and regarding the internal structure, crystallinity and birefringence of the spherulites; moreover, information regarding the secondary crystallization and the distribution of spherulite sizes can be obtained.

Chapter II gives theoretical calculations on the "random orientation model" (Section 2), the perfect spherulite model (Section 3) and the combination model (Section 4); the calculations on the combination model do not include interference effects between the aggregates of crystallites. Section 5 of Chapter II deals with the influence of the distribution of spherulite sizes on the scattering by spherulites.

In Chapter III, Section 1, a brief description of the mechanism of polymer crystallization is given; Section 2 lists the known data about the crystalline state of isotactic polystyrene and isotactic polypropylene.

In Chapter IV the experimental techniques are dealt with: the preparation of the samples (Section 1) and the development of the light scattering photometer (Section 2). Special attention is paid to creating a means of measuring the whole spatial scattering envelope.

In Chapters VI and VII the experimental light scattering data are first compared with the theoretical calculations in order to test the applicability of the combination model. Secondly, these chapters discuss which information can be obtained from the experiments about the crystallization and morphology.

In Chapter VI the crystallization experiments on isotactic polystyrene with a discussion of the results is given. In Chapter VII extensive light scattering measurements on isotactic polystyrene and isotactic polypropylene are reported. Conclusions regarding the internal structure and crystallinity of the spherulites, the birefringence of spherulitic and non-spherulitic crystallites, the secondary crystallization, and the size distribution of the spherulites are drawn in this final chapter. 


\section{THEORETICAL LIGHT SCATTERING CALCULATIONS}

\section{II-1. Introduction}

The theoretical calculations of the light scattering by model structures in this chapter are carried out on the basis of the Rayleigh-Gans theory $1,2,3)$. Although this theory is not universally valid, its validity is not in question for our samples. Figure 1 taken from Heller ${ }^{1)}$ shows the area within which the re-

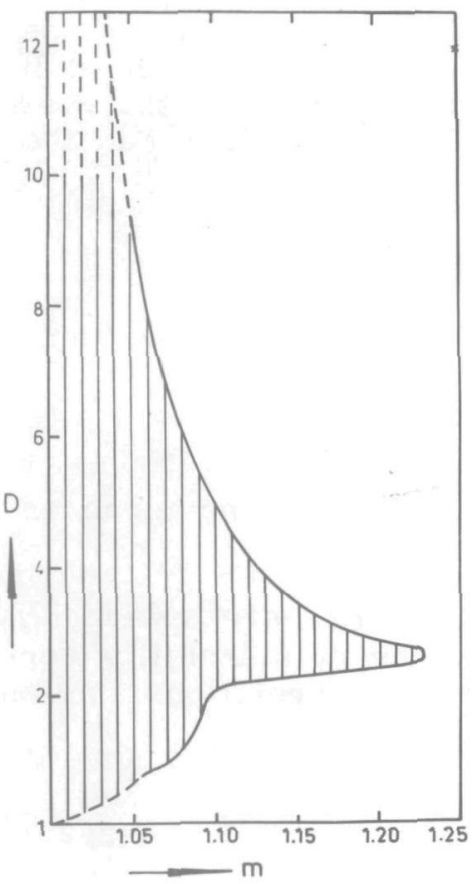

Fig. 1. The area within which the Rayleigh-Gans theory differs at most $5 \%$ from the Mie scattering theory. sults of the Rayleigh-Gans theory deviate at most $5 \%$ from the true values, obtained from the general light scattering theory of $\mathrm{Mie}^{5)}$. In this figure $m$ is the refractive index of the scattering units, relative to the medium, in which they are embedded, and $D=$ $\pi a / \lambda$, when $\lambda$ is the wavelength of the light in the medium and $a$ the characteristic dimension of the units. For our samples, the most unfavourable combinations are: $m=1.035 \quad D=12$, and $m=1.01 D=30$. Thus, although $D$ in the latter case is very large, the rather small value of $(m-1)$ compensates this.

The calculations are performed on two models: in Section 2 the "random orientation model" of Stein ${ }^{6,10)}$ is given and in Section 3 the perfect spherulite model. For the second model calculations have also been made by Goldstein ${ }^{11)}$ and Stein 7,8 ). In Section 4 is indicated how the spherulite- and "random orientation"- scattering can be separated, if in reality a combination of both models occurs. In this way a description is obtained for the usually imperfectly spherulitic crystallite assemblies occurring in crystallized polymer samples. Section 5 shows the dependence of the spherulite scattering on the distribution of spherulite radii.

\section{II-2. Scattering by the "Random Orientation Model"}

Stein, indeed, has already calculated the scattering by this 
10

model, but as the total scattering envelope should be known in Section 4 of this chapter, the derivation will be given here again in a somewhat more general way. Moreover, Stein ${ }^{7,8)}$ defines a vector $\underline{Q}$ (unit vector, perpendicular to the scattered beam and parallel to the polarization direction, which is transmitted by the analyser), which is not correct for the case of a fixed analyser, perpendicular to the transmitted primary beam, which is needed in our work. In Appendix I the correct definition of $\underline{O}$ and the allied problem of Fresnel reflections are dealt with.

The random orientation model of Stein can be defined as follows:

a. The scattering medium is thought to consist of a great number of small birefringent volume elements, the optical anisotropy of which is cylindrically symmetric: the polarizabilities in the principal direction of volume element $i$, defined by the unit vector $a_{\mathrm{i}}$, and in all directions perpendicular to $a_{i}$, are $\left(\alpha_{1 j}\right)_{i}$ and $\left(\alpha_{1}\right)_{i}$ respectively. For the mean polarizability $\alpha_{\mathrm{i}}$ and the anisotropy $\delta_{\mathrm{i}}$ of element $i$ can then be written:

$$
\alpha_{i}=\frac{1}{3}\left[\left(\alpha_{1}\right)_{i}+2\left(\alpha_{1}\right)_{i}\right] \text { and } \delta_{i}=\left(\alpha_{1}\right)_{i}-\left(\alpha_{1}\right)_{i}
$$

Further the polarizability and anisotropy fluctuations $\eta_{\mathrm{i}}$ and $\Delta_{\mathrm{i}}$ are defined by:

$$
\eta_{\mathrm{i}}=\alpha_{\mathrm{i}}-\alpha \text { and } \Delta_{\mathrm{i}}=\delta_{\mathrm{i}}-\delta
$$

where $\alpha$ and $\delta$ are the mean polarizability and the mean anisotropy of the sample.

b. There is no correlation between $\eta_{\mathrm{i}}$ and $\Delta_{\mathrm{i}}$.

c. The polarizability and anisotropy fluctuations are spherically symmetric. This can be expressed in the polarizability correlation function $\gamma(r)$ and the anisotropy correlation function $\Psi(r)$ :

$$
\begin{aligned}
& \gamma(r)=\frac{\left\langle\eta_{\mathrm{i}} \eta_{\mathrm{j}}\right\rangle_{\mathrm{r}}}{\left\langle\eta^{2}\right\rangle} \\
& \Psi(r)=\frac{\left\langle\Delta_{\mathrm{i}} \Delta_{\mathrm{j}}\right\rangle_{\mathrm{r}}}{\left\langle\Delta^{2}\right\rangle}
\end{aligned}
$$

where $\left\langle\eta_{i} \eta_{j}\right\rangle_{r}$ and $\left\langle\Delta_{i} \Delta_{j}\right\rangle_{r}$ represent the mean values of $\eta_{i} \eta_{j}$ and $\Delta_{i} \Delta_{j}$ respectively for all pairs of volume elements at a constant distance of separation $r ;\left\langle\eta^{2}\right\rangle$ and $\left\langle\Delta^{2}\right\rangle$ are the mean squares of the polarizability and the anisotropy fluctuations.

d. The scattering medium does not exhibit an overall macroscopic orientation.

e. The orientation fluctuation is. spherically symmetric ("random 
orientation fluctuation"); i.e., if $\theta_{\mathrm{ij}}$ is the angle between $\underline{a}_{\mathrm{i}}$ and $a_{j}, \cos ^{2} \theta_{i j}$ only depends on the length of $r_{i j}$ (the vector, that connects volume element $i$ with volume element $j$ ). This can be described by means of the orientation correlation function $f(r)$ :

$$
f(r)=\frac{\left.3<\cos ^{2} \theta_{\mathrm{ij}}\right\rangle_{\mathrm{r}}-1}{2}
$$

$\cos ^{2} \theta_{i j}>_{r}$ again represents the mean value of $\cos ^{2} \theta_{i j}$ for all pairs of volume elements at a constant separation $r$.

f. The axial ratio of the polarizability ellipsoid, $\alpha_{1,} / \alpha_{1}$, is a constant for all volume elements. As a consequence one has: $\Psi(r)=\gamma(r)$ and $\left\langle\Delta^{2}\right\rangle / \delta^{2}=\left\langle\eta^{2}\right\rangle / \alpha^{2}$.

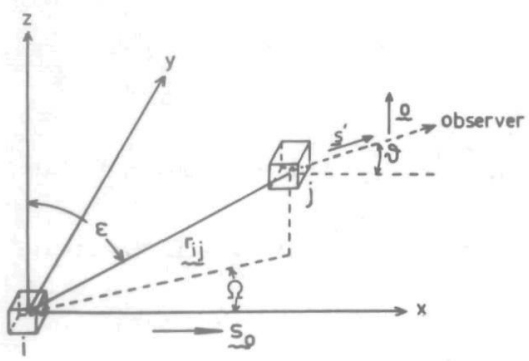

Figure 2. Schematic diagram of the scattering system.

Figure 2 is a schematic diagram of the scattering system, with the aid of which the scattering will be derived. The linearly polarized primary beam is parallel to the $X$-axis, and the scattered beam makes an angle $\theta$ with the $X$-axis. Starting point for the calculations is the well-known formula for the intensity $I$ of the scattered light ${ }^{9)}$ :

$$
I=\sum_{\mathrm{i}} \sum_{\mathrm{j}} A_{\mathrm{i}} A_{\mathrm{j}} \cos \left[k\left(\underline{r}_{\mathrm{ij}} \cdot \underline{\mathrm{s}}\right)\right]
$$

where $A_{\mathrm{i}}$ and $A_{\mathrm{j}}$ are the amplitudes of the scattered light from the $i^{\text {th }}$ and $j^{\text {th }}$ volume elements respectively, $k=2 \pi / \lambda, \lambda$ is the wavelength of the light in the scattering medium, and $\underline{s}=\underline{s}_{0}-\underline{s}^{\prime}$, where $\underline{s}_{0}$ and $\underline{s}^{\prime}$ are unit vectors in the direction of the primary and $\bar{s}$ cattere $\bar{d}$ beam respectively $(|\underline{s}|=2 \sin (\theta / 2)) . A_{\mathrm{i}}$ can be written as:

$$
A_{\mathrm{i}}=C\left(\underline{m}_{\mathrm{i}} * \underline{o}\right)
$$

since $\left(\underline{m}_{i} \cdot \underline{o}\right)$ is the component of the induced dipole moment $\underline{m}_{\mathrm{i}}$ in volume element $i$, which can be seen by the detector,

$$
\underline{m}_{\mathrm{i}}=\left(\alpha_{/ /}\right)_{\mathrm{i}}\left(\underline{E} \cdot \underline{a}_{\mathrm{i}}\right) \underline{a}_{\mathrm{i}}+\left(\alpha_{\perp}\right)_{\mathrm{i}}\left(\underline{E}-\left(\underline{E} \cdot \underline{a}_{\mathrm{i}}\right) \underline{a}_{\mathrm{i}}\right)=\delta_{\mathrm{i}}\left(\underline{E} \cdot \underline{a}_{\mathrm{i}}\right) \underline{a}_{\mathrm{i}}+\left(\alpha_{\perp}\right)_{\mathrm{i}} \underline{E}
$$

$C=4 \pi^{2} /\left(R \lambda_{0}^{2}\right)$, where $R$ is the distance between scattering point and observer and $\lambda_{0}$ the wavelength of the light in vacuum; $\underline{E}$ is the effective electric field of the incident light. When $\psi$ is the angle between the transmittance direction of the polarizer and the $Z$-axis (see figure 3 ) $\underline{E}$ will be:

$$
\underline{E}=(-\sin \psi \cdot \underline{j}+\cos \psi \cdot \underline{k}) E_{\mathrm{o}}
$$


12

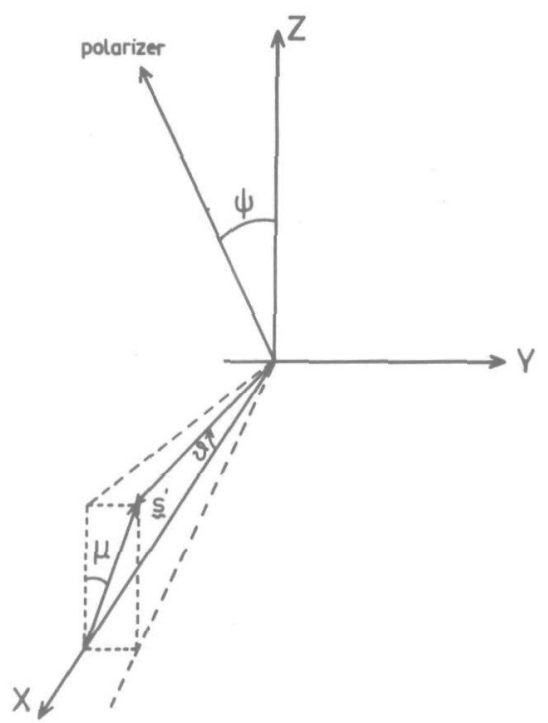

Figure 3. Diagram defining the directions' of the polarizer axis and the scattered beam. $i, j$ and $k$ are the unit vectors in the $X$-, $Y$ - and $Z$-directions respectivēly.

So:

$$
\begin{aligned}
\underline{m}_{i}=\delta_{i} & {\left[-\sin \psi\left(\underline{a}_{i} \cdot \underline{j}\right) \underline{a}_{i}+\cos \psi\left(\underline{a}_{i} \cdot \underline{k}\right) \underline{a}_{i}\right]+} \\
& +\left(\alpha_{\perp}\right)_{i}[-\sin \psi \cdot \underline{j}+\cos \psi \cdot \underline{k}]
\end{aligned}
$$

If we use the general expression for $\underline{o}$ :

$$
\underline{o}=x_{1} \underline{i}+x_{2} \underline{j}+x_{3} \underline{k}
$$

$A_{\mathrm{i}}$ will become:

$$
\begin{aligned}
A_{\mathrm{i}}=C \delta_{\mathrm{i}} & -x_{1} \sin \psi\left(\underline{a}_{\mathrm{i}} \cdot \underline{j}\right)\left(\underline{a}_{\mathrm{i}} \cdot \underline{i}\right)-x_{2} \sin \psi\left(\underline{a}_{\mathrm{i}} \cdot \underline{j}\right)^{2}+ \\
& -x_{3} \sin \psi\left(\underline{a}_{\mathrm{i}} \cdot \underline{j}\right)\left(\underline{a}_{\mathrm{i}} \cdot \underline{k}\right)+x_{1} \cos \psi\left(\underline{a}_{\mathrm{i}} \cdot \underline{k}\right)\left(\underline{a}_{\mathrm{i}} \cdot \underline{i}\right)+ \\
& \left.+x_{2} \cos \psi\left(\underline{a}_{\mathrm{i}} \cdot \underline{k}\right)\left(\underline{a}_{\mathrm{i}} \cdot \underline{j}\right)+x_{3} \cos \psi\left(\underline{a}_{\mathrm{i}} \cdot \underline{k}\right)^{2}\right]+ \\
& +C\left(\alpha_{\perp}\right)_{\mathrm{i}}\left[-x_{2} \sin \psi+x_{3} \cos \psi\right]
\end{aligned}
$$

An analogous equation holds for $A_{\mathrm{j}}$. For the random orientation model the mean values of the following scalar products of vectors are:

$$
\left(\underline{a}_{\mathrm{i}} \cdot \underline{k}\right)^{2}\left(\underline{a}_{\mathrm{j}} \cdot \underline{k}\right)\left(\underline{a}_{\mathrm{j}} \cdot \underline{j}\right)=\overline{\left(\underline{a}_{\mathrm{i}} \cdot \underline{i}\right)^{2}\left(\underline{a}_{\mathrm{j}} \cdot \underline{i}\right)\left(\underline{a}_{\mathrm{j}} \cdot \underline{k}\right)}=\overline{\left(\underline{a}_{\mathrm{i}} \cdot \underline{j}\right)^{2}\left(\underline{a}_{\mathrm{j}} \cdot \underline{j}\right)\left(\underline{a}_{\mathrm{j}} \cdot \underline{i}\right)}=0
$$


$\overline{\left(\underline{a}_{\mathrm{i}} \cdot \underline{k}\right)^{2}\left(\underline{a}_{\mathrm{j}} \cdot \underline{k}\right)\left(\underline{a}_{\mathrm{j}} \cdot \underline{i}\right)}=\overline{\left(\underline{a}_{\mathrm{i}} \cdot \underline{i}\right)^{2}\left(\underline{a}_{\mathrm{j}} \cdot \underline{i}\right)\left(\underline{a}_{\mathrm{j}} \cdot \underline{j}\right)}=\overline{\left(\underline{a}_{\mathrm{i}} \cdot \underline{j}\right)^{2}\left(\underline{a}_{\mathrm{j}} \cdot \underline{j}\right)\left(\underline{a}_{\mathrm{j}} \cdot \underline{k}\right)}=0$

$\overline{\left(\underline{a}_{\mathrm{i}} \cdot \underline{k}\right)^{2}\left(\underline{a}_{\mathrm{j}} \cdot \underline{j}\right)\left(\underline{a}_{\mathrm{j}} \cdot \underline{i}\right)}=\overline{\left(\underline{a}_{\mathrm{i}} \cdot \underline{i}\right)^{2}\left(\underline{a}_{\mathrm{j}} \cdot \underline{k}\right)\left(\underline{a}_{\mathrm{j}} \cdot \underline{j}\right)}=\overline{\left(\underline{a}_{\mathrm{i}} \cdot \underline{j}\right)^{2}\left(\underline{a}_{\mathrm{j}} \cdot \underline{i}\right)\left(\underline{a}_{\mathrm{j}} \cdot \underline{k}\right)}=0$

$\overline{\left(\underline{a}_{i} \cdot \underline{k}\right)^{2}\left(\underline{a}_{\mathrm{j}} \cdot \underline{k}\right)^{2}}=\overline{\left(\underline{a}_{\mathrm{i}} \cdot \underline{i}\right)^{2}\left(\underline{a}_{\mathrm{j}} \cdot \underline{i}\right)^{2}}=\overline{\left(\underline{a}_{\mathrm{i}} \cdot \underline{k}\right)^{2}\left(\underline{a}_{\mathrm{j}} \cdot \underline{k}\right)^{2}}=$

$=\frac{1}{15}\left(2 \cos ^{2} \theta_{i j}+1\right)=\frac{1}{30}\left(3 \cos ^{2} \theta_{i j}-1\right)+\frac{1}{30}\left(\cos ^{2} \theta_{i j}+3\right)$

$\overline{\left(\underline{a}_{\mathrm{i}} \cdot \underline{k}\right)^{2}\left(\underline{a}_{\mathrm{j}} \cdot \underline{j}\right)^{2}}=\overline{\left(\underline{a}_{\mathrm{i}} \cdot \underline{i}\right)^{2}\left(\underline{a}_{\mathrm{j}} \cdot \underline{k}\right)^{2}}=\overline{\left(\underline{a}_{\mathrm{i}} \cdot \underline{j}\right)^{2}\left(\underline{a}_{\mathrm{j}} \cdot \underline{i}\right)^{2}}=$

$=\frac{1}{15}\left(2-\cos ^{2} \theta_{i j}\right)=-\frac{1}{30}\left(3 \cos ^{2} \theta_{i j}-1\right)+\frac{1}{30}\left(\cos ^{2} \theta_{i j}+3\right)$

$\overline{\left(\underline{a}_{\mathrm{i}} \cdot \underline{k}\right)\left(\underline{a}_{\mathrm{i}} \cdot \underline{i}\right)\left(\underline{a}_{\mathrm{j}}-\underline{k}\right)\left(\underline{a}_{\mathrm{j}} \cdot \underline{i}\right)}=\overline{\left(\underline{a}_{\mathrm{i}} \cdot \underline{j}\right)\left(\underline{a}_{\mathrm{i}} \cdot \underline{i}\right)\left(\underline{a}_{\mathrm{j}} \cdot \underline{j}\right)\left(\underline{a}_{\mathrm{j}} \cdot \underline{i}\right)}=$

$=\overline{\left(\underline{a}_{\mathrm{i}} \cdot \underline{k}\right)\left(\underline{a}_{\mathrm{i}} \cdot \underline{j}\right)\left(\underline{a}_{\mathrm{j}} \cdot \underline{k}\right)\left(\underline{a}_{\mathrm{j}} \cdot \underline{j}\right)}=\frac{1}{30}\left(3 \cos ^{2} \theta_{\mathrm{ij}}-1\right)$

$\overline{\left(\underline{a}_{\mathrm{i}} \cdot \underline{\underline{k}}\right)^{2}}=\overline{\left(\underline{a}_{\mathrm{i}} \cdot \underline{\underline{j}}\right)^{2}}=\overline{\left(\underline{a}_{\mathrm{i}} \cdot \underline{i}\right)^{2}}=\overline{\left(\underline{a}_{\mathrm{j}} \cdot \underline{\underline{k}}\right)^{2}}=\overline{\left(\underline{a}_{\mathrm{j}} \cdot \underline{j}\right)^{2}}=\overline{\left(\underline{a}_{\mathrm{j}} \cdot \underline{\underline{i}}\right)^{2}}=\frac{1}{3}$

Vector products where $\underline{a}_{\mathrm{i}}$ and $\underline{a}_{\mathrm{j}}$ have changed places give the same results. In this way the ratio of the intensities of the scattered and incident light, $I / I_{0}$, using equations (2.2.4), (2.2.10) and (2.2.11) through $(2.2 .17)$ as well as the analogous expressions where $\underline{a}_{\mathrm{i}}$ and $\underline{a}_{\mathrm{j}}$ have changed places, becomes:

$\frac{I}{I_{\mathrm{o}}}=C^{2 \cdot} \sum_{\mathrm{i}} \sum_{\mathrm{j}}\left[\delta_{\mathrm{i}} \delta_{\mathrm{j}} \frac{1}{30}\left(3 \cos ^{2} \theta_{\mathrm{ij}}-1\right)\left(x_{1}^{2}+x_{2}^{2}+x_{3}^{2}\right)+\right.$

$+\left\{\delta_{i} \delta_{j} \frac{1}{30}\left(\cos ^{2} \theta_{i j}+3\right)+\frac{1}{3}\left(\delta_{i}\left(\alpha_{\perp}\right)_{j}+\delta_{j}\left(\alpha_{\perp}\right)_{i}\right)+\right.$

$\left.\left.+\left(\alpha_{\perp}\right)_{1}\left(\alpha_{\perp}\right)_{j}\right\}\left\{-x_{2} \sin \psi+x_{3} \cos \psi\right\}^{2}\right] \cos \left[k\left(\underline{r}_{\mathrm{ij}} \cdot \underline{s}\right)\right]$

or

$\frac{I}{I_{\mathrm{o}}}=4 \pi C^{2} \int_{0}^{\infty}\left[\left\langle\delta_{\mathrm{i}} \delta_{\mathrm{j}}\right\rangle_{\mathrm{r}} \frac{1}{30}\left(<3 \cos ^{2} \theta_{\mathrm{ij}}\right\rangle_{\mathrm{r}}-1\right)\left(x_{1}^{2}+x_{2}^{2}+x_{3}^{2}\right)+$

$+\left\{\left\langle\delta_{\mathrm{i}} \delta_{\mathrm{j}}\right\rangle_{\mathrm{r}} \frac{1}{30}\left(<\cos ^{2} \theta_{\mathrm{ij}}\right\rangle_{\mathrm{r}}+3\right)+\frac{1}{3}\left(\left\langle\delta_{\mathrm{i}}\left(\alpha_{\perp}\right)_{\mathrm{j}}\right\rangle_{\mathrm{r}}+\left\langle\delta_{\mathrm{j}}\left(\alpha_{\perp}\right)_{\mathrm{i}}\right\rangle_{\mathrm{r}}\right)+$

$\left.\left.+\left\langle\left(\alpha_{\perp}\right)_{\mathrm{i}}\left(\alpha_{\perp}\right)_{\mathrm{j}}\right\rangle_{\mathrm{r}}\right\}\left\{-x_{2} \sin \psi+x_{3} \cos \psi\right\}^{2}\right\rfloor \frac{\sin (h r)}{h r} r^{2} \mathrm{~d} r$ 
14

where $h=2 k \sin (\theta / 2)$.

\section{II-3. Scattering by Perfect Spherulites}

In this section the scattering by a perfect spherulite will be calculated. A perfect spherulite is a spherical aggregate of birefringent crystallites, the optical axes of which make a constant angle with the radius of the sphere. For brevity's sake, we will henceforth use "spherulite", when we mean "perfect spherulite".

The electrical vector of the linearly polarized incident light is given by:

$$
\underline{E}=E_{\circ}[-\sin \psi \underline{j}+\cos \psi \cdot \underline{k}]=E_{\mathrm{o}} \underline{t}_{\mathrm{p}}
$$

The optical axis $c$ of a volume element in the spherulite can be written as (see figure 4 ):

$$
\begin{aligned}
\underline{c}= & {[(\cos \beta \sin \epsilon+\sin \beta \cos \omega \cos \epsilon) \cos \Omega+\sin \beta \sin \omega \sin \Omega] \underline{i}+} \\
& +[(\cos \beta \sin \epsilon+\sin \beta \cos \omega \cos \epsilon) \sin \Omega-\sin \beta \sin \omega \cos \Omega] \underline{j}+ \\
& +[\cos \beta \cos \epsilon-\sin \beta \cos \omega \sin \epsilon] \underline{k}
\end{aligned}
$$

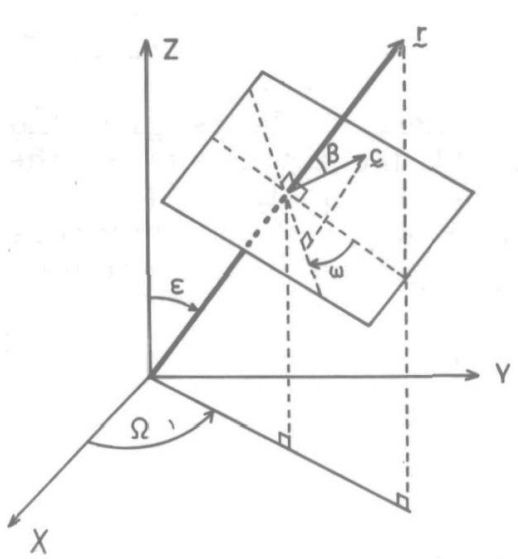

Figure 4. Coordinate system for the calculation of the spherulitic scattering.

where $\beta$ is the angle between the optical axis $c$ and the radius vector $r, \omega$ the angle between the projection of the optical axis $\underline{c}$ on a plane, perpendicular to $\underline{r}$, and the plane through $r$ and the $Z$-axis; $\epsilon$ is the angle between $r$ and the $Z$-axis, and $\Omega$ the angle between the projection of $r$ on the $X Y$-plane and the $X$-axis.

The induced dipole moment $\underline{m}$ is given by:

$$
\underline{m}=\alpha_{1}(\underline{E} \cdot \underline{c}) \underline{c}+\alpha_{2}(\underline{E} \cdot \underline{b}) \underline{b}
$$

$\alpha_{1}$ and $\alpha_{2}$ are the polarizabilities in the direction of $\underline{c}$ and perpendicular to $c$ respectivēly; $\underline{b}$ is a unit vector perpendicular to $\underline{c}$ in the plane through $\underline{c}$ and $\underline{E}$. So with (2.3.1) vector $\underline{b}$ can be expressed as:

$$
\underline{b}=\left[1-\left(\underline{c} \cdot \underline{t}_{\mathrm{p}}\right)^{2}\right]^{-\frac{1}{2}}\left[\underline{t}_{\mathrm{p}}-\left(\underline{c} \cdot \underline{t}_{\mathrm{p}}\right) \underline{c}\right]
$$


Substituting (2.3.4) into (2.3.3) and using (2.3.1) for $\underline{E}$, the induced dipole moment $\underline{m}$ can be found to be:

$$
\begin{aligned}
\underline{m}= & {[-\sin \psi(\underline{c} \cdot \underline{j})+\cos \psi(\underline{c} \cdot \underline{k})]\left(\alpha_{1}-\alpha_{2}\right) E_{\mathrm{o}} \underline{c}+} \\
& +\alpha_{2} E_{\mathrm{o}}[-\sin \psi \cdot \underline{j}+\cos \psi \cdot \underline{k}]
\end{aligned}
$$

The phase factor $\cos [k(\underline{r} \cdot \underline{s})]$ can be written as:

$\cos [k(r \cdot \underline{s})]=\cos [h r(\cos \delta \sin \epsilon \sin (\Omega-\gamma)+\sin \delta \cos \epsilon)]$ where

$$
\begin{aligned}
\cos \delta \sin \gamma & =\sin (\theta / 2) \\
\cos \delta \cos \gamma & =\cos (\theta / 2) \sin \mu \\
\sin \delta & =\cos (\theta / 2) \cos \mu
\end{aligned}
$$

The amplitude of the scattered light can be calculated from equation $(2.3 .10)$ :

where

$$
E_{s} \sim \frac{3}{U^{3}} \int_{0}^{\mathrm{U}} \int_{0}^{\pi} \int_{0}^{2 \pi}(\underline{m} \cdot \underline{\underline{o}}) \sin \epsilon \cos [k(\underline{r} \cdot \underline{s})] \mathrm{d} \Omega \mathrm{d} \epsilon q^{2} \mathrm{~d} q(2.3 .10)
$$

$$
U=\frac{4 \pi \sin (\theta / 2)}{\lambda} R_{\mathrm{sf}}
$$

with $R_{\mathrm{sf}}$ the radius of the spherulite.

Using the general expression for $\underline{o}$ in equation (2.2.9) the pro$\operatorname{duct}(\underline{m} \cdot \underline{o})$ can be found from $(2, \overline{3}, 5)$ :

$$
\begin{aligned}
(\underline{m} \cdot \underline{o})= & \left(\alpha_{1}-\alpha_{2}\right) E_{0}\left[-x_{1} \sin \psi(\underline{c} \cdot \underline{j})(\underline{c} \cdot \underline{i})-x_{2} \sin \psi(\underline{c}, \underline{j})^{2}+\right. \\
& +\left(x_{2} \cos \psi-x_{3} \sin \psi\right)(\underline{c} \cdot \underline{j})(\underline{c} \cdot \underline{k})+x_{1} \cos \psi(\underline{c} \cdot \underline{k})(\underline{c}, \underline{i})+ \\
& \left.+x_{3} \cos \psi(\underline{c} \cdot \underline{k})^{2}\right]+\alpha_{2} E_{0}\left[-x_{2} \sin \psi+x_{3} \cos \psi\right]
\end{aligned}
$$

If it is assumed that the angle $\omega$ varies randomly, which means that $\frac{\sin \omega}{\sin \omega}=0$ and $\overline{\sin ^{2} \omega}=\overline{\cos ^{2} \omega}=\frac{1}{2}$, the following products yield:

$$
\begin{aligned}
(\underline{c} \cdot \underline{j})(\underline{c} \cdot \underline{i}) & =\frac{1}{2}\left(3 \cos ^{2} \beta-1\right) \sin ^{2} \epsilon \sin \Omega \cos \Omega \\
(\underline{c} \cdot \underline{j})(\underline{c} \cdot \underline{k}) & =\frac{1}{2}\left(3 \cos ^{2} \beta-1\right) \sin \epsilon \cos \epsilon \sin \Omega \\
(\underline{c} \cdot \underline{i})(\underline{c} \cdot \underline{k}) & =\frac{1}{2}\left(3 \cos ^{2} \beta-1\right) \sin \epsilon \cos \epsilon \cos \Omega \\
(\underline{c} \cdot \underline{j})^{2} & =\frac{1}{2}\left(3 \cos ^{2} \beta-1\right) \sin ^{2} \epsilon \sin ^{2} \Omega+\frac{1}{2} \sin ^{2} \beta \\
(\underline{c} \cdot \underline{k})^{2} & =\frac{1}{2}\left(3 \cos ^{2} \beta-1\right) \cos ^{2} \epsilon+\frac{1}{2} \sin ^{2} \beta
\end{aligned}
$$


16

The solution of the integrals, required for the elaboration of equation (2.3.10), will be as follows:

$\frac{3}{U^{3}} \int_{0}^{\mathrm{U}} \int_{0}^{\pi} \int_{0}^{2 \pi} \sin ^{2} \epsilon \sin \Omega \cos \Omega \sin \epsilon \cos [k(\underline{r} \cdot \underline{s})] \mathrm{d} \Omega \mathrm{d} \epsilon q^{2} \mathrm{~d} q=$

$=2 \pi \sin \gamma \cos \gamma\left(2 I_{3}-I_{1}\right)$

$\frac{3}{U^{3}} \int_{0}^{\mathrm{U}} \int_{0}^{\pi} \int_{0}^{2 \pi} \sin \epsilon \cos \epsilon \sin \Omega \sin \epsilon \cos [k(\underline{r} \cdot \underline{s})] \mathrm{d} \Omega \mathrm{d} \epsilon q^{2} \mathrm{~d} q=-2 \pi \cos \gamma I_{4}$

$\frac{3}{U^{3}} \int_{0}^{\mathrm{U}} \int_{0}^{\pi} \int_{0}^{2 \pi} \sin \epsilon \cos \epsilon \cos \Omega \sin \epsilon \cos [k(\underline{r} \cdot \underline{s})] \mathrm{d} \Omega \mathrm{d} \epsilon q^{2} \mathrm{~d} q=2 \pi \sin \gamma I_{4}$

$\frac{3}{U^{3}} \int_{0}^{U} \int_{0}^{\pi} \int_{0}^{2 \pi} \cos ^{2} \epsilon \sin \epsilon \cos [k(\underline{r} \cdot \underline{s})] \mathrm{d} \Omega \mathrm{d} \epsilon q^{2} \mathrm{~d} q=2 \pi\left(I_{2}-I_{1}\right)$

where

$$
\begin{aligned}
& I_{1}=2\left[S_{3}-S_{1}-S_{2} \sin ^{2} \delta\right] \\
& I_{2}=2 S_{3} \\
& I_{3}=2 S_{1} \\
& I_{4}=-2 \sin \delta \cos \delta S_{2}
\end{aligned}
$$

and

$$
\begin{aligned}
S_{1} & =\frac{3(\operatorname{Si} U-\sin U)}{U^{3}} \\
S_{2} & =\frac{3(4 \sin U-U \cos U-3 \operatorname{Si} U)}{U^{3}} \\
S_{3} & =\frac{3(\sin U-U \cos U)}{U^{3}} \\
\operatorname{Si} U & =\int_{0}^{U} \frac{\sin x}{x} d x
\end{aligned}
$$

Now the amplitude $E_{\mathrm{s}}$ of the light, scattered by a spherulite, from equation (2.3.10) will become: 


$$
\begin{aligned}
E_{\mathrm{s}} \sim & 4 \pi E_{\mathrm{o}}\left(\alpha_{1}-\alpha_{2}\right)\left(\frac{3 \cos ^{2} \beta-1}{2}\right) S_{2}\left[x_{1} \sin \psi \sin \gamma \cos \gamma \cos ^{2} \delta+\right. \\
& -x_{2} \sin \psi \cos ^{2} \gamma \cos ^{2} \delta+x_{3} \cos \psi \sin ^{2} \delta+ \\
& \left.-\left\{\left(x_{3} \sin \psi-x_{2} \cos \psi\right) \cos \gamma+x_{1} \cos \psi \sin \gamma\right\} \sin \delta \cos \delta\right]+ \\
& +4 \pi E_{\mathrm{o}}\left[\left\{\alpha_{2}+\frac{1}{2}\left(\alpha_{1}-\alpha_{2}\right) \sin ^{2} \beta\right\} S_{4}+\left(\alpha_{1}-\alpha_{2}\right)\left(\frac{3 \cos ^{2} \beta-1}{2}\right) S_{1}\right] \\
& \left(-x_{2} \sin \psi+x_{3} \cos \psi\right)
\end{aligned}
$$

If

and

$$
A=4 \pi\left(\alpha_{1}-\alpha_{2}\right)\left(\frac{3 \cos ^{2} \beta-1}{2}\right) S_{2}
$$

$$
B=4 \pi\left[\left\{\alpha_{2}+\frac{1}{2} \sin ^{2} \beta\left(\alpha_{1}-\alpha_{2}\right)\right\} S_{3}+\left(\alpha_{1}-\alpha_{2}\right)\left(\frac{3 \cos ^{2} \beta-1}{2}\right) S_{1}\right]
$$

it is found that the ratio of the scattered and primary intensities $I / I_{0}$ will be:

$$
\begin{aligned}
I / I_{\mathrm{o}}= & \left(E_{\mathrm{s}} / E_{\mathrm{o}}\right)^{2}=P^{2}\left[A \left\{x_{1} \sin \psi \sin (\theta / 2) \cos (\theta / 2) \sin \mu+\right.\right. \\
& -x_{2} \sin \psi \cos ^{2}(\theta / 2) \sin ^{2} \mu+x_{3} \cos \psi \cos ^{2}(\theta / 2) \cos ^{2} \mu+ \\
& -\left(x_{3} \sin \psi-x_{2} \cos \psi\right) \cos ^{2}(\theta / 2) \sin \mu \cos \mu+ \\
& \left.\left.-x_{1} \cos \psi \sin (\theta / 2) \cos (\theta / 2) \cos \mu\right\}+B\left\{-x_{2} \sin \psi+x_{3} \cos \psi\right\}\right]^{2}
\end{aligned}
$$

where $P$ is a constant, given by:

$$
P=\frac{4}{3} \pi R_{\mathrm{sf}}^{3} \cdot \frac{\pi}{R} \lambda_{\mathrm{o}}^{2}
$$

II-4. Scattering by Imperfectly Spherulitic Samples; The Superposition of Random Orientation Crystallites and Perfectly Spherulitic Assemblies

For the calculation of the scattering by these samples, it is assumed that the intensities of the random orientation model and the spherulites are additive.

As derived in Appendix I for parallel polarizer and analyser the components of vector $\underline{0}$, defined by equation (2.2.9), will be for $\underline{o}_{s / 1}^{*}$, as defined in Appendix I:

$$
x_{1}=\frac{1}{N_{n}}[-\cos (\mu+\psi) \sin \theta]
$$


$x_{2}=\frac{1}{N_{l \prime}}\left[\cos (\mu+\psi) \cos \theta \sin \mu-\cos \theta_{\mathrm{p}}^{*} \sin (\mu+\psi) \cos \mu\right]$

$x_{3}=\frac{1}{N_{\| \prime}}\left[\cos (\mu+\psi) \cos \theta \cos \mu-\cos \theta_{\mathrm{p}}^{*} \sin (\mu+\psi) \sin \mu\right]$

$N_{\| \prime}=\left[R_{\mathrm{p}}^{2} \cos ^{2}(\mu+\psi)+R_{\mathrm{q}}^{2} \cos ^{2} \theta_{\mathrm{p}}^{*} \sin ^{2}(\mu+\psi)\right]^{\frac{1}{2}}$

For crossed polarizer and analyser, Appendix I shows the components of $\underline{o}_{s+}^{*}$ to be:

$x_{1}=\frac{1}{N_{+}}[-\sin (\mu+\psi) \sin \theta]$

$x_{2}=\frac{1}{N_{+}}\left[\sin (\mu+\psi) \cos \theta \sin \mu+\cos \theta_{\mathrm{p}}^{*} \cos (\mu+\psi) \cos \mu\right]$

$x_{3}=\frac{1}{N_{+}}\left[\sin (\mu+\psi) \cos \theta \cos \mu-\cos \theta_{\mathrm{p}}^{*} \cos (\mu+\psi) \sin \mu\right]$

$N_{+}=\left[R_{\mathrm{p}}^{2} \sin ^{2}(\mu+\psi)+R_{\mathrm{q}}^{2} \cos ^{2} \theta_{\mathrm{p}}^{*} \cos ^{2}(\mu+\psi)\right]^{\frac{1}{2}}$

$\theta_{\mathrm{p}}^{*}$ is a somewhat modified scattering angle within the Polaroid analyser, defined by equation (a.1.15) in Appendix I. Besides, as mentioned in Appendix $I$, the vectors $\underline{o}_{s / /}^{*}$ and $\underline{o}_{s+}^{*}$, used here, are not true unit vectors because in these vectors is already accounted for the corrections due to Fresnel reflection of the scattered ray, when leaving the sample and entering and leaving the Polaroid analyser.

Using the foregoing expressions for $x_{1}, x_{2}$ and $x_{3}$, the scattered intensities of the spherulitic and random orientation- part can be calculated from equations $(2.3 .33)$ and $(2.2 .19)$ respectively.

Expressed in terms of Rayleigh ratios (defined by equation (4.2.1) in Chapter IV) the intensities of the spherulitic part for crossed and parallel polarizer and analyser will be given by $(2.4 .9)$ and $(2.4 .10)$ respectively:

$$
\begin{aligned}
\Re_{+}^{\text {sf }} & =\frac{\kappa \sin ^{2}(\mu+\psi) \cos ^{2}(\mu+\psi)}{R_{\mathrm{p}}^{2} \sin ^{2}(\mu+\psi)+R_{\mathrm{q}}^{2} \cos ^{2} \theta_{\mathrm{p}}^{*} \cos ^{2}(\mu+\psi)}\left[A \cos ^{2}(\theta / 2)+B(\cos \theta+\right. \\
& \left.\left.-\cos \theta_{\mathrm{p}}^{*}\right)\right]^{2}
\end{aligned}
$$




$$
\begin{aligned}
\Re_{\|}^{\text {sf }} & =\frac{\kappa}{R_{\mathrm{p}}^{2} \cos ^{2}(\mu+\psi)+R_{\mathrm{q}}^{2} \cos ^{2} \theta_{\mathrm{p}}^{*} \sin ^{2}(\mu+\psi)}\left[A \cos ^{2}(\theta / 2) \cos ^{2}(\mu+\psi)+\right. \\
& \left.+B\left\{\cos \theta \cos ^{2}(\mu+\psi)+\cos \theta_{\mathrm{p}}^{*} \sin ^{2}(\mu+\psi)\right\}\right]^{2}
\end{aligned}
$$

where

$$
\kappa=N_{\mathrm{sf}}\left(\frac{4}{3} \pi R_{\mathrm{sf}}^{3}\right)^{2} \cdot \frac{\pi^{2}}{\lambda_{\mathrm{o}}^{4}}
$$

$N_{\text {sf }}$ is the number of spherulites per $\mathrm{cm}^{3}$.

Equation (2.4.9) exhibits the well-known four-leaf clover pattern of spherulitic scattering for crossed polarizer and analyser (see figure 14); in the expression, given by $S$ tein ${ }^{7,8)}$, the term $B\left(\cos \theta-\cos \theta_{\mathrm{p}}^{*}\right)$ does not occur because of the difference in the definition of $o$. For small scattering angles Stein's expression holds rather well, for in that case $\left(\cos \theta-\cos \theta_{\mathrm{p}}^{*}\right)$ is very small. Only at larger angles there is an important difference between Stein's and our results (values of $\left(\cos \theta-\cos \theta_{\mathrm{p}}^{* *}\right)$ for $\theta=10^{\circ}, 20^{\circ}$ and $25^{\circ}$ are about $0.02,0.10$ and 0.16 respectively). Now we define the various components of the scattered light as follows: For the parallel position of polarizer and analyser the component, measured at $\mu=90^{\circ}$ and $\psi=0^{\circ}$ is called $V_{\mathrm{v}}$, and at $\mu=90^{\circ}$ and $\psi=90^{\circ} H_{\mathrm{h}}$. For the crossed position the measured components are $H_{\mathrm{v}}$ for $\mu=90^{\circ}$ and $\psi=0^{\circ}, V_{\mathrm{h}}$ for $\mu=90^{\circ}$ and $\psi=90^{\circ}$ and $K_{\mathrm{d}}$ for $\mu=90^{\circ}$ and $\psi=45^{\circ}$.

These different components can be calculated from (2.4.9) and (2.4.10) for the spherulitic part of the scattering:

$$
\begin{aligned}
\left(V_{\mathrm{v}}\right)_{\mathrm{sf}}= & \frac{\kappa B^{2}}{R_{\mathrm{q}}^{2}} \\
\left(H_{\mathrm{h}}\right)_{\mathrm{sf}}= & \frac{\kappa}{R_{\mathrm{p}}^{2}}\left[A^{2} \cos ^{4}(\theta / 2)+2 A B \cos ^{2}(\theta / 2) \cos \theta+B^{2} \cos ^{2} \theta\right](2 . \\
\left(H_{\mathrm{v}}\right)_{\mathrm{sf}}= & \left(V_{\mathrm{h}}\right)_{\mathrm{sf}}=0 \\
\left(K_{\mathrm{d}}\right)_{\mathrm{sf}}= & \frac{\kappa}{2\left(R_{\mathrm{p}}^{2}+R_{\mathrm{q}}^{2} \cos ^{2} \theta_{\mathrm{p}}^{*}\right)}\left[A^{2} \cos ^{4}(\theta / 2)+\right. \\
& \left.+2 A B \cos ^{2}(\theta / 2)\left(\cos \theta-\cos \theta_{\mathrm{p}}^{*}\right)+B^{2}\left(\cos \theta-\cos \theta_{\mathrm{p}}^{*}\right)^{2}\right]
\end{aligned}
$$

For the random orientation-part we first define two quantities $O$ and $Q$ :

$O=K\left[\left\langle\eta^{2}\right\rangle \int_{0}^{\infty} \gamma(r) \frac{\sin h r}{h r} r^{2} \mathrm{~d} r+\frac{4}{45} \delta^{2} \int_{0}^{\infty} f(r) \mu(r) \frac{\sin h r}{h r} r^{2} \mathrm{~d} r\right]$ 


$$
Q=\frac{1}{15} K \delta^{2} \int_{0}^{\infty} f(r) \mu(r) \frac{\sinh r}{h r} r^{2} \mathrm{~d} r
$$

where

and

$$
K=\frac{64 \pi^{5}}{\lambda_{0}^{4}}
$$

$$
\mu(r)=1+\frac{\left\langle\eta^{2}\right\rangle}{\alpha^{2}} \gamma(r)
$$

$O$ and $Q$ are the $V_{\mathrm{v}}$ and $H_{\mathrm{v}}$ components for the random orientation model, as calculated by Stein ${ }^{6)}$, using his definition of 0 . The difference between Stein's and our results (see equations $(2.4 .23)$ and $(2.4 .25))$ derives from the fact, that in our $o$ the reflection corrections have already been built in. The first term of $O$ in equation (2.4.16) is the isotropic part and the second term the anisotropic part of the random orientation-scattering. The intensities (in terms of Rayleigh ratios) for the parallel and crossed position of polarizer and analyser respectively will be:

$$
\begin{aligned}
\Re^{\text {rand }}=[ & \left.R_{\mathrm{p}}^{2} \cos ^{2}(\mu+\psi)+R_{\mathrm{q}}^{2} \cos ^{2} \theta_{\mathrm{p}}^{*} \sin ^{2}(\mu+\psi)\right]^{-1}\left[Q \left\{\cos ^{2}(\mu+\psi)+\right.\right. \\
& \left.+\cos ^{2} \theta_{\mathrm{p}}^{*} \sin ^{2}(\mu+\psi)\right\}+(O-Q)\left\{\cos \theta \cos ^{2}(\mu+\psi)+\right. \\
& \left.\left.+\cos \theta_{\mathrm{p}}^{*} \sin ^{2}(\mu+\psi)\right\}^{2}\right]
\end{aligned}
$$

$$
\begin{aligned}
\Re_{+}^{\text {rand }}= & {\left[R_{\mathrm{p}}^{2} \sin ^{2}(\mu+\psi)+R_{\mathrm{q}}^{2} \cos ^{2} \theta_{\mathrm{p}}^{*} \cos ^{2}(\mu+\psi)\right]^{-1}\left[Q \left\{\sin ^{2}(\mu+\psi)+\right.\right.} \\
& \left.+\cos ^{2} \theta_{\mathrm{p}}^{*} \cos ^{2}(\mu+\psi)\right\}+(O-Q)\left(\cos \theta-\cos \theta_{\mathrm{p}}^{*}\right)^{2} \sin ^{2}(\mu+\psi) \\
& \left.\cos ^{2}(\mu+\psi)\right]
\end{aligned}
$$

Defining a new quantity $X$,

$$
X=O-Q
$$

we find from (2.4.20) and (2.4.21) for the different components of the scattered light:

$$
\begin{aligned}
& \left(V_{\mathrm{v}}\right)_{\text {rand }}=\frac{Q}{R_{\mathrm{q}}^{2}}+\frac{X}{R_{\mathrm{q}}^{2}} \\
& \left(H_{\mathrm{h}}\right)_{\text {rand }}=\frac{Q}{R_{\mathrm{p}}^{2}}+\frac{X_{\cos ^{2} \theta}}{R_{\mathrm{p}}^{2}} \\
& \left(H_{\mathrm{v}}\right)_{\text {rand }}=\frac{Q}{R_{\mathrm{p}}^{2}} \\
& \left(V_{\mathrm{h}}\right)_{\text {rand }}=\frac{Q}{R_{\mathrm{q}}^{2}}
\end{aligned}
$$


$\left(K_{\mathrm{d}}\right)_{\text {rand }}=\frac{1}{2\left(R_{\mathrm{p}}^{2}+R_{\mathrm{q}}^{2} \cos ^{2} \theta_{\mathrm{p}}^{*}\right)}\left[2 Q\left(1+\cos ^{2} \theta_{\mathrm{p}}^{*}\right)+X\left(\cos \theta-\cos \theta_{\mathrm{p}}^{*}\right)^{2}\right]$

Using (2.4.12) through (2.4.15) and (2.4.23) through (2.4.27) the following equations can be found:

$$
\begin{aligned}
i_{1} & =R_{\mathrm{q}}^{2}\left(V_{\mathrm{v}}\right)_{\text {tot }}=R_{\mathrm{q}}^{2}\left[\left(V_{\mathrm{v}}\right)_{\text {rand }}+\left(V_{\mathrm{v}}\right)_{\mathrm{sf}}\right]=Q+X+\kappa B^{2} \quad(2.4 .28) \\
i_{2} & =R_{\mathrm{p}}^{2}\left(H_{\mathrm{h}}\right)_{\text {tot }}=R_{\mathrm{p}}^{2}\left[\left(H_{\mathrm{h}}\right)_{\text {rand }}+\left(H_{\mathrm{h}}\right)_{\mathrm{sf}}\right]= \\
& =Q+\left(X+\kappa B^{2}\right) \cos ^{2} \theta+\kappa A^{2} \cos ^{4}(\theta / 2)+2 \kappa A B \cos ^{2}(\theta / 2) \cos \theta \\
i_{3} & =2\left(R_{\mathrm{p}}^{2}+R_{\mathrm{q}}^{2} \cos ^{2} \theta_{\mathrm{p}}^{*}\right)\left(K_{\mathrm{d}}\right)_{\text {tot }}=2\left(R_{\mathrm{p}}^{2}+R_{\mathrm{q}}^{2} \cos ^{2} \theta_{\mathrm{p}}^{*}\right)\left[\left(K_{\mathrm{d}}\right)_{\mathrm{rand}}+\left(K_{\mathrm{d}}\right)_{\mathrm{sf}}\right]= \\
& =2 Q\left(1+\cos ^{2} \theta_{\mathrm{p}}^{*}\right)+\left(X+\kappa B^{2}\right)\left(\cos \theta-\cos \theta_{\mathrm{p}}^{*}\right)^{2}+\kappa A^{2} \cos ^{4}(\theta / 2)+ \\
& +2 \kappa A B \cos ^{2}(\theta / 2)\left(\cos \theta-\cos \theta_{\mathrm{p}}^{*}\right) \\
i_{4} & =R_{\mathrm{p}}^{2}\left(H_{\mathrm{v}}\right)_{\text {tot }}=R_{\mathrm{p}}^{2}\left(H_{\mathrm{v}}\right)_{\text {rand }}=Q
\end{aligned}
$$

$\left(V_{\mathrm{v}}\right)_{\text {tot, }}\left(H_{\mathrm{h}}\right)_{\text {tot }}$ etc. are the measured components of the scattering by the sample.

From (2.4.28), (2.4.29) and (2.4.31) it follows that:

$\left(i_{2}-i_{4}\right)-\cos ^{2} \theta\left(i_{1}-i_{4}\right)=\kappa A^{2} \cos ^{4}(\theta / 2)+2 \kappa A B \cos ^{2}(\theta / 2) \cos \theta=T$

and from (2.4.29) through (2.4.31):

$$
\begin{aligned}
& \cos ^{2} \theta\left[i_{3}-2\left(1+\cos ^{2} \theta_{\mathrm{p}}^{*}\right) i_{4}\right]-\left(\cos \theta-\cos \theta_{\mathrm{p}}^{*}\right)^{2}\left(i_{2}-i_{4}\right)= \\
& =\kappa \cdot A^{2} \cos ^{4}(\theta / 2)\left[\cos ^{2} \theta-\left(\cos \theta-\cos \theta_{\mathrm{p}}^{*}\right)^{2}\right]+2 \kappa A B \cos ^{2}(\theta / 2)[(\cos \theta+ \\
& \left.\left.-\cos \theta_{\mathrm{p}}^{*}\right) \cos ^{2} \theta-\cos \theta\left(\cos \theta-\cos \theta_{\mathrm{p}}^{*}\right)^{2}\right]=V
\end{aligned}
$$

With (2.4.32) and (2.4.33) it is easily found that:

and

$$
\kappa A^{2}=\frac{V-T \cos \theta_{\mathrm{p}}^{*}\left(\cos \theta-\cos \theta_{\mathrm{p}}^{*}\right)}{\cos ^{4}(\theta / 2) \cos \theta_{\mathrm{p}}^{*} \cos \theta}
$$

$$
\kappa A B=\frac{T \cos \theta_{\mathrm{p}}^{*}\left(2 \cos \theta-\cos \theta_{\mathrm{p}}^{*}\right)-V}{2 \cos ^{2}(\theta / 2) \cos \theta_{\mathrm{p}}^{*} \cos \theta}
$$

In this way $\kappa A^{2}$ and $\kappa A B$ follow from experimental quantities; $\kappa B^{2}$ can sukvequently be calculated and used to determine $O$ from equation (2.4.28): 


$$
O=i_{1}-\kappa B^{2}
$$

It is thus feasible to separate the spherulitic and random orientation- scattering: $\kappa A^{2}$ is a measure for the spherulitic scattering, and $\kappa A^{2}$ as a function of the scattering angle $\theta$ gives information about the radius of the spherulites ( $\kappa A^{2}$ has a maximum for $U=4.10$, as will be shown in Section 5); knowing $O$ and $Q$ as functions of $\theta$ the correlation functions $\gamma(r)$ and $f(r)$ as well as $\left\langle\eta^{2}\right\rangle$ and $\delta^{2}$ can be calculated from

and

$$
O-\frac{4}{3} Q=K<\eta^{2}>\int_{0}^{\infty} \gamma(r) \frac{\sinh r}{h r} r^{2} \mathrm{~d} r
$$

$$
Q=\frac{1}{15} K \delta^{2} \int_{0}^{\infty} f(r) \mu(r) \frac{\sinh r}{h r} r^{2} \mathrm{~d} r
$$

by means of Fourier transformations:

$$
\begin{aligned}
& \gamma(r)=2\left(\pi K\left\langle\eta^{2}>r\right)^{-1} \int_{0}^{\infty}\left(O-\frac{4}{3} Q\right) h \sin (h r) \mathrm{d} h\right. \\
& \gamma(0)=1=2\left(\pi K\left\langle\eta^{2}\right\rangle\right)^{-1} \int_{0}^{\infty}\left(O-\frac{4}{3} Q\right) h^{2} \mathrm{~d} h \\
& f(r) \mu(r)=2\left(\pi K \delta^{2} r\right)^{-1} \int_{0}^{\infty} Q h \sin (h r) \mathrm{d} h \\
& f(0) \mu\left(0^{\prime}\right)=1+\frac{\left\langle\eta^{2}\right\rangle}{\alpha^{2}}=2\left(\pi K \delta^{2}\right)^{-1} \int_{0}^{\infty} Q h^{2} \mathrm{~d} h
\end{aligned}
$$

I-5. Dependence of the Spherulitic Scattering on the Distribution of Spherulite Sizes

The factor in $\kappa A^{2}$, which depends on the scattering angle $\theta$ (or $h$ ) and the radius of the spherulite, $R_{\text {sf }}$, is given by:

$W\left(h, R_{\mathrm{sf}}\right)=\left[\frac{4 \sin \left(h R_{\mathrm{sf}}\right)-h R_{\mathrm{sf}} \cos \left(h R_{\mathrm{sf}}\right)-3 \operatorname{Si}\left(h R_{\mathrm{sf}}\right)}{h^{3}}\right]^{2}$

For $R_{\text {sf }}=1, W$ as a function of $h$ is shown in figure 5. Maxima appear at the following values of $h$ (or $U$, for $U=h$ when $\left.R_{\text {sf }}=1\right): 4.10,8.90,12.0,15.4,18.5,21.75,24.85,28.1$.

For a collection of spherulites with a differential distribution function $g(r)$ with respect to the radius, the intensity of the scattered light will be: 
$I \sim \int_{0}^{\infty} g(r)\left[\frac{4 \sin (h r)-h r \cos (h r)-3 \operatorname{Si}(h r)}{h^{3}}\right]^{2} \mathrm{~d} r$

The influence of two kinds of distribution functions has been investigated: block distributions, where $g(r)=1$ for $1-\Delta r<r<$ $1+\Delta r$ and $g(r)=0$ for all other values of $r$, and gaussian distributions where $g(r)=\exp \left(-[r-1]^{2} / \sigma^{2}\right)$. For block distributions equation (2.5.2) can be solved:

$$
\begin{aligned}
I \sim & \frac{1}{h^{7}}\left[\frac{x^{3}}{6}+\frac{x^{2}}{2} \sin x \cos x+x\left\{\frac{29}{4}-\frac{9}{2} \sin ^{2} x+9[\operatorname{Si}(x)]^{2}+\right.\right. \\
& +6 \sin x \operatorname{Si}(x)\}+48 \cos x \operatorname{Si}(x)-\frac{29}{4} \sin x \cos x+ \\
& -24 \operatorname{Si}(2 x)\left[\begin{array}{l}
h(1+\Delta r) \\
h(1-\Delta r)
\end{array}\right]
\end{aligned}
$$

In figure $7 \log I$ has been plotted against $h$ for different values of $\Delta r$. Figure 8 gives the result for gaussian distributions with different values of $\sigma$. The calculations of $I$ have been performed numerically, using the gaussian distributions with a cut-off at $g(r)=0.01$ (see figure 6). Figures 7 and 8 show that, if the distribution gets broader, the higher order maxima and the intermediate lower maxima will vanish rather rapidly. Moreover, these figures reveal a shift of the first maxima to smaller angles. This will cause radii, calculated with the aid of the condition $U=4.10$, to be greater than the number average radius, which, for all distributions used, equals 1. Tables I and II show a very good correspondence, for block as well as gaussian distributions, between the radius $r_{\max }$, calculated from the first maximum with the aid of $U=4.10$, and the average radius $r_{\text {av }}$ according to:

$$
r_{\mathrm{av}}=\frac{\int g(r) r^{9} \mathrm{~d} r}{\int g(r) r^{8} \mathrm{~d} r}
$$

Table I

\begin{tabular}{|l|l|l|}
\hline$\Delta r$ & $r_{\max }$ & $r_{\mathrm{av}}$ \\
\hline 0.02 & 1.00 & 1.00 \\
0.11 & 1.03 & 1.03 \\
0.22 & 1.11 & 1.11 \\
0.40 & 1.26 & 1.26 \\
0.65 & 1.49 & 1.49 \\
0.86 & 1.67 & 1.67 \\
\hline
\end{tabular}

Table II

\begin{tabular}{|c|c|c|}
\hline$\sigma$ & $r_{\max }$ & $r_{a v}$ \\
\hline 0.01 & 1.00 & 1.00 \\
0.05 & 1.00 & 1.01 \\
0.10 & 1.04 & 1.04 \\
0.20 & 1.13 & 1.14 \\
0.30 & 1.26 & 1.27 \\
0.40 & 1.44 & 1.43 \\
\hline
\end{tabular}




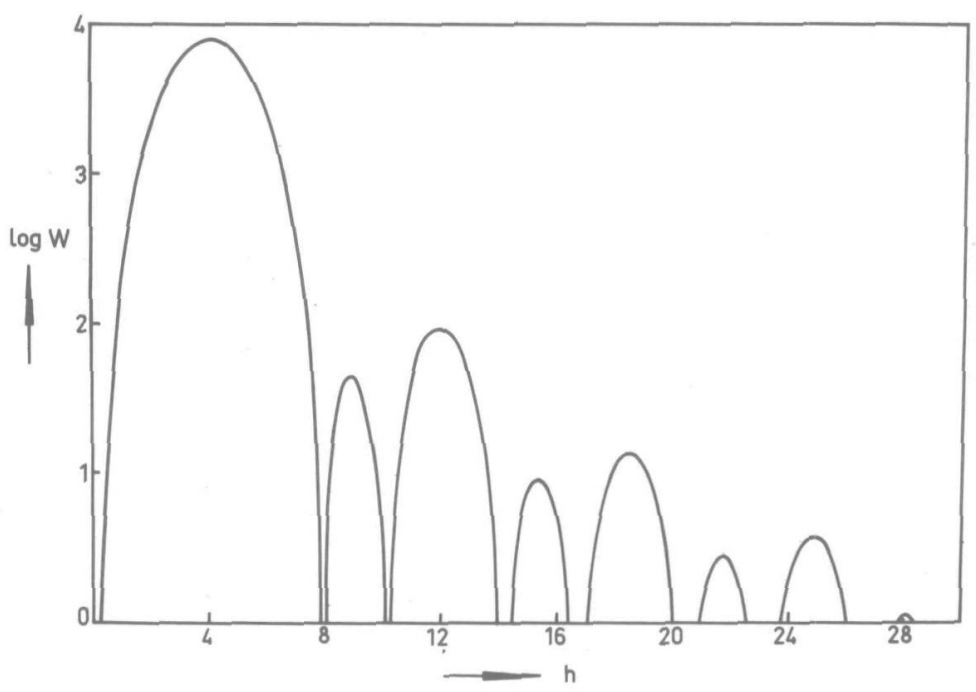

Figure 5. The spherulitic scattering $\mathrm{W}\left(\sim \kappa \mathrm{A}^{2}\right)$ as a function of $\mathrm{h}(=4 \pi \sin (\theta / 2) / \lambda)$.

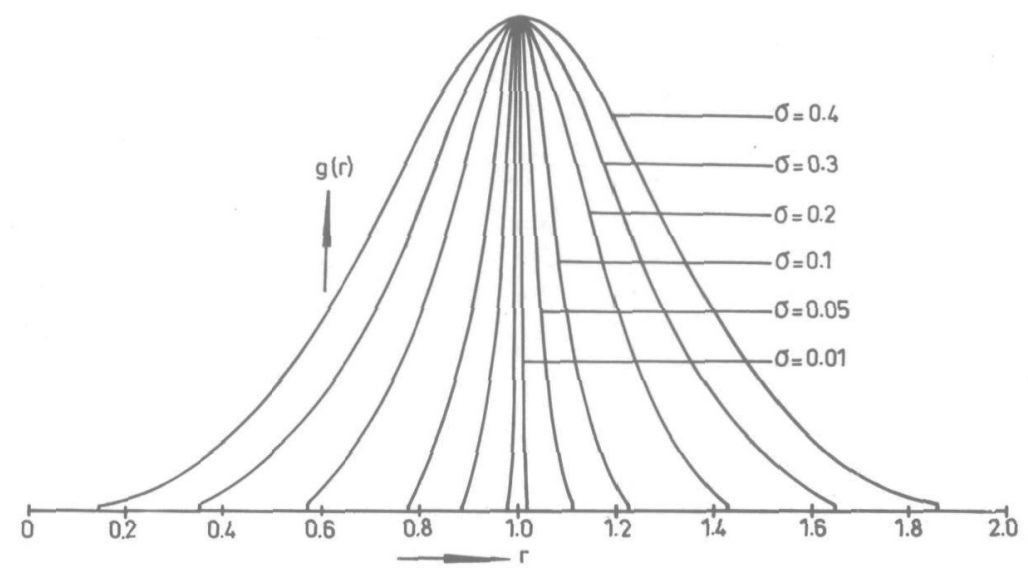

Figure 6. Gaussian size distributions used in the calculations of spherulitic scattering. 


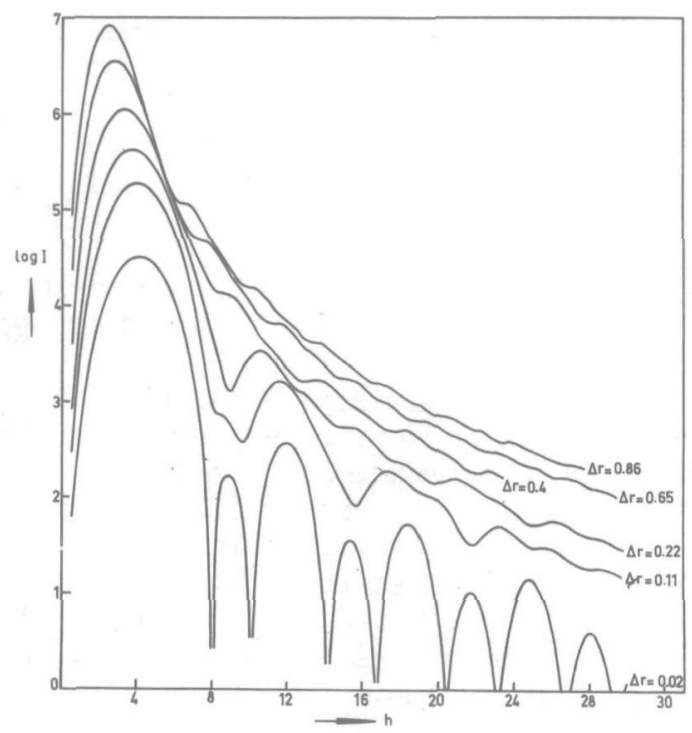

Figure 7. Spherulitic scattering for various block distributions.

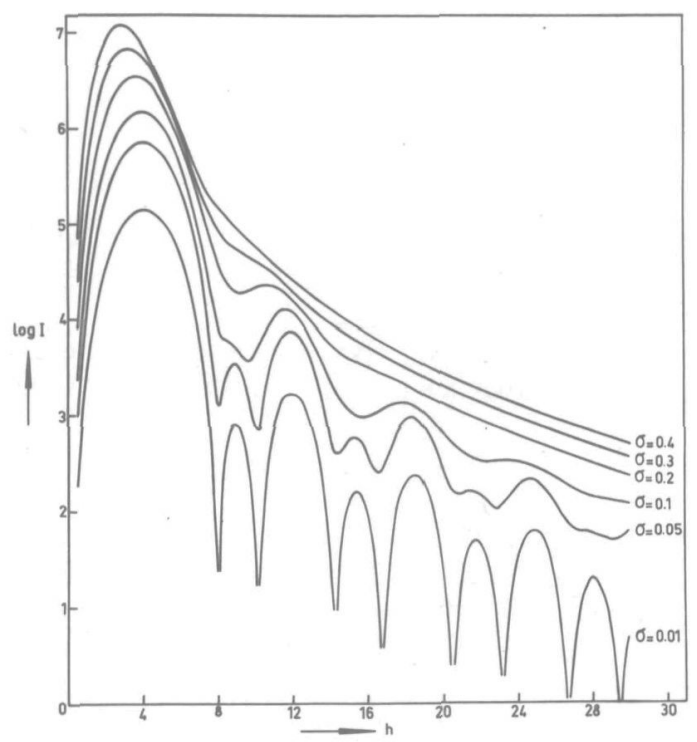

Figure 8. Spherulitic scattering for various gaussian distributions. 


\section{CRYSTALLIZATION FROM THE MELT}

\section{III-1. The Mechanism of Crystallization}

PRIMARY OR SPHERULITIC CRYSTALLIZATION

When high polymers crystallize from the melt, the crystallites are usually arranged in spherically symmetric aggregates, called spherulites.

The growth of a spherulite starts with the formation of a primary nucleus, often on heterogenities occurring in the melt, and enlarge radially. Consequently, in order to account for the growth of the spherulite, new crystallites must be developed on new (secondary) nuclei. The secondary nucleation occurs on or near the already formed crystallites at the surface of the spherulite, which may be regarded as catalysts for the process. The number of secondary nuclei, formed per unit of time, and so the growth rate of the spherulite volume $V_{\text {sf }}$ will therefore be proportional to the area of the spherulite:

$$
\frac{\mathrm{d} V_{\mathrm{sf}}}{\mathrm{d} t}=v_{\mathrm{r}} 4 \pi R_{\mathrm{sf}}^{2}
$$

or

$$
\frac{\mathrm{d} R_{\mathrm{sf}}}{\mathrm{d} t}=v_{\mathrm{r}}
$$

from which follows that the radial growth rate is constant as indeed is observed for most polymers ${ }^{12)}$.

Generally the course of the crystallization as a function of time can be described very well by the Avrami-equation 13):

$$
1-f=\exp \left(-k_{\mathrm{o}} t^{\mathrm{n}}\right)
$$

where $f$ is the mass fraction, transformed into the spherulitestate, $t$ the crystallization time, $k_{0}$ a constant which depends only on the temperature of crystallization and $n$ a number which gives information about the mechanism of the primary nucleation. Three different cases of primary nucleation will be dealt with: a. The number of nuclei $N$ is constant, i.e. all nuclei arise at the same time, when the crystallization starts.

For this case it can be derived that $13,14,15)$ : 


$$
-\ln (1-f)=k_{\mathrm{o}} t^{\mathrm{n}}=\frac{4 \pi N V_{\mathrm{o}} v_{\mathrm{r}}^{3} t^{3}}{3 V_{\mathrm{s}}}
$$

$V_{\mathrm{o}}$ and $V_{\mathrm{s}}$ are the specific volumes of the amorphous and spherulitic phase respectively. From (3.1.4) it follows that $n=3$.

b. The nucleation rate, $\dot{N}$, is constant.

For this case the crystallization can be described by ${ }^{13,14,15)}$ :

$$
-\ln (1-f)=k_{\mathrm{o}} t^{\mathrm{n}}=\frac{\pi \dot{N} V_{\mathrm{o}} v_{\mathrm{r}}^{3} t^{4}}{3 V_{\mathrm{s}}}
$$

which yields $n=4$.

c. The nucleation rate, $\dot{N}$, is time dependent.

It will be assumed that the nucleation rate can be expressed by:

$$
\dot{N}(t)=\nu N_{\mathrm{s}, \mathrm{o}} \exp (-\nu t)
$$

Actually such a decreasing function for the nucleation rate will occur, when at the beginning of the crystallization $N_{\mathrm{s} \text {, o }}$ subcritical nuclei are present, which have a probability $\nu$ per unit of time to become critical; the crystallization equation can then be found to be 13,15$)$ :

$-\ln (1-f)=k_{\mathrm{o}} t^{\mathrm{n}}=\frac{8 \pi N_{\mathrm{s}, \mathrm{o}} V_{\mathrm{o}} v_{\mathrm{r}}^{3}}{V_{\mathrm{s}} \nu^{3}}\left[\exp (-\nu t)-1+\nu t-\frac{\nu^{2} t^{2}}{2}+\frac{\nu^{3} t^{3}}{6}\right]$

When $\nu t$ is small $(3.1 .7)$ will change into (3.1.5) with $\dot{N}=$

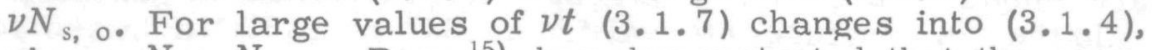
where $N=N_{\text {s, o. Boon }}{ }^{15)}$ has demonstrated that the crystallization can be described to a good approximation by equations (3.1.5) and (3.1.7) for $\nu t<1$ and $\nu t>30$ respectively.

\section{SECONDARY CRYSTALLIZATION}

Besides the primary spherulitic crystallization another relatively slow, secondary crystallization is observed for many polymers $16,17,18)$. Usually this can be detected easily, because the crystallinity continues to increase even after the sample volume has already been completely filled by spherulites. The secondary crystallization can be considered as an additional crystallization within the spherulites or as an increase in perfection of already existing intraspherulitic crystallites. According to several investigators $19,20,21)$ the secondary crystallization within an existing spherulite can be described by the same type of equation as $(3.1 .3)$. 
III-2. The Crystalline State of Isotactic Polystyrene and Isotactic Polypropylene

ISOTACTIC POLYSTYRENE

Isotactic polystyrene crystallizes in spherulites with a positive birefringence (the refractive index in radial direction is larger than in tangential direction).

Investigation by means of $X$-ray diffraction has revealed only one crystal modification. The unit cell is rhombohedral with the following cell constants ${ }^{22)}$ :

$$
\begin{gathered}
a=b=21.9 \AA \\
c=6.65 \AA
\end{gathered}
$$

Spherulitic crystallization, growth rate and nucleation, has been investigated extensively by several investigators $15,23,24$ ) , most recently by Boon ${ }^{15)}$. Generally the nucleation rate appears to decrease with time and can be described very well on the basis of equation (3.1.6).

\section{ISOTACTIC POLYPROPYLENE}

Padden and Keith ${ }^{25)}$ have distinguished four types of spherulites for isotactic polypropylene:

Type I occurs at crystallization temperatures below $134^{\circ} \mathrm{C}$ and exhibits a weakly positive birefringence.

Type II grows at temperatures above $138^{\circ} \mathrm{C}$ and has a weakly negative birefringence.

Type III spherulites appear below $128^{\circ} \mathrm{C}$ in the midst of type I spherulites. The birefringence is strongly negative.

Type IV spherulites are found sporadically in the midst of type I in the temperature interval of $128^{\circ}$ to $132^{\circ} \mathrm{C}$. These spherulites are ringed and exhibit a strongly negative birefringence.

In the temperature interval from $134^{\circ}$ to $138^{\circ} \mathrm{C}$ a mixed form of type I and II spherulites occurs. Under a polarizing microscope these spherulites do not show a distinct Maltese cross.

$X$-ray investigation of the crystal modification of isotactic polypropylene have yielded three different modifications: the $\alpha, \beta$ and $\gamma$ modifications. The $\alpha$-form appears in type I and II spherulites ${ }^{26)}$. The unit cell is monoclinic and its cell constants are ${ }^{22)}$ :

$$
\begin{aligned}
& a=6.65 \AA \quad \mathrm{o}=20.96 \AA \\
& \mathrm{c}=6.50 \AA \quad \beta=90^{\circ} 20^{\prime}
\end{aligned}
$$

The $\beta$-form is hexagonal with the unit cell constants ${ }^{22)}$ :

$$
\begin{gathered}
a=b=12.74 \AA \\
c=6.35 \AA
\end{gathered}
$$

This form is observed in type III and IV spherulites ${ }^{26)}$. The $\gamma$ 
modification probably has a triclinic unit cell ${ }^{27)}$. Up to the present a complete clarification of this structure has not been given. The $\gamma$-form appears to be stable especially at high pressures ${ }^{28)}$.

From the dilatome tric investigations by von Falkai and Stuart 29,30 ) into the spherulitic crystallization of isotactic polypropylene, it is evident that the primary nucleation is heterogeneous: all nuclei arise at the beginning of the crystallization, which therefore can be described by equation (3.1.4). 


\section{EXPERIMENTAL ARRANGEMENTS}

\section{IV-1. Sample Preparation}

\section{MATERIALS}

Isotactic polystyrene and isotactic polypropylene were kindly supplied by the Central Research Institute of the A. K. U. . Arnhem, The Netherlands, and by Shell Plastics Laboratory, Delft, The Netherlands. According to the statements of the suppliers the viscosity and number average molecular weights of polystyrene (the same material on which Boon ${ }^{15}$ ) performed his measurements) were 330,000 and 185,000 respectively, the viscosity average molecular weight of polypropylene (sample N577) was 400,000.

\section{CRYSTALLIZATION}

For the preparation of the samples the molten polymer was first pressed between two quartz slides of $3 \mathrm{~mm}$ thickness. The slides were separated by two copper strips of required thickness, ensuring a plane-parallel polymer film. The melt was kept at the required temperature (polystyrene $265^{\circ} \mathrm{C}$, polypropylene $210^{\circ} \mathrm{C}$ ) for one hour so as to reduce macroscopic orientation, resulting from the streaming patterns, caused by pressing together the quartz slides. After a sometimes required quench, the sample was put quickly into the crystallization oven. The crystallization oven consisted of two copper blocks, through which by way of a series of channels a thermally regulated liquid (silicone oil) was circulated from a thermostat. Between these two blocks a copper plate was inserted out of which the oven cavity had been sawed. The cavity had somewhat larger dimensions than the quartz slides with the polymer. The temperature in the oven cavity could be kept constant to at least $0.1^{\circ} \mathrm{C}$. After the crystallization the sample was quenched rapidly in a liquid of the required temperature (melting acetone for $-95^{\circ} \mathrm{C}$ and water for temperatures from $0^{\circ}$ to $100^{\circ} \mathrm{C}$ ).

\section{IV-2. Light Scattering Instruments}

\section{LASER SET -UP}

In order to get a quick, but qualitative, idea of the light scattering pattern of a sample, a simple set-up is used as shown schematically in figure 9. The light source was a helium-neon gas laser $(\lambda=6328 \AA$, Nelas Division, Wallsend, Northcum- 


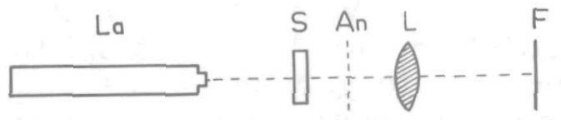

Figure 9. Schematic diagram of the laser set-up. La = laser; $\mathrm{S}$ = sample; $\mathrm{An}=$ analyser; $\mathrm{L}=$ lens; $\mathrm{F}=$ photografic plate in the focal plane of $\mathrm{L}$.

berland, England) because of its high intensity and beam parallelism. As the laser beam already is linearly polarized, there was no need for a polarizer. Lens $L$ focusses the scattered light on to a photographic plate in the focal plane $F$. The photographs were taken with a Polaroid Land camera (without the lens system), so the results were visible within one minute. Because these photographs cannot be accurately photometered, they only give a qualitative idea of the light scattering, with the aid of which for instance the order of magnitude of the spherulite size can be determined (from the angle of maximum scattering).

\section{THE LOW-ANGLE LIGHT SCATTERING PHOTOMETER}

Figure 10 shows a diagram of the low-angle light scattering photometer, which has been developed in order to make possible accurate measurements of the absolute intensity of the light scattering. Figure 11 is a photograph of the apparatus.

The condensor lens L1 and diaphragm D render the light parallel with a divergency of about $10^{\prime}$.

The light beam enters the sample in sampleholder S. The sampleholder is of the same type as the one described by Stein and Keane ${ }^{29)}$ : ' the sample - standing vertically- can be turned to any wanted angle $\varphi$ with the primary beam $(\varphi$ is the angle between the normal to the sample and the primary beam). The polymer film is kept between two glass slides; an immersion fluid with proper refractive index takes care of a good optical contact between sample and glass slides. The holder also provides space for a blank, consisting of just the glass slides and an immersion fluid between them. The blank assembly can also be rotated through the angle $\varphi$. The detection system consists of lens L2, pinhole IP and photomultiplier $\mathrm{Ph}$. The solid angle, intercepted by the photomultiplier, is fixed by the focal length of lens L2 and the diameter of pinhole IP in the focus of L2. Half of the solid angle, $\gamma$, is about 17'. Hence, taking into account the divergency of the primary beam (10') the scattering can be measured down to 27 ' deviation from the primary beam.

The photomultiplier current is measured by means of a recording dc amplifier (type BD-1, Kipp en Zonen, Delft, The Netherlands, 
f. s.d. from $0.1 \mu \mathrm{A}$ to $5 \mu \mathrm{A})$. When the intensity becomes so high, that the photomultiplier no longer amplifies linearly or the photocurrent could no longer be measured by the recorder $(\max .5 \mu \mathrm{A})$, a number of neutral density filters is inserted into the filter holders Fh. The transmittances of the filters are determined by never inserting or removing at the same time more filters than are required to reduce the transmitted intensity at most a factor of 10 (this is amply within the measuring range of the recorder), and measuring the photocurrent before and after the alteration.

The accuracy of the measurements mainly depends on the stability of the mercury arc. To this end a selection should be made. In this selection, attention should be paid to a constant light output and a quiet, stable discharge, because shifting of the discharge locus causes a change of the direction of the primary beam and thus also a difference in the real scattering angle. Slowly raising the discharge current especially for new arcs appeared to be essential for obtaining a quiet discharge. Using a selected mercury arc the intensity of the scattering can be measured with an accuracy of about $0.5 \%$. Only for low scattered intensities the accuracy diminishes, because the accuracy is then determined by the variations in the dark current of the photomultiplier. The photomultiplier is operated off a constant voltage power supply (type 412B, John Fluke, Seattle, U.S.A.). The mercury arc is fed by a current of about 4 Amp., which is kept fairly constant by a series connection of the arc and an adjusted resistance of about $25 \mathrm{Ohm}$ with a constant voltage supply of 115 Volt.

The conversion of measured photocurrents to absolute Rayleigh ratios can be achieved without a secondary scattering standard, because the geometry is such that energies rather than intensities are obtained. The Rayleigh ratio $\Re(\theta)$ is defined as

$$
\Re(\theta)=\frac{I(\theta) R^{2}}{I_{0} V}
$$

where $I(\theta)$ is the intensity of the scattered light at anangle $\theta$, $R$ the distance between sample and detector, $I_{0}$ the intensity of the primary beam and $V$ the scattering volume. Now, in the focal plane of lens L2, before the photomultiplier, two interchangeable pinholes (IP) of diameters 0.2 and $1.0 \mathrm{~cm}$ respectively have been mounted. Using the $1.0 \mathrm{~cm}$ pinhole at $\theta=0^{\circ}$ all the light of the primary beam is collected on to the photocathode. Thus $I_{\mathrm{o}}=E_{\mathrm{n}}(\mathrm{o}) / \dot{S}$, if $E_{\mathrm{n}}(\mathrm{o})$ is the total energy measured at $\theta=0^{\circ}$ and $S$ the cross-section of the primary beam. For scattering measurements at $\theta \neq 0^{\circ}$, the $0.2 \mathrm{~cm}$ pinhole is used in order to increase the angular resolution. In this case, therefore, the scattered energy is measured over an area $\pi R^{2} \operatorname{tg}^{2} \gamma$, where $\operatorname{tg} \gamma=0.005$ (i.e. the ratio of the radius of the pinhole and the 


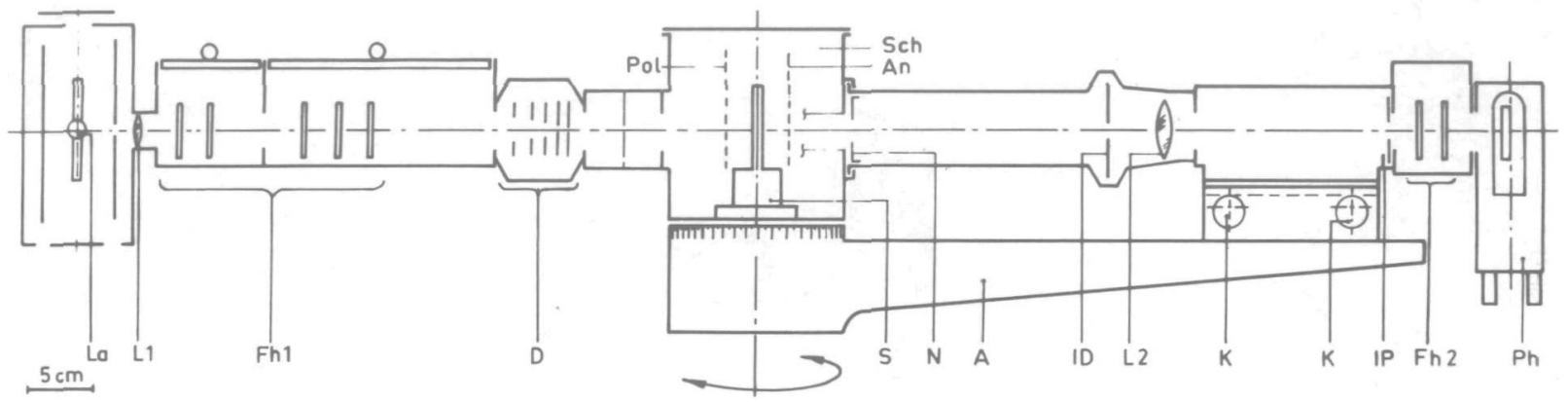

Figure 10. Diagram of the low-angle light scattering photometer. La $=$ light source, consisting of a $100-\mathrm{W}$ high-pressure mercury arc with a $0.3-\mathrm{mm}$ electrode distance (Osram A.E.G., type H.B.O. 100); L1 = condensor lens, biconvex, focal length $5 \mathrm{~cm}$; Fh1 and $\mathrm{Fh} 2=$ filter holders (neutral density filters, fixed Polaroid polarizer and analyser, and monochromatization filters); $\mathrm{D}=$ iris diaphragm and interchangeable pinholes of various sizes to adjust the cross-section of the primary beam from 0.1 to $2 \mathrm{~cm}$; S and $\mathrm{Sch}=$ sample holder and sample chamber respectively; Pol and $\mathrm{An}=$ coupled polarizer and analyser (see text); $\mathrm{N}=$ diaphragm of $2.0 \mathrm{~cm}$, preventing stray light from reaching the detector photomultiplier Ph (RCA, 1P28); ID = iris diaphragm; L2 = receiver lens, focal length $20 \mathrm{~cm}$, which defines together with the diameter of pinhole IP the solid angle, intercepted by $\mathrm{Ph}$; IP = interchangeable pinholes (in the focus of $\mathrm{L} 2)$, of which the larger one $(1.0 \mathrm{~cm}$ diameter) is used to measure the energy of the entire beam in the zero-degree position of the measuring arm A (see text); $\mathrm{K}=$ knobs to align the detection system on the optical axis. 


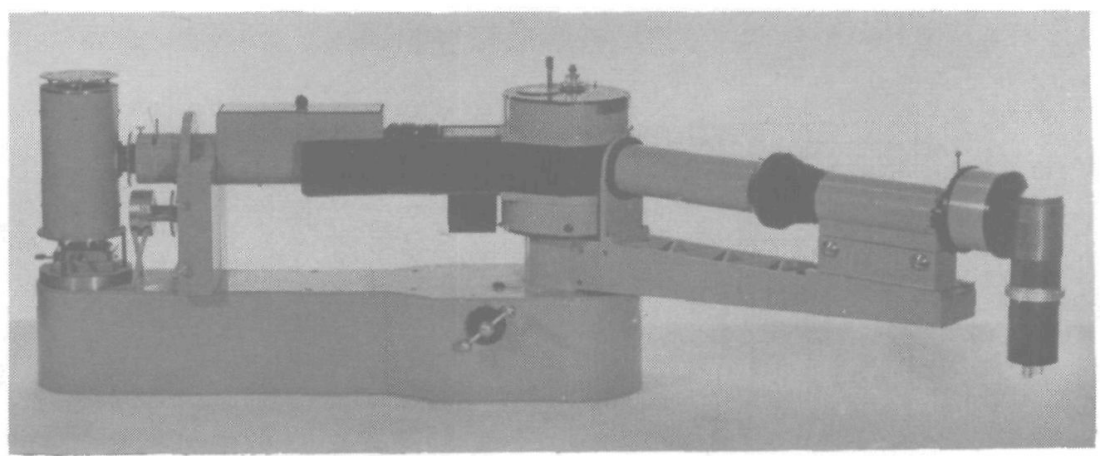

Figure 11. Photograph of the low-angle light scattering photometer.

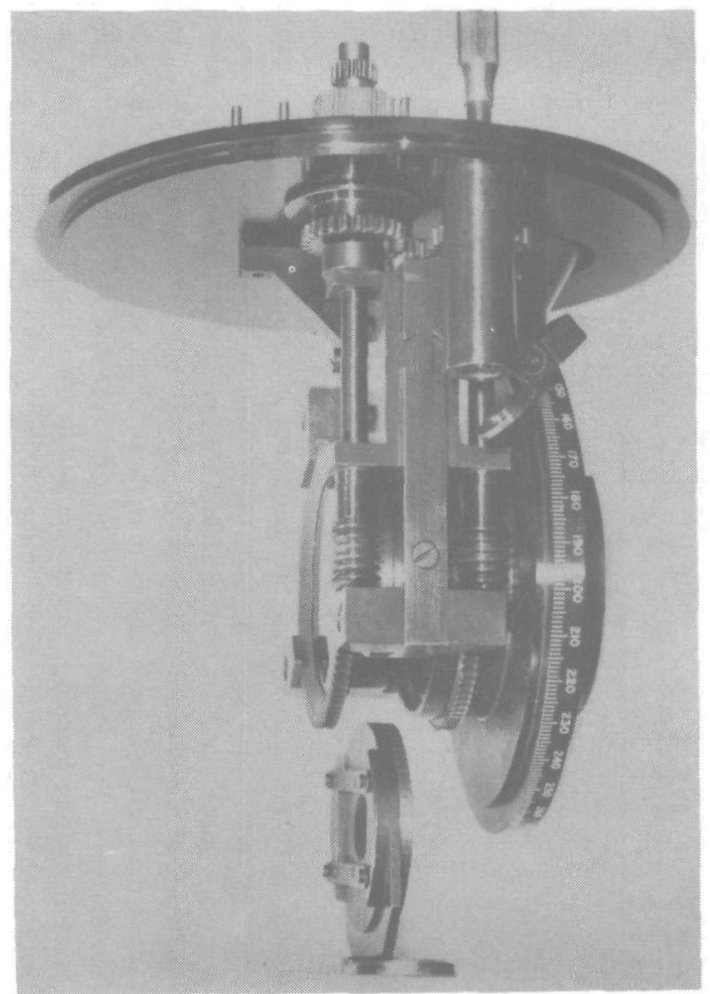

Figure 12. Photograph of the sample holder and the auxiliary apparatus with coupled polarization filters; the sample holder just fits between the analyser filter (at the left) and the polarizer filter (at the right, not visible). 


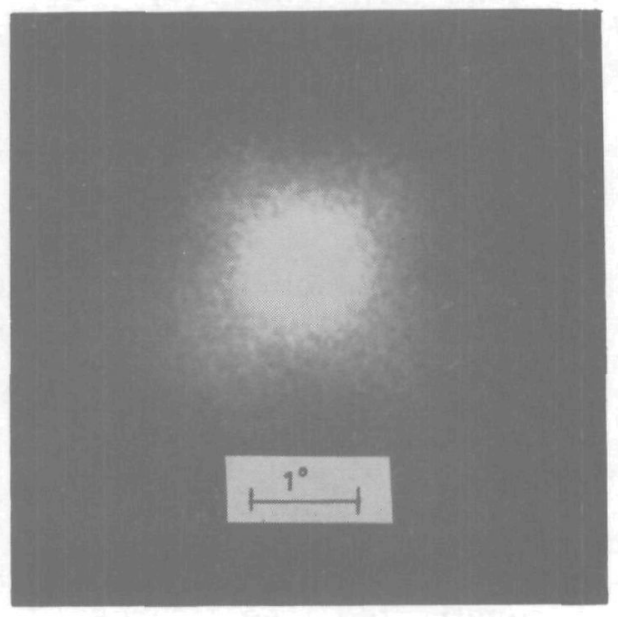

Figure 13. Scattering pattern (for the crossed position of polarizer and analyser) of quenched (to $0^{\circ} \mathrm{C}$ ) polypropylene (sample pp2).

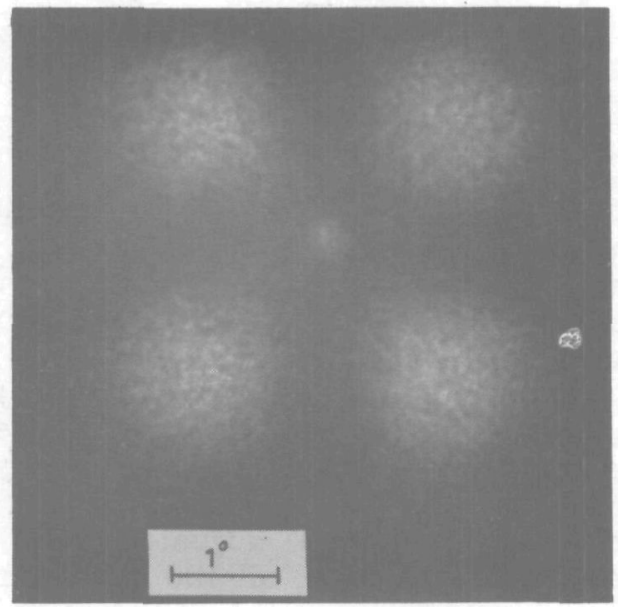

Figure 14. Scattering pattern (for the crossed position of polarizer and analyser) of deeply quenched (to $-95^{\circ} \mathrm{C}$ ) polypropylene (sample pp3). 
focal length of the lens L2). Thus $I(\theta)=E_{\mathrm{n}}(\theta) / \pi \mathrm{R}^{2} \operatorname{tg}^{2} \gamma$. With $V=S d$, where $d$ is the thickness of the sample, we thus have:

$$
\Re(\theta)=\frac{E_{\mathrm{n}}(\theta)}{E_{\mathrm{n}}(0) \pi d \operatorname{tg}^{2} \gamma}=\frac{i(\theta)}{i(0) \pi d \operatorname{tg}^{2} \gamma}
$$

$i(\theta)$ and $i(0)$ are the measured photocurrents of the scattered light at angle $\theta$ and the primary beam at $0^{\circ}$ respectively, both corrected for the use of neutral density filters.

If only the $V_{\mathrm{v}}, H_{\mathrm{h}}, V_{\mathrm{h}}$ and $H_{\mathrm{v}}$ components of the scattering have to be measured, a fixed Polaroid polarizer and a fixed Polaroid analyser in filterholders Fh1 and Fh2 can be used. For the measurement of other components $\psi$ should be varied, because the scattering can be measured only at $\mu=90^{\circ}$ (see figure 3) in the present apparatus. In order to realize this an auxiliary apparatus has been constructed (see figures 12 and 15). In this

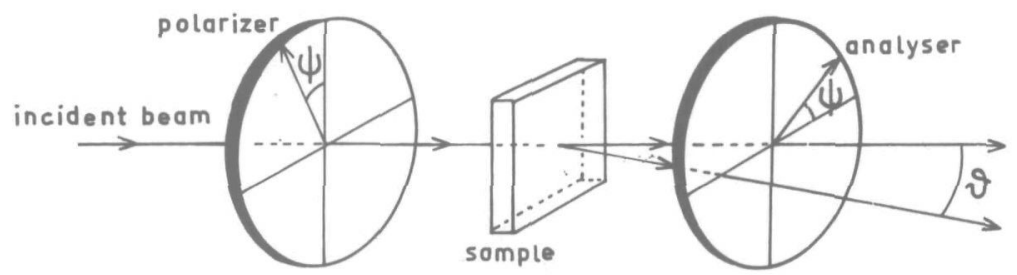

Figure 15. Schematic diagram of the coupled polarizer and analyser filters.

apparatus two Polaroid filters, coupled by means of wormgear, can be rotated through an angle $\psi$ simultaneously (see figure 15). If for example the polarizer and analyser are crossed, they are kept crossed for any value of $\psi$. The auxiliary apparatus can be slided into the sample chamber in such a way that the sample holder just fits between the polarizer and analyser. When this apparatus is used, measurements can only be performed at $\varphi=$ $0^{\circ}$, i.e. sample as well as polarizer and analyser are always normal to the primary beam.

Polarizer and analyser were adjusted with the aid of the reflection at Brewster's angle. For the adjustment of the fixed horizontal polarizer in Fh1 a glass slide with known refractive index was put into the sample holder and $\varphi$ was set at Brewster's angle. After that the polarizer axis was rotated in such a way that the reflection by the glass slide, measured at $\theta=180^{\circ}-2 \varphi$, was at a minimum. A similar procedure was followed for the horizontal analyser in Fh2. The vertical polarizer and analyser were adjusted by crossing them with the already adjusted horizontal analyser and polarizer. The horizontal and vertical direction of the polarization filters of the auxiliary apparatus were obtained with the aid of the adjusted fixed polarization filters. 
A parallel primary beam was obtained by arranging the distance between mercury arc and lens L1 in such a way that the image of the discharge on a distant wall was as sharp as possible. To this end the detection part could be removed. The criterion that the primary beam runs along the axis of the apparatus is the fact that the centres of the shadow of the iris diaphragm D and the image of the discharge coincide. To attain this, the mercury arc could be moved in three directions.

The vertical position of the sample and $\varphi=0^{\circ}$, i.e. the normal situation, could be fixed by having the primary beam reflected back by the sample just through a diaphragm in Fh1, which transmits the primary beam on its way to the sample chamber.

The detection system is well adjusted when the discharge gives a sharp image just in the pinhole IP. The distance between lens L2 and pinhole IP can be regulated to obtain a sharp image and with the knobs $\mathrm{K}$ the image can be set at the right place (just in the pinhole).

A check for the proper rotation around the vertical axis of the sample holder $(\varphi)$ and the detection $\operatorname{arm}(\theta)$ is as follows: for any $\varphi$ the sharp image of the discharge should be visible in the pinhole IP at $\theta=180^{\circ}-2 \varphi$. 


\section{V-1. The Raw Data}

All light scattering measurements with the low-angle light scattering photometer were performed with the aid of the auxiliary apparatus with the coupled polarization filters; this means that the sample was always perpendicular to the primary beam $\left(\varphi=0^{\circ}\right)$. In all cases the wavelength of the light was $\lambda_{0}=5460 \AA$.

For each sample four series of measurements were made: the $V_{\mathrm{v}}, H_{\mathrm{h}}, V_{\mathrm{h}}$ and $K_{\mathrm{d}}$ series. This means that in the parallel position of polarizer and analyser series for $\psi=0^{\circ}$ and $\psi=90^{\circ}$ were taken, and in the crossed position series for $\psi=90^{\circ}$ and $\psi=45^{\circ}$. ${ }^{*}$ For each series the scattering was measured over an external angular range from $\theta_{\mathrm{u}}=30^{\prime}$ to a maximum value of $\theta_{\mathrm{u}}=40^{\circ}$. Depending on the steepness of the scattering curve the angular range was scanned in steps of $15^{\prime}, 30^{\prime}$ or $1^{\circ}$. A check on the constancy of the intensity of the primary beam during the four series was made afterwards, by comparing the ratios of the different components at an arbitrary angle at that moment, with the ratios as they appeared in the measured series. The intensity of the primary beam was measured as follows: the photocurrent, caused by the primary beam which was reduced by the necessary number of neutral density filters, was measured at $\theta_{\mathrm{u}}=0^{\circ}$ in the $V_{\mathrm{v}}$ position of the polarization filters; the $1.0 \mathrm{~cm}$ pinhole IP (see figure 10) was used and the sample was removed from the beam. After that the $0.2 \mathrm{~cm}$ pinhole IP was inserted, the sample was placed into the beam and $\theta_{\mathrm{u}}$ was raised to such an extent that the photocurrent was about $10 \%$ of the originally measured value; at this moment a factor of about 10 of neutral density filters was removed and the current was measured again, in order to determine the transmittance of the removed filters. This procedure was repeated until an arbitrary reference angle (usually the same angle as was used for the check on the constancy of $I_{0}$ ) was reached. With the aid of the transmittances, measured in this way, the real photocurrent of the primary beam, $i(0)$ from equation (4.2.2), could be expressed in the units in which the $V_{\mathrm{v}}$-component at the reference angle was measured. The reference angle was chosen in such a way that the $V_{\mathrm{v}}$-component at that

\footnotetext{
* The intensities of the scattered light at a constant external angle $\theta_{\mathrm{u}}$ for $\psi=0^{\circ}$ and $\psi=180^{\circ}$ did not appear to be different, neither in the parallel nor in the crossed position of polarizer and analyser. Other pairs of $\psi$-values, $\psi=90^{\circ}$ and $-90^{\circ}$ and $\psi=45^{\circ}$ and $-45^{\circ}$, gave the same results. This proves both the correct adjustment of the polarizing filters and the absence of macroscopic orientation in the sample.
} 
angle could be measured without using neutral density filters. Thus $i(0)$ is valid for all scattering components at any angle, provided the measured currents are converted by means of the transmittances of the density filters (if used) to the situation without neutral density filters.

The determination of the turbidity $\tau$, which is needed for the correction of the raw scattering data (see next section), was achieved by measuring the photocurrents $i_{1}(0)$ and $i_{2}(0)$ of the primary beam at $\theta_{\mathrm{u}}=0^{\circ}$ with the sample (1) and with a glass slide only (2) in the beam respectively; then $\tau$ can be calculated from:

$$
\frac{i_{1}(0)}{i_{2}(0)}=\exp (-\tau d)
$$

where $d$ is the thickness of the sample. In order to capture as little forward scattering as possible, these measurements were performed with the $0.2 \mathrm{~cm}$ pinhole IP.

The thickness $d$ of the sample was measured under a measuring microscope with an accuracy of about $0.001 \mathrm{~mm}$. The polystyrene and polypropylene samples had thicknesses of about 0.020 and $0.100 \mathrm{~mm}$ respectively.

The refractive index $n$ of the sample, which is also needed for the various corrections (see next section), was determined with an Abbe refractometer.

\section{V-2. Optical Corrections}

As already described by Stein and Keane ${ }^{29)}$ the measured results have to be corrected in several ways, which are inherent to the geometry of the light scattering apparatus. In addition, for the evaluation of the results, the scattering should be known as a function of the internal scattering angle $\theta$, while the external scattering angle $\theta_{\mathrm{u}}$ is measured. Since for our measurements $\varphi$ always equals zero, only those corrections will be reviewed here, which concern the $\varphi=0^{\circ}$ situation. For a more detailed description the reader is referred to Stein and Keane ${ }^{29)}$.

a. THE INTERNAL SCATTERING ANGLE

From the refraction law of Snellius the following relation between $\theta$ and $\theta_{\mathrm{u}}$ easily can be found:

$$
\theta=\arcsin \left[\frac{\sin \theta_{u}}{n}\right]
$$

b. CURRREC'IICN - TR THE TURBIDITY

As a result of the scattering the intensity of the primary 
as well as the scattered beam, on their way through the sample, will be reduced. The correction, to be applied for this, can be derived with the aid of figure 16. The intensity of the primary beam in the plane

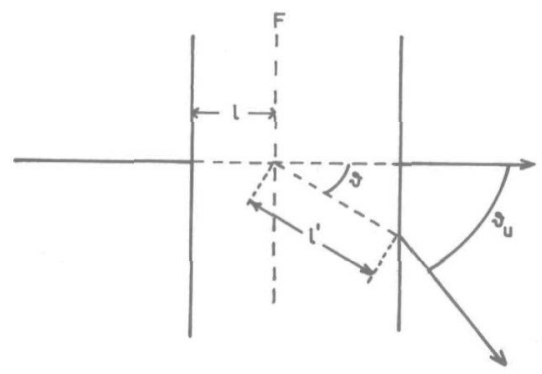

Figure 16. Diagram for the calculation of the turbidity correction. $F$ in the sample will be:

$$
I=I_{\mathrm{o}} \exp (-\tau \ell)
$$

where $I_{0}$ is the intensity of the primary beam, entering the sample. A fraction $x(\mathrm{~d} l / d)$ of $I$ will be scattered by a volume element $S \mathrm{~d} l$ ( $S$ is the cross-section of the primary beam) so:

$$
\Delta I_{\mathrm{s}}=\frac{x}{d} I_{\mathrm{o}} \exp (-\tau \ell) \mathrm{d} \ell
$$

This scattered ray still has to travel a distance $\ell^{\prime}$ through the sample, so that the remaining intensity $\Delta I !$ outside the sample will be:

$$
\Delta I_{s}^{\prime}=\frac{x}{d} I_{\mathrm{o}} \exp \left[-\tau\left(\ell+\ell^{\prime}\right)\right] \mathrm{d} \ell
$$

or, since $\ell^{\prime}=(d-\ell) / \cos \theta$ :

$$
\Delta I_{\mathrm{s}}^{\prime}=\frac{x}{d} I_{\mathrm{o}} \exp \left[-\tau\left(\ell+\frac{d-\ell}{\cos \theta}\right)\right] \mathrm{d} \ell
$$

The total measured scattering $I_{\mathrm{s}}^{\prime}$ will be now:

$$
I_{\mathrm{s}}^{\prime}=\frac{x}{d} I_{\mathrm{o}} \int_{\mathrm{o}}^{\mathrm{d}} \exp \left[-\tau\left(\ell+\frac{d-\ell}{\cos \theta}\right)\right] \mathrm{d} \ell=\frac{\left[\exp (-\tau d)-\exp \left(\frac{-\tau d}{\cos \theta}\right)\right]}{\tau d\left(\frac{1}{\cos \theta}-1\right)} I_{\mathrm{o}}
$$

If the intensity were not reduced as a result of the turbidity, the real scattering $I_{s}^{\prime \prime}$ would have been:

$$
I_{\mathrm{s}}^{\prime \prime}=x I_{\mathrm{o}}
$$

So the real scattering can be found by multiplying the measured scattering by: 


$$
K_{\mathrm{f}}=\frac{\tau d\left(\frac{1}{\cos \theta}-1\right)}{\exp (-\tau d)-\exp \left(\frac{-\tau d}{\cos \theta}\right)}=\frac{\tau d\left[\left(1-\frac{\sin ^{2} \theta_{\mathrm{u}}}{n^{2}}\right)^{-\frac{1}{2}}-1\right]}{\exp (-\tau d)-\exp \left\{(-\tau d)\left(1-\frac{\sin ^{2} \theta_{\mathrm{u}}}{n^{2}}\right)^{-\frac{1}{2}}\right\}}
$$

The case treated here is only valid for forward scattering. A different correction is required for backward scattering ${ }^{29}$ ).

c. CORRECTION FOR THE CHANGE OF THE SOLID ANGLE, VIEWED BY THE DETECTOR, IN THE SAMPLE

For the calculation of the Rayleigh ratio (equation (4.2.2)) the half solid angle $\gamma$, viewed by the detection system, is used. Figure 17 shows that as a result of refraction the real

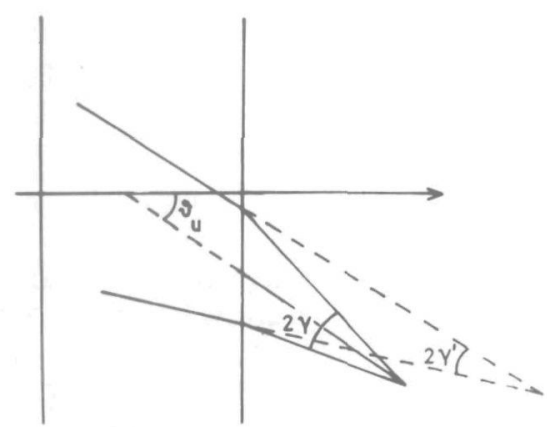

(a)

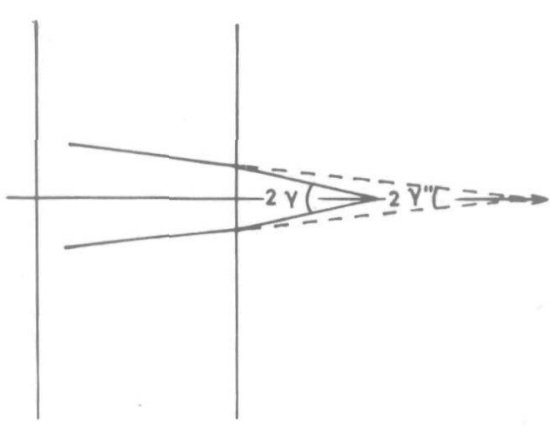

(b)

Figure 17. The real solid angles in the sample in the horizontal plane (a) and in the vertical plane (b).

solid angle in the sample differs from $2 \gamma$ : in the horizontal plane the solid angle will be $2 \gamma^{\prime}$ and in the vertical plane it will be $2 \gamma^{\prime \prime} \cdot \gamma^{\prime \prime}$ and $\gamma^{\prime}$ are given by:

$$
\begin{gathered}
\gamma^{\prime \prime}=\arcsin \left[\frac{\sin \gamma}{n}\right] \\
\gamma^{\prime}=\frac{1}{2} \arcsin \left[\frac{\sin \left(\theta_{\mathrm{u}}+\gamma\right)}{n}\right]-\frac{1}{2} \arcsin \left[\frac{\sin \left(\theta_{\mathrm{u}}-\gamma\right)}{n}\right]
\end{gathered}
$$

$(5.2 .10)$

As $\gamma$ is small $\left(\gamma=5 \cdot 10^{-3}\right), \gamma^{\prime}$ can be closely approximated by: 


$$
\gamma^{\prime}=\frac{\gamma \cos \theta_{\mathrm{u}}}{n\left(1-\frac{\sin ^{2} \theta_{\mathrm{u}}}{n^{2}}\right)^{\frac{1}{2}}}
$$

The correction factor $C_{\mathrm{n}}$, by which the measured scattering has to be multiplied in order to correct for this change of the solid angle, will be:

$$
C_{\mathrm{n}}=\frac{\operatorname{tg}^{2} \gamma}{\operatorname{tg} \gamma^{\prime} \operatorname{tg} \gamma^{\prime \prime}}
$$

As $\gamma, \gamma^{\prime}$ and $\gamma^{\prime \prime}$ are all very small the tangents may be replaced by the angles, so that:

$$
C_{\mathrm{n}}=\frac{\gamma^{2}}{\gamma^{\prime} \gamma^{\prime}}=\frac{n^{2}\left(1-\frac{\sin ^{2} \theta_{\mathrm{u}}}{n^{2}}\right)^{\frac{1}{2}}}{\cos \theta_{\mathrm{u}}}
$$

\section{d. REFLECTION CORRECTION}

From the reflection formulae of Fresnel it can be calculated that a fraction $(n-1)^{2} /(n+1)^{2}$ of the primary beam will be reflected by the first of the glass slides, by which the sample is supported. The reflection correction factor $C_{\mathrm{r}}$ will thus be:

$$
C_{\mathrm{r}}=\left[1-\left(\frac{n-1}{n+1}\right)^{2}\right]^{-1}
$$

The reflection of the scattered ray, leaving the sample at the glass-air interface, is already accounted for in the definition of the vector $\underline{O}$ (see Appendix I).

Summarizing, the total correction to be applied will be:

$$
K_{\mathrm{f}} C_{\mathrm{n}} C_{\mathrm{r}}=\frac{n^{2} \tau d\left[1-\left(1-\frac{\sin ^{2} \theta_{\mathrm{u}}}{n^{2}}\right)^{\frac{1}{2}}\right]}{\cos \theta_{\mathrm{u}}\left[\exp (-\tau d)-\exp \left\{(-\tau d)\left(1-\frac{\sin ^{2} \theta_{\mathrm{u}}}{n^{2}}\right)^{-\frac{1}{2}}\right\}\right]\left[1-\left(\frac{n-1}{n+1}\right)^{2}\right]}
$$

The correction according to (5.2.15) was performed on a TR-4 computer. The "Algol 60"-program for this calculation is given in Appendix II. 
V-3. Separation of the Spherulite- and Random OrientationScattering

After applying the corrections according to equation (5.2.15), $\kappa A^{2}, Q$ and $\left(O-\frac{4}{3} Q\right)$ were calculated from the various components of the scattering in the way described in Chapter II-3. This calculation was also performed on the TR-4 computer; the program, in "Algol 60", is given in Appendix II. 


\section{SPHERULITIC CRYSTALLIZATION OF ISOTACTIC POLYSTYRENE}

\section{VI-1. Results}

An attempt was made to determine the growth rate of the spherulites and the number of nuclei from the light scattering due to the perfectly spherulitic structures in the polystyrene samples. For this purpose four series of samples were prepared. In table III the thermal history of these four series is given: $T_{1}$ is the melting temperature, $T_{2}$ the nucleation temperature at which the sample was brought before the crystallization at temperature $T_{\mathrm{x}} ; t_{1}$ and $t_{2}$ are the residence times at $T_{1}$ and $T_{2}$. After the crystallization the samples were quenched to $20^{\circ} \mathrm{C}$. The samples of series 3 were brought directly from the melt to the crystallization temperature.

Table III

\begin{tabular}{|c|c|c|c|c|c|}
\hline series no. & $\mathrm{T}_{1}\left[{ }^{\circ} \mathrm{C}\right]$ & $\mathrm{t}_{1}[\mathrm{~min}]$ & $\mathrm{T}_{2}\left[{ }^{\circ} \mathrm{C}\right]$ & $\mathrm{t}_{2}[\mathrm{~min}]$ & $\mathrm{T}_{\mathbf{X}}\left[{ }^{\circ} \mathrm{C}\right]$ \\
\hline 1 & 265 & 60 & 20 & 10 & 140 \\
2 & 265 & 60 & 98 & 30 & 140 \\
3 & 265 & 60 & - & - & 140 \\
4 & 265 & 60 & 98 & 30 & 140 \\
\hline
\end{tabular}

With the low-angle light scattering photometer, described in Chapter IV-2, for all samples the angle $\theta_{u}^{\max }$ was determined, at which $\left(K_{\mathrm{d}}\right)$ tot (crossed polarizer and analyser, $\psi=45^{\circ}$ ) was at a maximum. The maxima of $\left(K_{\mathrm{d}}\right)_{\text {tot }}$ and $\left(K_{\mathrm{d}}\right)_{\mathrm{sf}}$ (the latter is the spherulitic part of the scattering) approximately coincide, so that this procedure is permitted. The mean radius of the spherulites was determined from this angle $\theta_{\mathrm{u}}^{\max }$ (at the maximum $U=4.10)$ :

$$
R_{\mathrm{sf}}=\frac{4.1(\lambda / n)}{4 \pi \sin \left[0.5 \arcsin \left(\frac{\sin \theta_{u}^{\max }}{n}\right)\right]}
$$

In the figures 18 to $21 R_{\text {sf }}$, measured in this way, is plotted against the crystallization time for series 1 to 4 . 


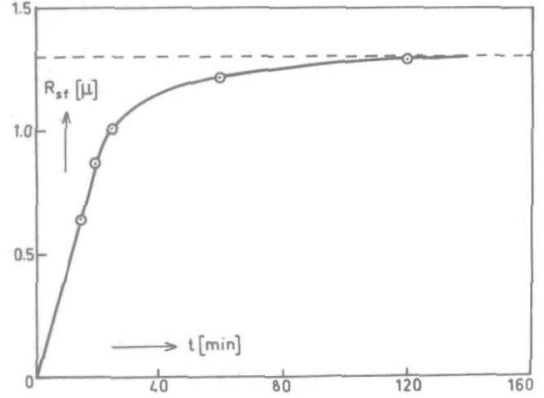

Figure 18. Crystallization curve of polystyrene, series 1 .

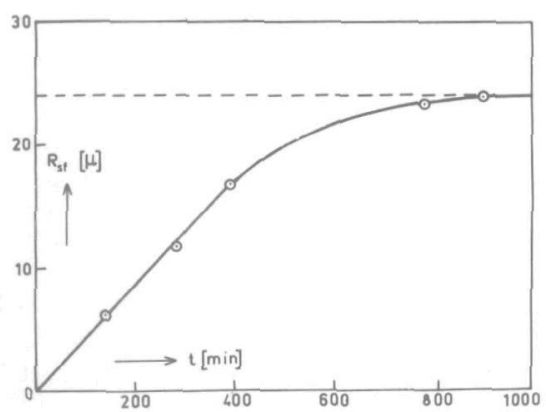

Figure 20. Crystallization curve of polystyrene, series 3 .

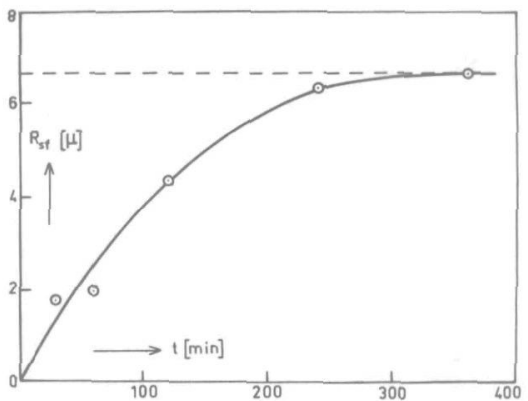

Figure 19. Crystallization curve of polystyrene, series 2.

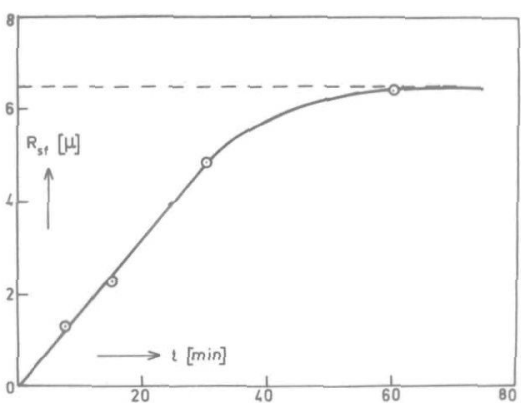

Figure 21. Crystallization curve of polystyrene, series 4.

For all series $R_{\text {sf }}$ appears to increase linearly with $t$ in the beginning and later approaches asymptotically a certain end value. At small $t$ values the spherulites still do not touch each other and can grow unhindered, but with increasing $t$ more and more spherulites will be stopped in their growth by impingement.

The radial growth rate $v_{\mathrm{r}}$ was determined from the initial slopes of the curves. According to Boon ${ }^{15)}$ the nucleation can be described by equation (3.1.6). This result indicates that new nuclei will arise during the crystallization, which implies that $v_{\mathrm{r}}$ should not really be obtainable in the foregoing way.

The number of spherulites per $\mathrm{cm}^{3}, N_{\text {sf }}$, was calculated from the maximum value, which $R_{\text {sf }}$ can reach for a series $\left(R_{\mathrm{sf}}^{\max }\right)$; in that situation the sample has been filled up totally by spherulites, so that

$$
x=N_{\mathrm{sf}} \frac{4}{3} \pi\left(R_{\mathrm{sf}}^{\max }\right)^{3}
$$

where $x$ is the fraction of the volume, occupied by the spherulites. For monodisperse spheres and a cubical packing $x=0.52$, for hexagonal packing $x=0.74$. Since the degree of dispersity 
and the packing are unknown, the order of magnitude of $N_{\mathrm{sf}}$ is determined by putting $x=1$. In table IV $v_{\mathrm{r}}$ and $N_{\mathrm{sf}}$ from the various series are compared with the values as measured by Boon ${ }^{15)} ; N_{\mathrm{sf}}$ is compared with the number of subcritical nuclei

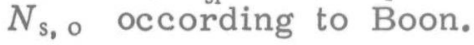

Table IV

\begin{tabular}{|c|l|l|c|c|c|c|}
\hline series no. & $\mathrm{T}_{\mathrm{x}}\left[{ }^{\mathrm{o}} \mathrm{C}\right]$ & $\mathrm{v}_{\mathrm{r}}[\boldsymbol{\mu} / \mathrm{min}]$ & $\left.\mathrm{v}_{\mathrm{r}(\text { Boon })[\mu / \mathrm{min}}\right]$ & $\mathrm{T}_{2}\left[{ }^{\mathrm{o}} \mathrm{C}\right]$ & $\mathrm{N}_{\mathrm{sf}}\left[\mathrm{cm}^{-3}\right]$ & $\mathrm{N}_{\mathrm{s}, \mathrm{o}(\text { Boon })}\left[\mathrm{cm}^{-3}\right]$ \\
\hline 1 & 140 & 0.043 & 0.036 & 20 & $1.1 \cdot 10^{11}$ & $3.4 \cdot 10^{11}$ \\
2 & 140 & 0.045 & 0.036 & 98 & $0.7 \cdot 10^{9}$ & $1.1 \cdot 10^{9}$ \\
3 & 140 & 0.044 & 0.036 & 140 & $1.7 \cdot 10^{7}$ & $1.0 \cdot 10^{7}$ \\
4 & 160 & 0.16 & 0.15 & 98 & $0.9 \cdot 10^{9}$ & $1.1 \cdot 10^{9}$ \\
\hline
\end{tabular}

$\mathrm{T}_{2}=100^{\circ} \mathrm{C}$

\section{VI-2. Discussion}

The radial growth rate at $T_{\mathrm{x}}=160^{\circ} \mathrm{C}$ appears to correspond quite well with the value, measured by Boon, but at $T_{\mathrm{x}}=140^{\circ} \mathrm{C}$ the microscopical investigation by Boon reveals a considerably lower growth rate. The cause of this great difference cannot be found in the fact that our calculations do not take into account a continuing nucleation during the crystallization, because in that case $v_{\mathrm{r}}$ would be found to be too low compared with Boon's value. In addition the crystallization curves do not give any indication about a continuing nucleation: the slopes are initially all constant. At the first measuring point $\nu t$ is presumably already so large that the greater part of the total possible number of nuclei already has been formed.

It might be speculated that in our case the growth rates are measured on much smaller spherulites $\left(R_{\mathrm{sf}}<5 \mu\right)$ than in the microscopical investigation by Boon $\left(R_{\mathrm{sf}}>5 \mu\right)$. This might indicate a larger growth rate at the beginning of the crystallization at $140^{\circ} \mathrm{C}$. An error in $T_{\mathrm{x}}$ seems to be more probable, however. According to the data of Boon $\mathrm{d} v_{\mathrm{r}} / \mathrm{d} T$ at $140{ }^{\circ} \mathrm{C}$ is about $0.005 \mu /\left({ }^{\circ} \mathrm{C} \mathrm{min}\right):$ the difference in $v_{\mathrm{r}}$ is then explainable when an error of $1.6^{\circ} \mathrm{C}$ in the $T_{\mathrm{x}}$ is assumed. *

If one considers the values of $N_{\text {sf }}$, obtained from our measurements, it appears that there is a good correspondence with the dilatometrically measured $N_{\mathrm{s}}$, o of Boon, in spite of the approximate nature of our calculation. Any discrepancy between

- The crystallization temperatures in our case were determined by means of a calibrated thermometer; a private communication from Boon revealed a possible error of 1 to $1.5^{\circ} \mathrm{C}$ for his crystallization temperatures. Boon kept the temperatures accurately constant, but did not use a calibrated thermometer. 
$N_{\text {sf }}$ and $N_{\mathrm{s} \text {, o }}$ should be negligible because $N_{\text {sf }}$ is determined from $R_{\mathrm{sf}}^{\max }$, which is obtained at very large values of $\nu t$.

\section{CONCLUSIONS}

In the case of isotactic polystyrene the number of subcritical nuclei (i.e. the total number of spherulites in a sample, totally filled up by spherulites), determined by means of the light scattering technique, corresponds very well with the dilatometrically found values. Besides, light scattering is a simple and successful technique for the determination of the growth rate of spherulites. 
LIGHT SCATTERING MEASUREMENTS ON ISOTACTIC POLYSTYRENE AND ISOTACTIC POLYPROPYLENE

\section{VII-1. Results}

Extensive light scattering measurements have been performed on 5 polystyrene samples and 3 polypropylene samples. The thermal history of these samples can be found in Tables $V$ and VI respectively.

Table V

\begin{tabular}{|l|l|l|l|l|l|l|}
\hline code & $\mathrm{T}_{1}\left[{ }^{\circ} \mathrm{C}\right]$ & $\mathrm{t}_{1}[\mathrm{~min}]$ & $\mathrm{T}_{2}\left[{ }^{\mathrm{O}} \mathrm{C}\right]$ & $\mathrm{t}_{2}[\mathrm{~min}]$ & $\mathrm{T}_{\mathrm{x}}\left[{ }^{\circ} \mathrm{C}\right]$ & $\mathrm{t}_{\mathrm{x}}[\mathrm{min}]$ \\
\hline ps1 & 265 & 60 & 20 & 10 & 140 & 15 \\
ps2 & 265 & 60 & 20 & 10 & 140 & 20 \\
ps3 & 265 & 60 & 20 & 10 & 140 & 25 \\
ps4 & 265 & 60 & 98 & 30 & 140 & 240 \\
ps5 & 265 & 60 & - & - & 140 & 140 \\
\hline
\end{tabular}

Thermal history of the polystyrene samples.

Table VI

\begin{tabular}{|l|c|c|c|l|}
\hline code & $\mathrm{T}_{1}\left[{ }^{\mathrm{o}} \mathrm{C}\right]$ & $\mathrm{t}_{1}[\mathrm{~min}]$ & $\mathrm{T}_{4}\left[{ }^{\mathrm{o}} \mathrm{C}\right]$ & $\mathrm{t}_{4}[\mathrm{~min}]$ \\
\hline pp1 & 210 & 60 & 98 & 30 \\
pp2 & 210 & 60 & 0 & 30 \\
pp3 & 210 & 60 & -95 & 30 \\
\hline
\end{tabular}

Thermal history of the polypropylene samples.

The samples ps1, ps2 and ps3 were taken from series 1 of the crystallization experiments described in Chapter VI, ps4 and ps5 were from series 2 and 3 (samples ps1, ps2, ps3 and ps5 contain "free" not impinged spherulites, in ps4 impingement of the spherulites does occur). The polypropylene samples were made by quenching from the melt to a temperature $T_{4}$. After a residence time of 30 minutes at $T_{4}$ they were brought to room temperature.

An attempt was made to separate the spherulite- and random orientation- scattering by evaluating the measurements as described in Chapters $V$ and II-4. The values of $\kappa A^{2}, Q$ and $\left(O-\frac{4}{3} Q\right)$, obtained in this way, were plotted: figures 22 through 


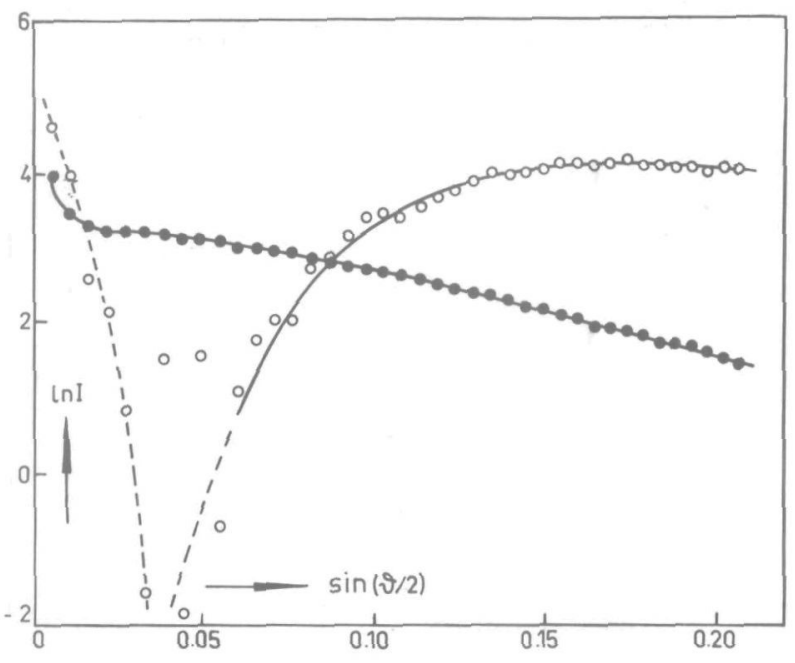

Figure 22. Scattering curves of sample psl; $\bullet=\operatorname{lnQ}, \quad 0=\ln \kappa \mathrm{A}^{2}$.

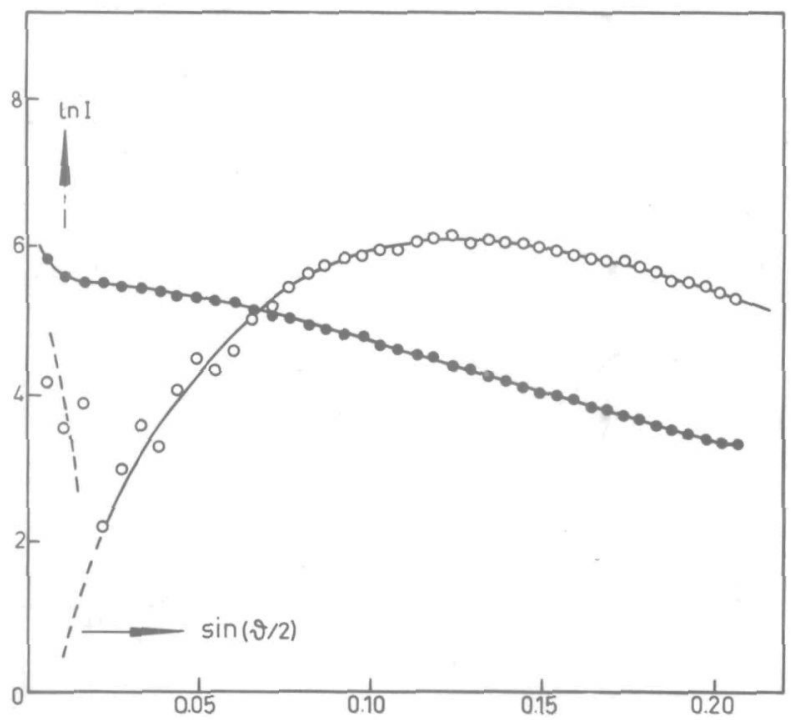

Figure 23. Scattering curves of sample ps2; $=\ln \mathrm{Q}, \mathrm{o}=\ln \kappa \mathrm{A}^{2}$. 


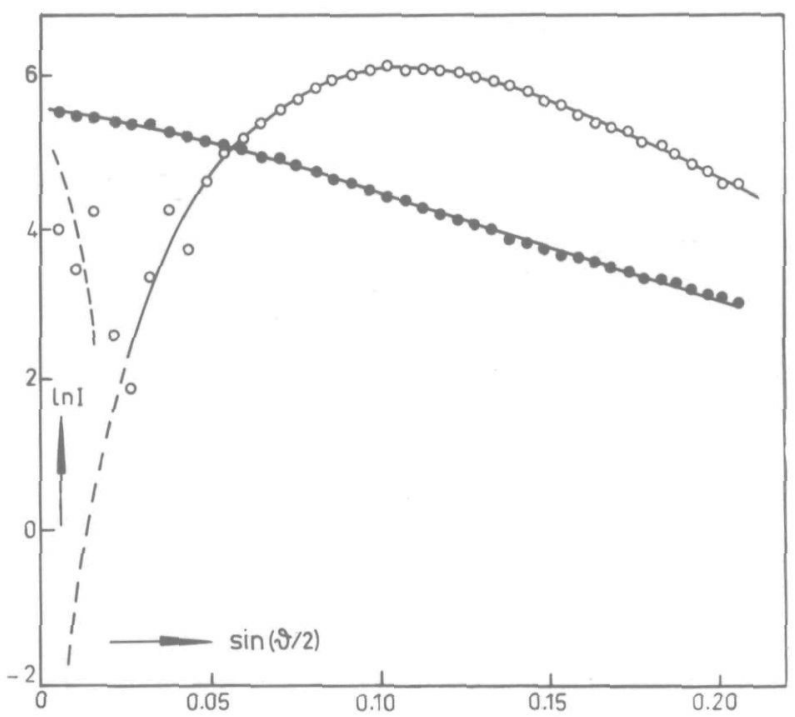

Figure 24. Scattering curves of sample ps3; $\bullet=\ln Q, 0=\ln \kappa A^{2}$.

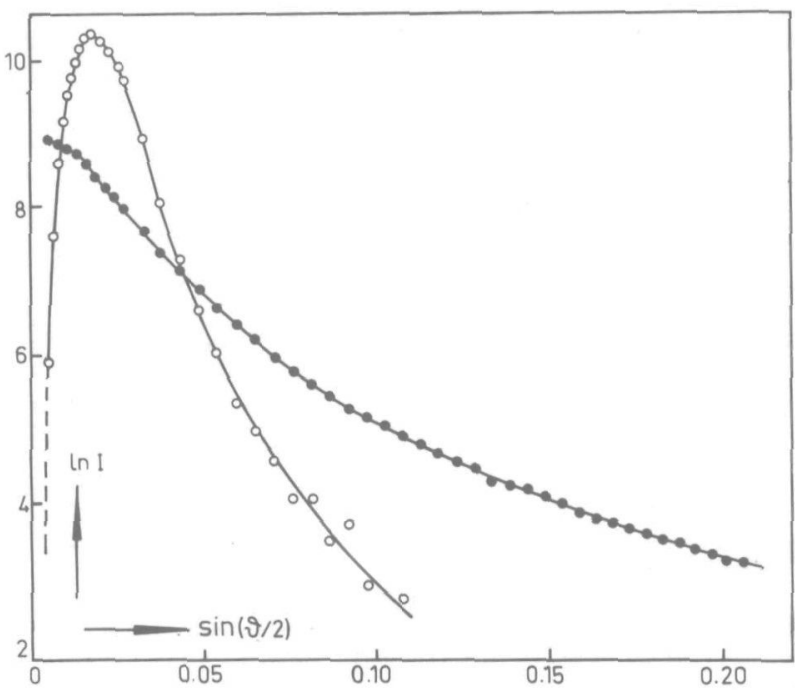

Figure 25. Scattering curves of sample ps4; $\bullet=\ln Q, 0=\ln \kappa A^{2}$. 


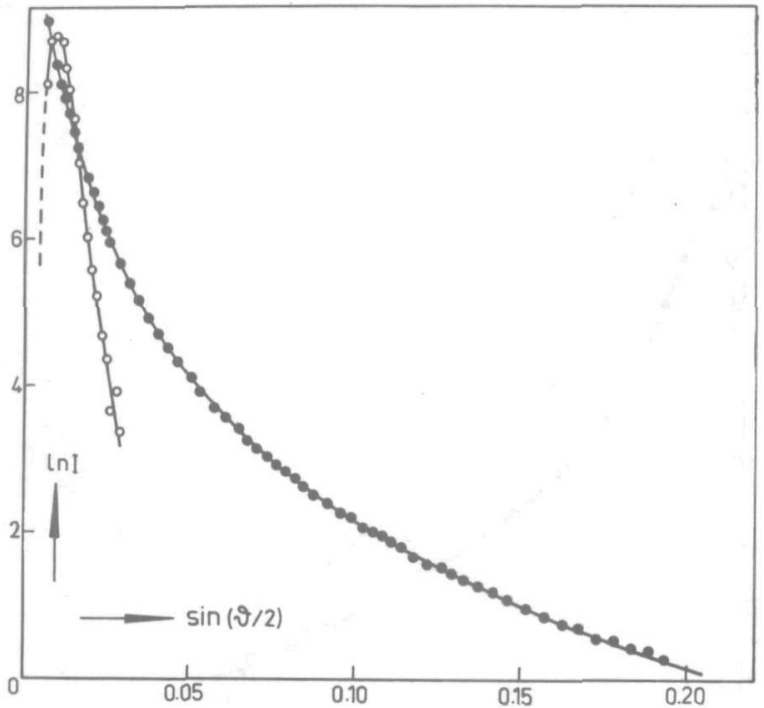

Figure 26. Scattering curves of sample ppl; $\bullet=\ln Q, 0=\ln k A^{2}$.

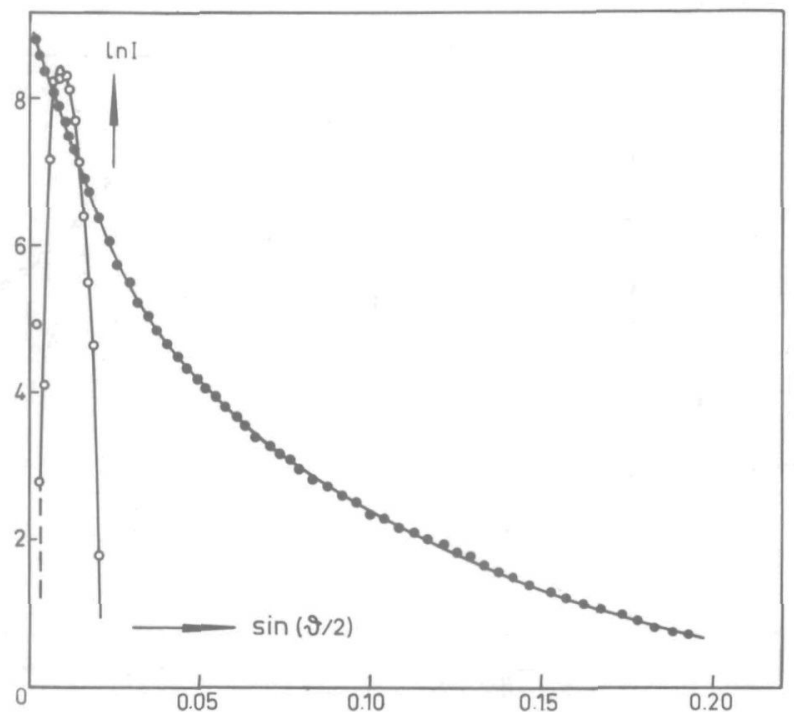

Figure 27. Scattering curves of sample pp2; $\bullet=\ln Q, 0=\ln k A^{2}$. 


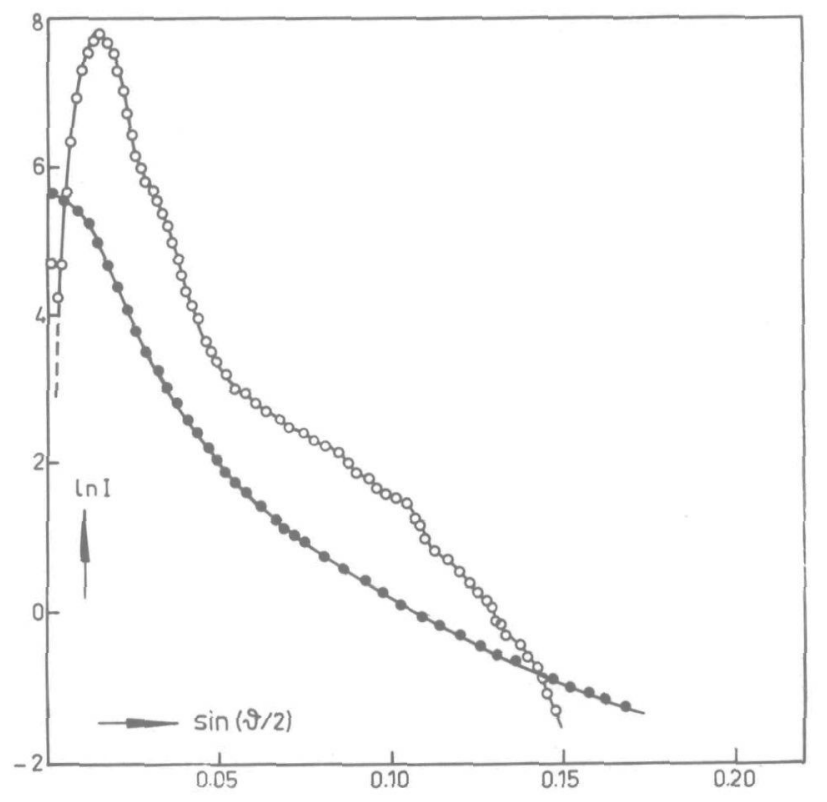

Figure 28. Scattering curves of sample $\mathrm{pp} 3 ; \bullet=\ln \mathrm{Q}, \mathrm{o}=\ln \kappa \mathrm{A}^{2}$.

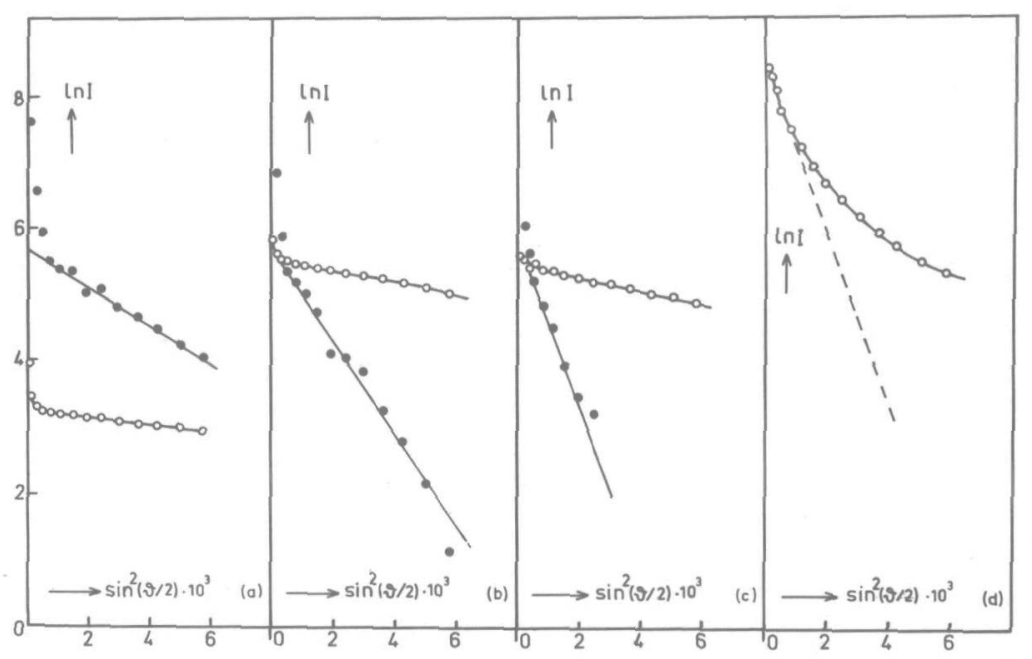

Figure 29. Random orientation part of the scattering; $a=p s 1, b=p s 2, c=p s 3, d=p s 4$; $\bullet=\ln \left(O-\frac{4}{3} Q\right), \quad o=\ln Q$. 


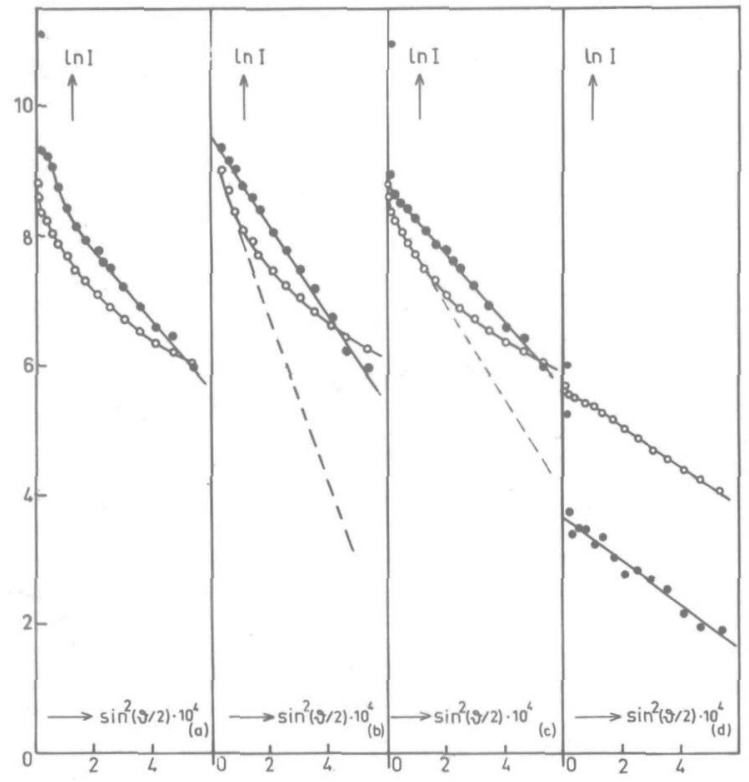

Figure 30. Random orientation part of the scattering: $a=p p 2$, not accounting for the spherulitic scattering, $b=p p 1, c=p p 2, d=p p 3 ; \quad=\ln \left(O-\frac{4}{3} Q\right), \quad o=\ln Q$.

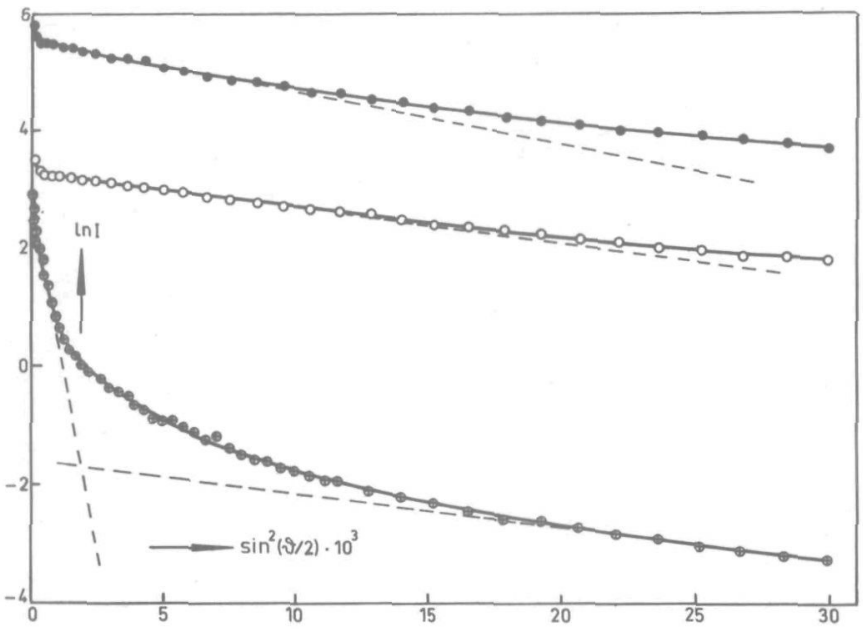

Figure 31 . The anisotropic part $(\operatorname{lnQ})$ of the random orientation scattering; $o=p s 1, \bullet=p s 2$, $\bullet=\mathrm{ps} 5$. 


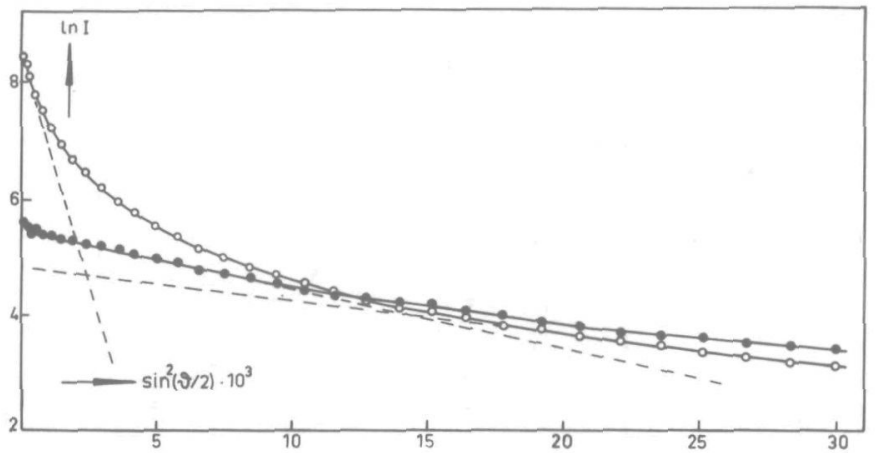

Figure 32. The anisotropic part $(\operatorname{lnQ})$ of the random orientation scattering; $\bullet=p s 3,0=p s 4$.

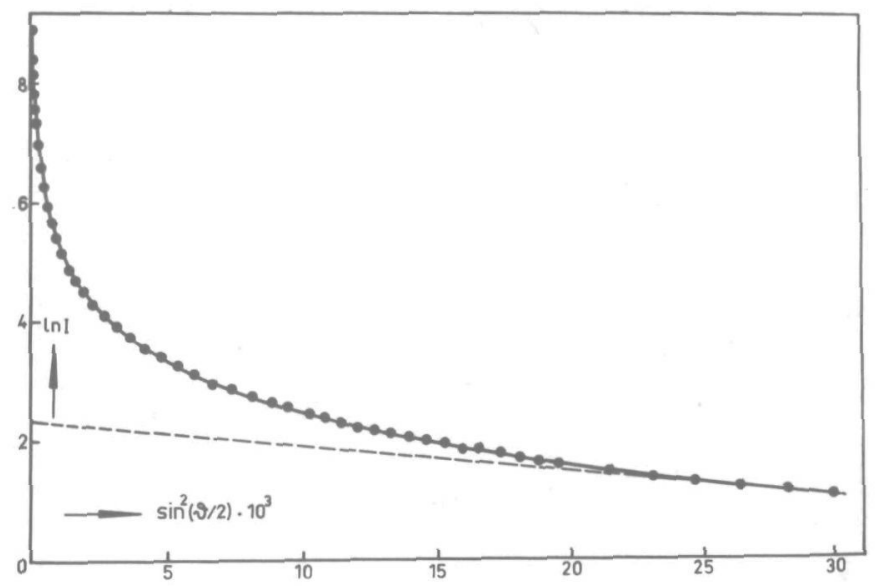

Figure 33. The anisotropic part (lnQ) of the random orientation scattering of sample pp2. 


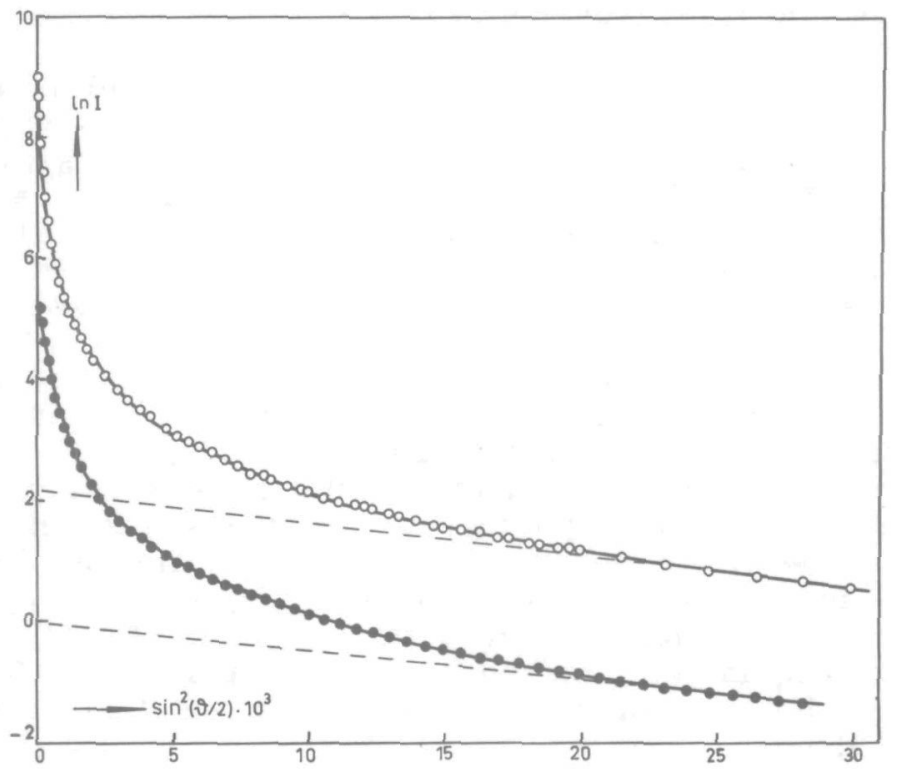

Figure 34 , The anisotropic part $(\ln \mathrm{Q})$ of the random orientation scattering; $0=p p l, \bullet=p p 3$.

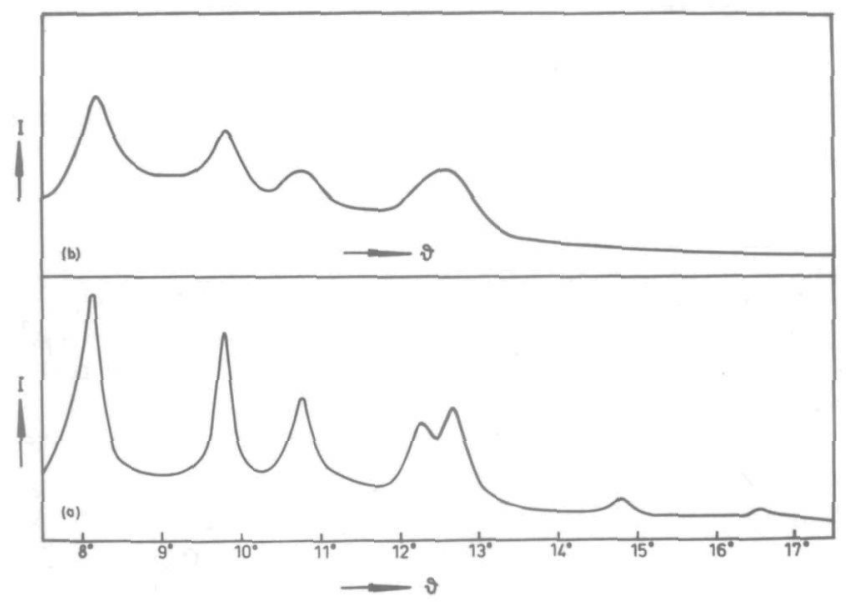

Figure 35. X-ray diagrams of sample $\mathrm{pp} 3$ (a) and sample pp2 (b). 
28 show $\ln k A^{2}$ and $\ln Q$ versus $\sin (\theta / 2)$, figures 29 and $30 \ln Q$ and $\ln \left(O-\frac{4}{3} Q\right)$ versus $\sin ^{2}(\theta / 2)$ in the angular interval, within which $\left(O-\frac{4}{3} Q\right)$ could be determined, and figures 31 through 34 $\ln Q$ versus $\sin ^{2}(\theta / 2)$ for the whole angular range, over which measurements were made.

For the samples ps4, pp1 and pp2, $k A^{2}$ is known only in a small angular interval because at larger angles $\kappa A^{2}$ becomes smaller than the accuracy, with which $\left(K_{\mathrm{d}}\right)_{\text {tot }}$ and $\left(V_{\mathrm{h}}\right)_{\text {tot }}$ can be measured ( $\kappa A^{2}$ is mainly determined by the difference between $\left(K_{\mathrm{d}}\right)_{\text {tot }}$ and $\left.\left(V_{\mathrm{h}}\right)_{\text {tot }}\right)$; this follows from equations $(2.4 .15),(2.4 .27)$ and (2.4.31) putting $\cos \theta_{\mathrm{p}}=\cos \theta_{\mathrm{p}}^{*}$. This is clearly demonstrated by the course of $Q$ (a measure for $\left(V_{\mathrm{h}}\right)$ tot $)$ with respect to $\kappa A^{2}$ in the figures 25 through 27.

Comparing the figures 26 and 27 with figure 28 it is conspicuous that the level of $Q$ for pp1 and pp2 is much higher than for pp3. In the former case the spherulitic scattering will be almost totally buried under the random orientation-scattering. This is also clearly revealed by photographs of the scattering pattern, made with the laser set-up (Chapter IV-2); figures 13 and 14 show these photographs for pp2 and pp3 respectively: pp3 shows a well formed four-leaf clover pattern, typical for the spherulitic scattering in the crossed position of polarizer and analyser, but in the case of pp2 hardly anything of this pattern can be observed.

The mean radii of the spherulites, as given in table VII, were calculated from the condition that $U=4.1$ at the maximum of $\kappa A^{2}$; the radius of the spherulites in sample ps5, of which only the $V_{\mathrm{h}}$ component was measured accurately, was obtained in the way indicated in Chapter VI.

According to equations (2.3.27), (2.3.31) and (2.4.11) $\kappa A^{2}$ is given by:

$\kappa A^{2}=\frac{256 \pi^{6}}{\lambda_{\mathrm{o}}^{4}} N_{\mathrm{sf}} R_{\mathrm{sf}}^{6}\left(\frac{3 \cos ^{2} \beta-1}{2}\right)^{2}\left(\alpha_{1}-\alpha_{2}\right)^{2}\left[\frac{4 \sin U-U \cos U-3 \mathrm{Si} U}{U^{3}}\right]^{2}$

At the maximum the values of $\kappa A^{2}$ and $U(=4.10)$ are known: $N_{\text {sf }}$ values for ps1 through ps 4 have already been calculated in Chapter VI and for pp1 through pp3 $N_{\text {sf }}$ can be determined in the same way by using equation (6.1.2) (the volume of the polypropylene sample is completely filled by spherulites). So with the aid of equation (7.1.1) now $\left(3 \cos ^{2} \beta-1\right)\left(\alpha_{1}-\alpha_{2}\right) / 2$ can be calculated. For small values of $\left(\alpha_{1}-\alpha_{2}\right)$, one has to a good approximation $\alpha_{\mathrm{r}}-\alpha_{\mathrm{t}}=\left(3 \cos ^{2} \beta-1\right)\left(\alpha_{1}-\alpha_{2}\right) / 2$, if $\alpha_{\mathrm{r}}$ and $\alpha_{\mathrm{t}}$ represent the polarizabilities in radial and tangential direction respectively. These polarizability differences, calculated in the foregoing way, are given in table VII.

In figure $29 \ln \left(O^{-}-\frac{4}{3} Q\right)$ is plotted against $\sin ^{2}(\theta / 2)$ for ps 1 through ps3. For ps4 $\left(O-\frac{4}{3} Q\right)$ could not be determined; with increasing spherulite dimension (ps1, ps2, ps3) the decrease of 
$\left(O-\frac{4}{3} Q\right)$ with $\sin ^{2}(\theta / 2)$ evidently becomes steeper and steeper, so that for ps4, which contains still larger spherulites, already at the first measuring point $\left(O-\frac{4}{3} Q\right)$ is smaller than the accuracy, with which $O$ and $Q$ can be measured. For samples ps1 through ps3 as well as for pp1 through pp3 (figure $30 \mathrm{~b}, \mathrm{c}$ and d) $\ln \left(O-\frac{4}{3} Q\right)$ obviously decreases linearly with $\sin ^{2}(\theta / 2)$; in this case the Fourier transformation according to equation (2.4.39), which yields $\gamma(r)$ and $\left\langle\eta^{2}\right\rangle$, can be evaded. Keijzers, van Aartsen and Prins ${ }^{30}$ ) have shown that in such cases $\gamma(r)$ is gaussian:

$$
\gamma(r)=\exp \left(-r^{2} / a^{2}\right)
$$

where $a$ is a characteristic correlation distance. The elaboration of equation (2.4.37), with the aid of equation (7.1.2), gives:

$$
\left(O-\frac{4}{3} Q\right)=\frac{1}{4} K<\eta^{2}>a \sqrt{\pi} \exp \left(-h^{2} a^{2} / 4\right)
$$

Thus, $a$ and $\left\langle\eta^{2}\right\rangle$ can be calculated from the slope and the intercept in the plot of $\ln \left(O-\frac{4}{3} Q\right)$ versus $h^{2}$ (or $\left.\sin ^{2}(\theta / 2)\right)$. The values of $a$ and $\left\langle\eta^{2}\right\rangle^{\frac{1}{2}}$, calculated in this way, are shown in table VII.

The feasibility of determining $\gamma(r)$, with the neglection of the spherulite scattering, as formerly done by the author in conjunction with van Aartsen and Prins ${ }^{30)}$, was investigated for sample pp2, which is similar to the one previously used ${ }^{30}$ ). For this end $R_{\mathrm{q}}^{2}\left[\left(V_{\mathrm{v}}\right)_{\text {tot }}-\frac{4}{3}\left(V_{\mathrm{h}}\right)\right.$ tot $]$ was used in stead of $\left(O-\frac{4}{3} Q\right)$. Except for very small angles, figure $30 \mathrm{a}$ obviously shows the same course as figure $30 \mathrm{c}$. In the latter the spherulitic scattering has been accounted for. Clearly, the contribution of the spherulitic scattering to $\left(V_{\mathrm{v}}\right)_{\text {tot }}$ is so small, that no separation is needed in order to obtain the isotropic part of the random orientation scattering $(\gamma(r))$; at small angles, however, the influence of the spherulitic scattering can still be noticed, but an extrapolation to $\sin ^{2}(\theta / 2)=0$ is still quite feasible. An attempt to follow the same procedure with pp3 failed completely. This is not surprising because of the high spherulitic scattering, shown in figure 28. The description of the light scattering by quenched isotactic polypropylene, given by Keijzers, van Aartsen and Prins, thus appears to have been successful because of a favourable choice of sample. ${ }^{*}$

The orientation correlation function $f(r)$ has been determined in a way similar to the determination of $\gamma(r)$. The following expression, already formerly found for polypropylene ${ }^{30}$ ), has been used:

$$
f(r)=f_{1}(r)+f_{2}(r)
$$

\footnotetext{
- The choice of the sample was not made quite fortuitously, as at that moment it was thought that no spherulitic scattering occurred because the scattering of the sample did.not show a four-leaf clover pattern.
} 
where

$$
f_{1}(r)=x \exp \left(-r^{2} / b^{2}\right)
$$

and

$$
f_{2}(r)=(1-x) \exp \left(-r^{2} / c^{2}\right)
$$

The orientation correlation function, as represented in equation (7.1.4), can be thought to consist of two different gaussian correlation functions. Besides $f(r)$, also $\mu(r)$ has to be known in order to solve equation (2.4.38); the mean polarizability $\alpha$ of the sample can be calculated by means of the Lorenz-Lorentz equation:

$$
\alpha=\frac{3 \pi\left(n^{2}-1\right)}{4\left(n^{2}+2\right)}
$$

from which follows that $\alpha=7,12 \cdot 10^{-2}$ for polypropylene $(n=$ $1.51)$ and $\alpha=8.12 \cdot 10^{-2}$ for polystyrene $(n=1.595)$. With the use of the already known values of $\left\langle\eta^{2}\right\rangle^{\frac{1}{2}}$ (see table VII), $\mu(r)$ can be found to be at most:

$$
\mu(r)=1+7 \cdot 7 \cdot 10^{-5} \gamma(r)
$$

As $\gamma(r) \leqslant 1$, one has to a good approximation $\mu(r)=1$ for all values of $r$. The solution of equation (2.4.38) will then be:

$$
Q=\frac{1}{15} K \delta^{2}\left[\frac{x b^{3} \sqrt{\pi}}{4} \exp \left(-\frac{h^{2} b^{2}}{4}\right)+\frac{(1-x) c^{3} \sqrt{\pi}}{4} \exp \left(-\frac{h^{2} c^{2}}{4}\right)\right]
$$

The plots of $\ln Q$ versus $\sin ^{2}(\theta / 2)$ appear to be linear over a rather wide angular interval for ps1 through ps3 (figures 31 and 32 ), so that one can put $x=1 ; b$ was calculated from the slope and $\delta$ from the intercept. For all other samples (figures 31 through 34) $c$ was calculated from the slope at small $\sin ^{2}(\theta / 2)$ (see also figures 29 and 30 ) and $b$ from the slope at the end of the curves. The values of $x$ and $\delta$ were determined from the intercepts, resulting from the extrapolations of both straight lines to $\sin ^{2}(\theta / 2)=0$. The values of $b, c, x$ and $\delta$ are collected in table VII. I This procedure may be applied for these samples because the first of the two terms between brackets in equation (7.1.9) is negligible at small angles; at large angles the opposite holds.

The Fourier transformations according to (2.4.39) and (2.4.40) will certainly not yield more accurate results for $\gamma(r), f(r)$, $\left\langle\eta^{2}\right\rangle$ and $\delta$, than the procedure just explained, because $\left(O-\frac{4}{3} Q\right)$ and $Q$ cannot be measured over a sufficiently large angular range.

Small refractive index differences may be calculated from equation (7.1.10), which can be obtained by differentiating the Lorenz-Lorentz equation (7.1.7):

$$
\Delta n=\frac{2 \pi\left(n^{2}+2\right)^{2}}{9 n} \Delta \alpha
$$




\begin{tabular}{|c|c|c|c|c|c|c|c|c|}
\hline sample & $\mathrm{R}_{\mathrm{sf}}[\mu]$ & $\mathrm{a}[\mu]$ & $\mathrm{b}[\mu]$ & $\mathrm{c}[\mu]$ & $\mathrm{x}$ & $\mathrm{m}^{2}>^{\frac{1}{2}} \cdot 10^{4}$ & $\delta \cdot 10^{3}$ & $\left(\alpha_{\mathrm{r}}-\alpha_{\mathrm{f}}\right) \cdot 10^{3}$ \\
\hline ps1 & 0.65 & 0.92 & 0.42 & - & 1 & 6.25 & 2.33 & 5.92 \\
ps2 & 0.88 & 1.44 & 0.51 & - & 1 & 3.25 & 5.39 & 6.49 \\
ps3 & 1.02 & 1.94 & 0.54 & - & 1 & 2.18 & 4.74 & 4.30 \\
ps4 & 6.27 & - & 0.42 & 1.95 & 0.73 & - & 6.12 & 1.80 \\
ps5 & 6.30 & - & 0.41 & 2.23 & 0.72 & - & 0.25 & - \\
pp1 & 13.9 & 4.80 & 0.42 & 6.57 & 0.73 & 3.64 & 1.59 & 0.218 \\
pp2 & 13.1 & 4.07 & 0.37 & 4.92 & 0.83 & 3.24 & 1.92 & 0.200 \\
pp3 & 8.03 & 3.35 & 0.38 & 3.17 & 0.66 & 0.32 & 0.63 & 0.304 \\
\hline
\end{tabular}

Putting $\left\langle\eta^{2}\right\rangle^{\frac{1}{2}}$ into $(7.1 .10)$ instead of $\Delta \alpha$, a mean refractive index fluctuation $(\Delta n)_{1}$ is obtained; the mean birefringence $(\Delta n)_{2}$ of the random orientation crystallites and the mean birefringence of the spherulites $(\Delta n)_{\text {sf }}$ (the difference of the refractive indices in radial and tangential direction) can be obtained by using $\delta$ and $\left(\alpha_{\mathrm{r}}-\alpha_{\mathrm{t}}\right)$ respectively instead of $\Delta \alpha$. The refractive index differences, calculated with the aid of (7.1.10), are given in Table VIII.

Table VIII

\begin{tabular}{|l|c|c|c|c|}
\hline sample & $(\Delta \mathrm{n})_{1} \cdot 10^{3}$ & $(\Delta \mathrm{n})_{2} \cdot 10^{3}$ & $(\Delta \mathrm{n})_{\mathrm{sf}} \cdot 10^{3}$ & $\mathrm{R}_{\mathrm{sf}}[\mu]$ \\
\hline ps1 & 5.64 & 21.0 & 53.5 & 0.65 \\
ps2 & 2.93 & 48.7 & 58.6 & 0.88 \\
ps3 & 1.97 & 42.8 & 38.8 & 1.02 \\
ps4 & - & 55.3 & 16.3 & 6.27 \\
ps5 & - & 2.26 & - & 6.30 \\
pp1 & 3.08 & 13.5 & 1.84 & 13.9 \\
pp2 & 2.74 & 16.2 & 1.68 & 13.1 \\
pp3 & 0.27 & 5.33 & 2.58 & 8.03 \\
\hline
\end{tabular}

\section{VII-2. Discussion}

The separation of the scattering in a perfectly spherulitic and a random orientation part, as performed in the previous section, appears to be possible. In general the separation can be fully 
achieved, if both parts of the scattering are of the same order of magnitude; the anisotropic part $(Q)$ of the random orientationscattering $(f(r))$, moreover, can always be obtained, because $\left(V_{\mathrm{h}}\right)_{\text {tot }}$ and $\left(H_{\mathrm{v}}\right)_{\text {tot }}$ are exclusively related to $Q$.

In figures 22 through 24 the plotted values for $k A^{2}$ show an upturn at small angles instead of a continuing decrease as would be expected from the theory. A possible explanation for this phenomenon might be thought to lie in the existence of relatively large birefringent areas (e.g. streaming patterns, left over from the melt, in spite of all precautions). Sample ps 4 does not exhibit this increase at small angles (see figure 25); this should then not be ascribed to the absence of such oriented regions, but rather to the fact that the scattering by these birefringent areas is masked by the spherulitic scattering, which is much higher at small angles in this case than for samples ps1, ps2 and ps3.

Information about the size distribution of the spherulites from the measured course of $k A^{2}$ (figures 22 through 28) is rather limited since, on the one hand for ps1, ps 2 and ps $3 k A^{2}$ has not been measured far enough beyond the first maximum and on the ohter hand for ps4, pp1 and pp2 $k A^{2}$ could not be determined far enough beyond the first maximum because of the high random orientation- scattering. Only in the case of pp3 $k A^{2}$ is shown rather far beyond the maximum in figure 28. Starting from a random disposition of nuclei the spherulites cannot be of equal size if the volume is completely filled with spherulites as was the case for all our polypropylene samples. In spite of this, remains of the higher order maxima are indicated by the shoulders in figure 28 ( $\mathrm{cp}$. figures 7 and 8 in Chapter II). The very steep decrease of $k A^{2}$ in figures 26 and 27 also suggests an originally (before impingement of the spherulites) rather narrow distribution for the polypropylene samples. And indeed, the constant number of nuclei during the crystallization of polypropylene, as found by von Falkai and Stuart 31,32), should lead to spherulites of equal size as long as their growth would not be impeded by impingement. Unfortunately, even a very quick quench from the melt (pp3) did not yield a sample with "free" spherulites. From the data of Padden and Keith"25) and von Falkai and Stuart 31,32 ) about the radial growth rate of the spherulites (ca. $130 \mu / \mathrm{min})$ and the number of nuclei $\left(10^{8}\right.$ to $10^{9} \mathrm{~cm}^{-3}$ ) at $110^{\circ} \mathrm{C}$, it can be calculated that at $110^{\circ} \mathrm{C}$ the sample will be totally filled by spherulites within 2 seconds. So it will be very difficult, if not impossible, to obtain a polypropylene sample with "free" spherulites, the more so as at lower temperatures the number of nuclei will still increase and the growth rate will probably be still increasing, too.

A comparison of $a$ and $R_{\text {sf }}$ in table VII reveals that there is a correlation between these two quantities; a functional correlation (possibly linear) cannot be determined from the available data. For polystyrene $a$ is consistently larger and for polypropylene consistently smaller than $R_{\text {sf }}$. The value of $b$ seems to 
be a constant for each separate polymer: for polystyrene ca. $0.44 \mu$ and for polypropylene ca. $0.39 \mu$. It is very plausible to consider $b$ as a measure for the irregular centre of the spherulites, which has been observed by many investigators $22,33,34,35)$

The correlation distance $c$ should then originate from the irregularity of the whole spherulite, or - in other words - from the non-spherulitically crystallized part of the material within the spherulite. For the samples ps1, ps2 and ps3 no $c$ value is detectable because in these cases $c$ is of the same order of magnitude as $b$ and/or the contribution $(1-x)$ is so small that the "c-scattering" will vanish into the scattering, caused by $b$.

Originally the series of polystyrene samples consisted of ps 1 through ps4; ps1, ps2 and ps3 contain "free" spherulites and in ps4 the spherulites already impinge (about $75 \%$ of the volume is occupied by the spherulites). At that moment it was conjectured that $c$ had its origin in the impingement of the spherulites. This idea was, however, not verified by the measurements on sample ps5, containing "free" spherulites: in this sample an important $c$ value was found as well.

When, for the polystyrene samples, the various values of $(\Delta n)_{1},(\Delta n)_{2}$ and $(\Delta n)_{\text {sf }}$ (see table VIII) and $\left\langle\eta^{2}\right\rangle^{\frac{1}{2}}, \delta$ and $\left(\alpha_{\mathrm{r}}-\alpha_{\mathrm{t}}\right)$ are compared, the following is obvious: $(\Delta n)_{1}$ and $\left\langle\eta^{2}\right\rangle^{\frac{1}{2}}$ decrease from ps1 to ps3; this can be explained, if the isotropic scattering is caused by the spherulites: then $(\Delta n)_{1}$ is the difference between the mean refractive indices of the spherulites and the medium, in which the spherulites are embedded. From ps1 to ps 3 the fraction of the volume, occupied by the spherulites, increases, and consequently the refractive index of the medium will gradually approach the refractive index of the spherulites. The result will be a decrease of $(\Delta n)_{1}$.

$(\Delta n)_{2}$ and $\delta$ obviously increase from ps1 to ps4; sample ps5, however, shows extremely small values. $\delta$ is the anisotropy, averaged over the whole sample, but, as only a fraction $f$ of the sample has been crystallized (i.e. occupied by spherulites), it is more relevant to compare $(\Delta n)_{2} / f$ or $\delta / f$ for the various samples. Table IX shows the values of $\delta / f$ for samples ps 1

Table IX

\begin{tabular}{|l|l|l|l|l|l|}
\hline sample & $\mathrm{ps} 1$ & $\mathrm{ps} 2$ & $\mathrm{ps} 3$ & $\mathrm{ps} 4$ & $\mathrm{ps5}$ \\
\hline$(\boldsymbol{\delta} / \mathrm{f}) \cdot 10^{3}$ & 19.4 & 22.0 & 9.3 & 6.2 & 14.0 \\
\hline $\mathrm{R}_{\mathrm{sf}}[\mu]$ & 0.65 & 0.88 & 1.02 & 6.27 & 6.30 \\
\hline
\end{tabular}

through ps5, $f$ was calculated from equation (3.1.4): for $N$ and $v_{\mathrm{r}}$ the values, found in Chapter VI (table IV), were taken, and the approximation $V_{\mathrm{o}}=V_{\mathrm{s}}$ was used. Excluding ps5 a decrease of $\delta / f$ with increasing radius of the spherulites is observed. 
This could be an indication that the crystallinity within the spherulites is decreasing with the radius; the crystallinity is maximal at the centre of the spherulites. The value for ps5, which is too large in this connection, cannot be explained. The course of $(\Delta n)_{\text {sf }}$ or $\left(\alpha_{\mathrm{r}}-\alpha_{\mathrm{t}}\right)$ also favours this interpretation. It should be noted that in this case the crystallinity of the spherulitically arranged crystallites is involved whereas, considering $\delta / f$, the crystallinity of the non-spherulitically arranged ("random orientation"-) crystallites was dealt with.

The decrease of both kinds of crystallinities can be understood from the growth of the spherulite as observed by several investigators $12,22,36,37)$ : from the centre of the spherulite fibrillar crystals (spherulitic crystals) grow out in radial direction and branch (mainly forming "random orientation"- crystallites) at a later stage. It is imaginable (and in some cases it can be distinctly observed even under an optical microscope) that, in spite of the branching, the structure becomes more open as the spherulite grows, resulting in a decrease of the crystallinity. Only at a still later stage the open space will be filled by new crystalline material formed by secondary crystallization.

Summarizing, the anisotropic part of the random orientationscattering is caused on the one hand by the irregular centre of the spherulite (quantity $b$ ) and on the other hand by the branches of the fibrillar crystals and the "secondary" crystallites (quantity $c$ ); the perfectly spherulitic scattering originates from the radial fibrillar crystals.

The large decrease of the crystallinity with increasing radius of the spherulites, as suggested by the decrease of $\delta / f$ in table IX, does not agree with the starting point of the analysis of the crystallization measurements of Boon ${ }^{15)}$; a more extensive investigation, coupled with crystallinity measurements by the way of an independent method, would be useful as a verification of the light scattering results.

It should be mentioned that the values of $(\Delta n)_{\text {sf }}$ are in good correspondence with the birefringence of polystyrene spherulites $\left((\Delta n)_{\text {sf }}=32 \cdot 10^{-3}\right)$, measured by Picot, Weill and Benoit $\left.{ }^{38}\right)$, using the Becke line method under the microscope.

F or polypropylene the small value of $(\Delta n)_{1}$ for pp3, compared with pp1 and pp2, means a lower density with respect to the surroundings of the units, which cause the isotropic scattering. In connection with the structure of the samples this might signify a smaller total crystallinity of the spherulites for pp3 than for pp1 and pp2. The small value of $(\Delta n)_{2}$ for pp3 does indeed indicate that the crystallinity of the non-spherulitically crystalline part is considerably smaller than for pp1 and pp2. For all polypropylene samples $(\Delta n)_{\text {sf }}$ seems to be of about the same magnitude; for pp3, which contains smaller spherulites than pp1 and pp2, $(\Delta n)_{\text {sf }}$ might be somewhat larger. This could indicate a larger crystallinity of the spherulitical part for small spherulites, as already found in the case of polystyrene. 
The values of $(\Delta n)_{s f}$ are in good correspondence with the birefringences of type I $(\Delta n=0.002$ to 0.004$)$ and type II $(\Delta n=$ -0.0015 to -0.0025$)$ spherulites, as determined by Padden and Keith ${ }^{25}$, measuring path differences on a polarizing microscope with a Berek compensator (the determination of the sign of the birefringence is not possible by means of the light scattering method). All our polypropylene samples showed spherulites of the mixed type under the microscope.

The considerably smaller crystallinity values of the random orientation part for pp3 which follows from the $(\Delta n)_{1}$ and $(\Delta n)_{2}$ values, can be explained by assuming that the secondary, nonspherulitic, crystallization was suppressed because of the exceptionally deep quench to $-95^{\circ} \mathrm{C}$. As the spherulitic part hardly changes $\left((\Delta n)_{\text {sf }}\right.$ does not reveal important variations), new crystallites will be formed by the secondary crystallization. A gradual increase of the degree of perfection of spherulitical crystallites, as has sometimes been suggested ${ }^{14)}$, does not occur. The $X$-ray diagrams of pp2 and pp3 (shown in figure 35), clearly demonstrate that the secondary crystallization is better than the primary, spherulitic, crystallization: the much broader peaks for pp3 indicate that in this case the crystallites must be much smaller or much less regular. The calculated spacings prove that both kinds of crystallites have the $\alpha$-modification, as would indeed be expected for mixed-type spherulites. In table $\mathrm{X}$ the calculated spacings are compared with the values, which Turner Jones ${ }^{27)}$ has given for the $\alpha$-modification.

Table X

\begin{tabular}{|l|c|c|}
\hline pp2 & pp3 & $\begin{array}{c}\alpha \\
\text { (Turner Jones) }\end{array}$ \\
\hline $6.32 \AA$ & $6.30 \AA$ & $6.25 \AA$ \\
5.27 & 5.26 & 5.25 \\
4.80 & 4.80 & 4.75 \\
4.21 & - & 4.20 \\
4.08 & 4.10 & 4.05 \\
3.50 & - & 3.48 \\
3.14 & - & 3.13 \\
\hline
\end{tabular}

\section{CONCLUSIONS}

a. The light scattering by isotactic polystyrene as well as isotactic polypropylene can be described very well by a model, consisting of imperfect spherulites, which contain randomly correlated crystallites in addition to perfectly spherulitically arranged crystallites. 
64

b. With the aid of the above mentioned model it is possible to determine accurately the sizes of the spherulites from the scattering, often even in those cases where it is impossible by means of the current optical methods.

c. In accordance with published results from dilatometry the number of nuclei during the crystallization of polypropylene seems to be constant.

d. For polystyrene and perhaps for polypropylene too, the crystallinity of the spherulites appears to decrease with increasing radius.

e. The mean value of the birefringence of spherulites can be determined very well by means of the light scattering technique.

f. The secondary crystallization, in the case of polypropylene, is not spherulitical. It has to be ascribed to the formation of new crystallites and not to the perfection of already existing crystallites; the degree of perfection of the spherulites is not influenced by the secondary crystallization. 
FRESNEL CORRECTIONS AND THE EXACT DEFINITION OF THE VECTOR $O$ IN LIGHT SCATTERING THEORY

In light scattering theory one always needs to specify a vector $\underline{o}$, indicating which polarization direction is transmitted by the analyser. This appendix deals with the correct definition of the vector $\underline{o}$ and with the influence of the reflections of the scattered ray at the sample-air and analyser-air interfaces on the ultimate light scattering results, when a Polaroid (type HN22) analyser is used.

In the case of normal incidence of the light on to the Polaroid filter it is well known that the unit vector $o$ has to be perpendicular to the propagation direction of the light and parallel to the direction of the transmittance axis $\underline{t}_{\mathrm{a}}$ of the Polaroid filter. Now, according to Baxter ${ }^{39)}$, in the general case of oblique incidence the definition of the direction of $o$ should be as follows: $\underline{o}$ has to be perpendicular to the propagation direction of the ray (i.e. in light scattering theory, the direction of the scattered ray) and has to lie in a plane through $\underline{t}_{\mathrm{a}}$, perpendicular to the filter material (the analyser).*

If the direction of the transmittance axis of the analyser is fixed by the angle $\psi$ (that is the case in the parallel position of the polarizer and analyser axes; see figure 3 ) and the analyser plate is assumed to be perpendicular to the $X$-axis, $\underline{t}_{\mathrm{a}}$ is given by:

$$
\underline{t}_{\mathrm{a}}=-\sin \psi \cdot \underline{j}+\cos \psi \cdot \underline{k}
$$

where $j$ and $k$ are unit vectors in the directions of the $Y$ - and $Z$-axis respectively. The unit vector $S^{\prime}$ in the direction of the scattered beam (within the analyser filter) is specified by the angle of elevation, $\mu$ (see figure 3 ), and by $\theta_{\mathrm{p}}$ (the angle between the direction of the scattered beam within the Polaroid analyser and the $X$-axis; see also figure 37 ):

$$
\underline{s}^{\prime}=\cos \theta_{\mathrm{p}} \cdot \underline{i}+\sin \theta_{\mathrm{p}} \sin \mu \cdot \underline{j}+\sin \theta_{\mathrm{p}} \cos \mu \cdot \underline{k}
$$

$i$ is a unit vector in the $X$-direction.

$\overline{\text { From }}(\mathrm{a} .1 .1)$ and (a.1.2) one finds for the unit vector $\underline{o}$ within the Polaroid analyser:

$\underline{o}=\frac{1}{N_{1}}\left[-\sin \theta_{\mathrm{p}} \cos (\mu+\psi) \cdot \underline{i}-\cos \theta_{\mathrm{p}} \sin \psi \cdot \underline{j}+\cos \theta_{\mathrm{p}} \cos \psi \cdot \underline{k}\right]$

- Stein c.s. 7,8 ) erroneously assumed that o has to lie in the plane through the scattered ray and $\underline{t}_{a}$. The experiment to be described in this appendix proves the correct definition of $\underline{o}$, independently of Baxter's work, which was unknown to the author at that time. 
66

where

$$
N_{1}=\left[\cos ^{2} \theta_{p} \sin ^{2}(\mu+\psi)+\cos ^{2}(\mu+\psi)\right]^{\frac{1}{2}}
$$

An actual Polaroid filter can be quite generally thought to consist of a polarizing layer (numbered $k=0$, see figure 36 ) and $n$

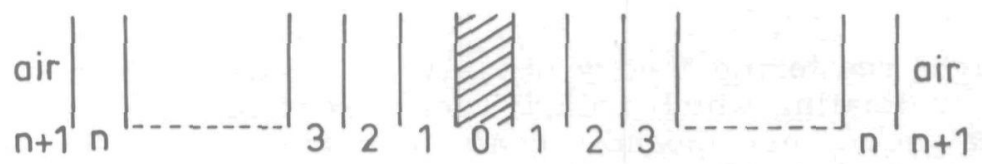

Figure 36. Layer structure of a Polaroid filter.

non-polarizing coatings (numbered $k=1$ to $n$ ). The scattered ray, leaving the analyser, will then be partly reflected at $n+1$ interfaces. Because of these reflections vector $\underline{o}$ will be changed in magnitude as well as in direction. In order to calculate this effect $o$ is divided into two vectors, one called $p_{1}$, in the plane through $\underline{s}^{\prime}$ and the $X$-axis, and the other $q_{1}$ perpendicular to this plane:

$\begin{aligned} \underline{p}_{1}=p_{1} \cdot \underline{p}=\left(N_{1}\right)^{-1} \cos (\mu+\psi)\left[-\sin \theta_{\mathrm{p}} \cdot \underline{i}\right. & +\cos \theta_{\mathrm{p}} \sin \mu \cdot \underline{j}+ \\ & \left.+\cos \theta_{\mathrm{p}} \cos \mu \cdot \underline{k}\right]\end{aligned}$

$\underline{q}_{1}=q_{1} \cdot \underline{q}=\left(N_{1}\right)^{-1} \cos \theta_{\mathrm{p}} \sin (\mu+\psi)[-\cos \mu \cdot \underline{j}+\sin \mu \cdot \underline{k}]$

where $p$ and $q$ are unit vectors in the directions of $\underline{p}_{1}$ and $q_{1}$ respectively. Upon leaving the Polaroid filter the vector $p$ is changed in direction because of refraction, so that outside the analyser the new vector $\underline{p}^{\prime}$ will be:

$$
\underline{p}^{\prime}=\left[-\sin \theta_{\mathrm{u}} \cdot \underline{i}+\cos \theta_{\mathrm{u}} \sin \mu \cdot \underline{j}+\cos \theta_{\mathrm{u}} \cos \mu \cdot \underline{k}\right]
$$

The vector $q$ remains the same:

$$
\underline{q}^{\prime}=\underline{q}=[-\cos \mu \cdot \underline{j}+\sin \mu \cdot \underline{k}]
$$

The magnitude of $\underline{p}_{1}$ and $\underline{q}_{1}$ is influenced by reflection, so that $\underline{o}$ will be changed into a new vector $\underline{o}_{0}^{\prime}$ outside the analyser filter:

$$
\underline{o}_{0}^{\prime}=\prod_{\mathrm{k}=0}^{\mathrm{n}}\left(1-r_{\mathrm{kp}}^{2}\right)^{\frac{1}{2}} p_{1} \cdot \underline{p}^{\prime}+\prod_{\mathrm{k}=0}^{\mathrm{n}}\left(1-r_{\mathrm{kq}}^{2}\right)^{\frac{1}{2}} q_{1} \cdot \underline{q}^{\prime} \quad \text { (a.1.9) }
$$

where

$$
r_{\mathrm{kp}}^{2}=\frac{\operatorname{tg}^{2}\left(\theta_{\mathrm{k}}-\theta_{\mathrm{k}+1}\right)}{\operatorname{tg}^{2}\left(\theta_{\mathrm{k}}+\theta_{\mathrm{k}+1}\right)}
$$




$$
r_{\mathrm{kq}}^{2}=\frac{\sin ^{2}\left(\theta_{\mathrm{k}}-\theta_{\mathrm{k}+1}\right)}{\sin ^{2}\left(\theta_{\mathrm{k}}+\theta_{\mathrm{k}+1}\right)}
$$

$\theta_{0}=\theta_{\mathrm{p}}$ and $\theta_{\mathrm{n}+1}=\theta_{\mathrm{u}}$.

Normalizing $\underline{o}_{0}^{f}$ one obtains the unit vector $\underline{o}_{o}$ outside the analyser:

where

$$
\underline{o}_{\mathrm{o}}=p_{\mathrm{o}} \cdot \underline{p}^{\prime}+q_{\mathrm{o}} \cdot \underline{q}^{\prime}
$$

$$
\begin{gathered}
p_{\mathrm{o}}=\left(N_{2}\right)^{-1} \cos (\mu+\psi) \\
q_{\mathrm{o}}=\left(N_{2}\right)^{-1} \cos \theta_{\mathrm{p}}^{* *} \sin (\mu+\psi)
\end{gathered}
$$

and

$$
\begin{gathered}
\cos \theta_{\mathrm{p}}^{*}=\cos \theta_{\mathrm{p}} \prod_{\mathrm{k}=0}^{\mathrm{n}} \frac{\left(1-r_{\mathrm{kq}}^{2}\right)^{\frac{1}{2}}}{\left(1-r_{\mathrm{kp}}^{2}\right)^{\frac{1}{2}}}=\cos \theta_{\mathrm{p}} \prod_{\mathrm{k}=0}^{\mathrm{n}} \cos \left(\theta_{\mathrm{k}}-\theta_{\mathrm{k}+1}\right) \\
N_{2}=\left[\cos ^{2} \theta_{\mathrm{p}}^{*} \sin ^{2}(\mu+\psi)+\cos ^{2}(\mu+\psi)\right]
\end{gathered}
$$

Now, a unit amplitude in the direction of $\underline{o}_{0}$ behind the analyser will correspond to a vector $\underline{o}_{s}^{\prime \prime}$ in the sample:

where

$$
\underline{o}_{\mathrm{s}}^{\prime \prime}=R_{\mathrm{p}} p_{\mathrm{o}} \cdot \underline{p}^{\prime \prime}+R_{\mathrm{q}} q_{\mathrm{o}} \cdot \underline{q}^{\prime \prime}
$$

$$
\begin{array}{cc}
\underline{p}^{\prime \prime}=[-\sin \theta \cdot \underline{i}+\cos \theta \sin \mu \cdot \underline{j}+\cos \theta \cos \mu \cdot \underline{k}] & (\text { a. 1. 18) } \\
\underline{q}^{\prime \prime}=\underline{q}^{\prime}=\underline{q}=[-\cos \mu \cdot \underline{j}+\sin \mu \cdot \underline{k}] & \text { (a.1.19) } \\
R_{\mathrm{p}}=\left[\left(1-r_{\mathrm{sp}}^{2}\right) \prod_{\mathrm{k}=0}^{\mathrm{n}}\left(1-r_{\mathrm{kp}}^{2}\right) \prod_{\mathrm{k}=0}^{\mathrm{n}}\left(1-r_{\mathrm{kp}}^{2}\right)\right]^{-\frac{1}{2}} & (\mathrm{a} \cdot 1.20) \\
R_{\mathrm{q}}=\left[\left(1-r_{\mathrm{sq}}^{2}\right) \prod_{\mathrm{k}=0}^{\mathrm{n}}\left(1-r_{\mathrm{kq}}^{2}\right) \prod_{\mathrm{k}=0}^{\mathrm{n}}\left(1-r_{\mathrm{kq}}^{2}\right)\right]^{-\frac{1}{2}} & (\text { a. } 1.21)
\end{array}
$$

The quantities $r_{\mathrm{kp}}^{2}$ and $r_{\mathrm{kq}}^{2}$ are given in (a.1.10) and (a.1.11) whereas

$$
\begin{aligned}
& r_{\mathrm{sp}}^{2}=\frac{\operatorname{tg}^{2}\left(\theta-\theta_{\mathrm{u}}\right)}{\operatorname{tg}^{2}\left(\theta+\theta_{\mathrm{u}}\right)} \\
& r_{\mathrm{sq}}^{2}=\frac{\sin ^{2}\left(\theta-\theta_{\mathrm{u}}\right)}{\sin ^{2}\left(\theta+\theta_{\mathrm{u}}\right)}
\end{aligned}
$$

Normalizing $\underline{o}_{\mathrm{s}}^{\prime \prime}$ gives the unit vector $\underline{o}_{\mathrm{s}}$ in the sample:

$$
\underline{o}_{\mathrm{s}}=\left(R_{\mathrm{p}}^{2} p_{\mathrm{o}}^{2}+R_{\mathrm{q}}^{2} q_{\mathrm{o}}^{2}\right)^{-\frac{1}{2}}\left(R_{\mathrm{p}} p_{\mathrm{o}} \cdot \underline{p}^{\prime \prime}+R_{\mathrm{q}} q_{\mathrm{o}} \cdot \underline{q}^{\prime \prime}\right)
$$


However, from this vector one sees only a fraction $R_{\mathrm{p}}^{-1}$ in the direction of $p^{\prime \prime}$ and a fraction $R_{\mathrm{q}}^{-1}$ in the direction of $q^{\prime \prime}$, so that the vector $\underline{O}_{\mathrm{s}}^{*}$, which must be used in theoretical light scattering calculations in order to give the measured intensities, will be given by:

$$
\underline{o}_{\mathrm{s}}^{2_{\mathrm{k}}}=\left(R_{\mathrm{p}}^{2} p_{\mathrm{o}}^{2}+R_{\mathrm{q}}^{2} q_{\mathrm{o}}^{2}\right)^{-\frac{1}{2}}\left(p_{\mathrm{o}} \cdot \underline{p}^{\prime \prime}+q_{\mathrm{o}} \cdot \underline{q}^{\prime \prime}\right)
$$

Thus, one obtains finally for the parallel position of polarizer and analyser (cp. Chapter II, figure 3) $\underline{O}_{s / /}^{* k}\left(=\underline{O}_{s}^{* k}\right)$ :

$$
\begin{aligned}
\underline{o}_{s / /}^{* *}=\left[R_{\mathrm{p}}^{2} \cos ^{2}(\mu+\psi)\right. & \left.+R_{\mathrm{q}}^{2} \cos ^{2} \theta_{\mathrm{p}}^{* \cdot} \sin ^{2}(\mu+\psi)\right]^{-\frac{1}{2}}\left(\cos (\mu+\psi) \cdot \underline{p}^{\prime \prime}+\right. \\
& \left.+\cos \theta_{\mathrm{p}}^{* *} \sin (\mu+\psi) \cdot \underline{q}^{\prime \prime}\right)
\end{aligned}
$$

For the crossed position of polarizer and analyser the vector $O^{* *}$ can be found from $(a .1 .26)$ by substituting $\psi$ by $\psi-90^{\circ}$ or $\bar{\psi}+90^{\circ}$ :

$$
\begin{aligned}
\underline{o}_{\mathrm{s}+}^{* *}=\left[R_{\mathrm{p}}^{2} \sin ^{2}(\mu+\psi)\right. & \left.+R_{\mathrm{q}}^{2} \cos ^{2} \theta_{\mathrm{p}}^{* k} \cos ^{2}(\mu+\psi)\right]^{-\frac{1}{2}}\left(\sin (\mu+\psi) \cdot \underline{p}^{\prime \prime}+\right. \\
& \left.+\cos \theta_{\mathrm{p}}^{* k} \cos (\mu+\psi) \cdot \underline{q}^{\prime \prime}\right)
\end{aligned}
$$

The above definition of $o$ was experimentally checked for a type HN22 Polaroid filter mounted between glass slides by measuring the transmittance direction. In order to accomplish this, the following experiment was set up (see figure 37): A Polaroid filter was put in such a position, that its normal made an angle

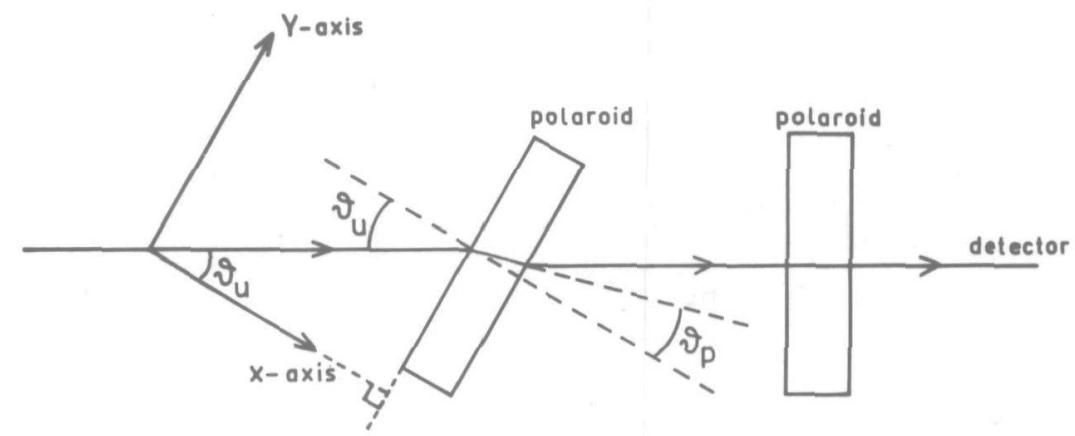

Figure 37. Schematic sketch of the experimental set-up to measure the transmittance direction of a Polaroid filter.

$\theta_{u}$ with a parallel beam of unpolarized light. The transmittance axis of the filter made an angle $\psi_{1}$ with the vertical. A second Polaroid filter, the transmittance axis of which made an angle $\psi_{2}$ with the vertical, was placed perpendicular to the light beam which issued from the first filter. Both filters were perpendicular to the horizontal plane. In all formulae therefore $\mu$ should be set 
equal to $90^{\circ}$. The intensity, measured by the detector behind the second Polaroid filter, will now be given by:

$$
I \sim\left(\underline{o}_{0} \cdot \underline{t}\right)^{2}
$$

where

$$
\underline{t}=\sin \psi_{2} \cdot \underline{p}^{\prime}+\cos \psi_{2} \cdot \underline{k}
$$

is the transmittance direction of the second Polaroid filter. The value of $\psi_{2}$ for which the intensity is minimal was then determined. This $\psi_{2}^{\mathrm{m}}$ is given by:

$$
-\sin \psi_{1} \sin \psi_{2}^{m}+\cos \theta_{\mathrm{p}}^{*} \cos \psi_{1} \cos \psi_{2}^{\mathrm{m}}=0
$$

or

$$
\operatorname{tg} \psi_{2}^{\mathrm{m}}=\cos \theta_{\mathrm{p}}^{* \mathrm{c}} \operatorname{ctg} \psi_{1}
$$

With the aid of $($ a. 1.31$)$ the value of $(\Delta \psi)_{\text {th }}=\psi_{2}^{\mathrm{m}}-\psi_{1}-90^{\circ}$ could be calculated for any given combination of $\theta_{u}$ and $\psi_{1}$, if the layer structure of the polaroid is known. In table XI the measured values of $\Delta \psi$ are compared for various combinations of $\theta_{u}$ and $\psi_{1}$ with the theoretical values of $(\Delta \psi)_{\text {th }}$, as calculated from $(a .1 .31)$ on the assumption that the polarizing layer as well as all protective layers have the refractive index $n=1.518$

\begin{tabular}{|c|c|c|c|c|c|c|}
\hline \multirow{2}{*}{$\theta_{\mathrm{u}}$} & \multicolumn{2}{|c|}{$\psi_{1}=30^{\circ}$} & \multicolumn{2}{|c|}{$\psi_{1}=50^{\circ}$} & \multicolumn{2}{|c|}{$\psi_{1}=70^{\circ}$} \\
\hline & $\Delta \psi$ & $(\Delta \psi)_{\text {th }}$ & $\Delta \psi$ & $(\Delta \psi)_{\text {th }}$ & $\Delta \psi$ & $(\Delta \psi)_{\text {th }}$ \\
\hline $20^{\circ}$ & $45^{\prime}$ & $50^{\prime}$ & $50^{\circ}$ & $56^{\prime}$ & $25^{\prime}$ & $37^{\prime}$ \\
\hline $30^{\circ}$ & $1^{\circ} 55^{\prime}$ & $1^{\circ} 54^{\prime}$ & $2^{\circ} 05^{\prime}$ & $2^{\circ} 06^{\prime}$ & $1^{\circ} 20^{\prime}$ & $1^{\mathrm{o}_{21}}$, \\
\hline $35^{\circ}$ & $2^{\mathrm{O}_{25}}$, & $2^{\circ} 36$, & $2^{\mathrm{O}}{ }_{50}$ & $2^{\circ} 51$. & $1^{\circ} 50^{\prime}$ & $1^{\circ} 49^{\prime}$ \\
\hline $40^{\circ}$ & $3^{\mathrm{O}_{2}} 25^{\prime}$ & $3^{\mathrm{O}} 24^{\prime}$ & $3^{\mathrm{o}_{4}}$. & $3^{\circ} 42^{\prime}$ & $2^{\circ} 30^{\prime}$ & $2^{\mathrm{O}} 20^{\prime}$ \\
\hline $45^{\circ}$ & $4^{0}$ & $4^{\mathrm{O}_{20}}$ & $4^{\mathrm{O}} 30^{\prime}$ & $4^{\circ} 39^{\prime}$ & $2^{\circ} 50^{\prime}$ & $2^{\mathrm{O}} 54^{\prime}$ \\
\hline $50^{\circ}$ & $5^{\circ} 10^{\prime}$ & $5^{\circ} 23^{\prime}$ & $5^{\circ} 35^{\prime}$ & $5^{\circ} 42^{\prime}$ & $3^{\circ} 30^{\prime}$ & $3^{\mathrm{O}} 31^{\prime}$ \\
\hline
\end{tabular}
of the glass mounts. A very good correspondence was found between theory and experiment.

Table XI

It should be noted that measurements on the same type Polaroid filter HN22, but laminated between cellulose acetate butyrate sheets did not conform to this theory. The "entrance" and "exit" directions of polarization were not the same for these filters. 
"ALGOL 60" - PROGRAMS

CORRECTION OF THE SCATTERING MEASUREMENTS

'begin' print('corr.light scatt.'');

'begin' 'integer' gamma,i; 'real' n,teta,t,tr,toac, a, d, tt, e, aa, c, rtetac, k, r, ra;

nul: $\quad$ read (gamma); 'if' gamma 'equal' 0 'then' read(i) 'else' 'go to' tien;

'if' i 'equal'o 'then' 'go to' exit;

$\operatorname{read}(\mathrm{n}, \mathrm{toac}, \mathrm{a}, \mathrm{d}, \mathrm{tt})$;

tien: $\quad$ read (teta,t,tr); print $\left(+k l o k,{ }^{\prime} '=k l o k '\right.$ ');

ra: $=(n-1)$ 'power' $2 /(n+1)$ 'power'2;

teta: =teta*3.1415926536/180;

aa: $=\sin ($ teta $) / n$;

'if' abs(aa) 'greater' 1 'then' 'go to' fout; c: $=\operatorname{sqrt}\left(1-a a^{\prime}\right.$ power'2);

'begin' 'real' $\mathrm{zz}, \mathrm{z}, \mathrm{r1}, \mathrm{r2}, \mathrm{r3} ; \mathrm{zz}:=\arcsin (\mathrm{aa})$;

$\mathrm{z}:=\mathrm{zz} * 180 / 3 \cdot 1415926536$;

$r a:=1-r a ; r:=1 / r a$;

$r 1:=t t *(c-1) ; r 2:=-t t / c ; r 3:=-t t ;$

$r 2:=\exp (r 2) ; r 3:=\exp (r 3) ; r 2:=r 2-r 3$;

$\mathrm{k}:=\mathrm{r} 1 / \mathrm{r} 2 ; \mathrm{r} 1:=\mathrm{n}^{\prime}$ power' $2 * \mathrm{k} * \mathrm{r} / \cos ($ teta);

rtetac $:=r 1 * t /($ toac*tr*a*d);

'end' ; print (' 'rtetac=' ', rtetac, ' 'tetaccent=' ',z);

negen: teta:=teta*180/3.1415926536;

print (' teta $=$ '", teta,"'

'i); 'go to' nul;

fout: $\operatorname{print}(\mathrm{aa}$, ''arcsin''); 'go to' negen;

exit:

'end' ;

'end' ; 
SEPARATION OF THE SPHERULITIC AND THE RANDOM ORIENTATION SCATTERING

'begin' print('sep. random and spher. scatt.' ');

'begin' 'real' $a, b, c, d, f, g, h, l, p, r, s, t, f p, g p, i 1, e$, csf, csg, i2, i3, i4, $\mathrm{kr}, \mathrm{kb} 2, \mathrm{vv}, \mathrm{hv}, \mathrm{m} 1, \mathrm{~m} 2, \mathrm{n} 1, \mathrm{n} 2$, b2, n, ivvt, ihht, ivht, ikrt, csp, csp2, rp2, rq2, teta, tetau, tetap, min, max, delta; $\operatorname{read}(n, \min$, delta,max);

'for' tetau:=min 'step' deltạ 'until' $\max$ ' do'

'begin' read(ivht,ikrt,ivvt,ihht); tetau:=tetau*3.1415926536/180;

$c:=\sin ($ tetau); $a:=c / n$;

teta: $=\arcsin (\mathrm{a}) ; \mathrm{b}:=\cos ($ teta) $; \mathrm{b} 2:=\mathrm{b} * \mathrm{~b}$;

$\mathrm{d}:=\mathrm{c} / 1.518 ;$ tetap $:=\arcsin (\mathrm{d}) ; \mathrm{e}:=\cos ($ tetap);

$\mathrm{f}:=$ tetau-teta; $\mathrm{g}:=$ tetau-tetap;

fp:=tetau+teta; $g p:=$ tetau+tetap;

$\operatorname{csf}:=\cos (f) ; \operatorname{csg}:=\cos (g)$;

$\operatorname{csp}:=e * \operatorname{csg} * \operatorname{csg} ; \operatorname{csp} 2:=\operatorname{csp} * \operatorname{csp}$;

$\mathrm{m} 1:=(\tan (\mathrm{f}) / \tan (\mathrm{fp}))$ 'power' $2 ; \mathrm{m} 1:=1-\mathrm{m} 1$;

$m 2:=(\tan (g) / \tan (g p)) '$ power' $2 ; m 2:=1-m 2$;

$r p 2:=(m 1 * m 2 * m 2) ; r p 2:=1 / r p 2$;

$n 1:=(\sin (f) / \sin (f p))^{\prime}$ power' $2 ; n 1:=1-n 1$;

$n 2:=(\sin (g) / \sin (g p))$ 'power' $2 ; n 2:=1-n 2$;

$r q 2:=(n 1 * n 2 * n 2) ; r q 2:=1 / r q 2$;

i1:=ivvt*rq2; i2:=ihht*rp2;

i3: $=2 *(r p 2+r q 2 * \operatorname{csp} 2) * i k r t ; i 4:=r q 2 * i v h t ;$

$1:=(\mathrm{b}-\mathrm{csp}) ; \mathrm{h}:=\cos ($ teta $/ 2) ; \mathrm{h}:=\mathrm{h} * \mathrm{~h}$;

$\mathrm{p}:=i 2-i 4-\mathrm{b} 2 *(i 1-i 4)$;

$r:=(i 3-2 * i 4 *(1+\operatorname{csp} 2)) * b 2$

$-(i 2-i 4) * 1$ 'power'2;

$\mathrm{s}:=(r-p * \operatorname{csp} * 1) /\left(h^{\prime}\right.$ power' $\left.2 * \operatorname{csp} * b\right)$;

$t:=(p * \operatorname{csp} *(2 * b-\operatorname{csp})-r) /(2 * h * \operatorname{csp} * b)$;

$\mathrm{kb2}:=t^{\prime}$ power' $2 / \mathrm{s}$; vv:=i1-kb2 ; hv:=i4; $\mathrm{kr}:=\mathrm{vv}-4 / 3 * \mathrm{hv} ; \mathrm{c}:=\sin ($ teta $/ 2)$ 'power' 2 ; print ( 1

$$
\begin{aligned}
& k a 2={ }^{\prime} \text { ', s, ' ' } \quad v v={ }^{\prime} \text { ', vv, } \\
& \text { ' 'hv=' ', hv,' ' vv- }(4 / 3) h v=1 \text { ', } \mathrm{kr} \text {, } \\
& \text { ' } \mathrm{s}=\text { ' ', c); }
\end{aligned}
$$

tetau:=tetau*180/3.1415926536;

'end'; print( ' tetau=" ', tetau);

'end';

'end'; 
1. LORD RAYLEIGH, Proc. Roy.Soc., A90 (1914), 219.

2. R. GANS, Ann. Physik, 76 (1925), 29.

3. H.C.VAN DE HULST, Light Scattering by Small Particles, John Wiley and Sons, New York, 1964.

4. W. HELLER in Proceedings of the Interdisciplinary Conference on Electromagnetic Scattering, edited by M. Kerker (Pergamon Press, Oxford, 1963), pp. 101-120.

5. G. MIE, Ann. Physik, 25 (1908), 377.

6. R.S.STEIN, P. R. WILSON, J.Appl. Phys., 33 (1962), 1914.

7. R.S.STEIN, M. B. RHODES, J.Appl. Phys., 31 (1960), 1873.

8. R.S.STEIN, P.R. WILSON, The Scattering of Light by Anisotropic Spheres and Discs, O. N.R. Report No.35, Polymer Research Institute, University of Massachusetts, Amherst, Massachusetts, U.S.A. (25 Aug.1961).

9. see e.g. R.W.JAMES, The Optical Principles of the Diffraction of X-rays, The MacMillan Company, New York, 1948.

10. R.S.STEIN et al., Ann. N.Y. Acad.Sci., 83 (1959), 37.

11. M. GOLDSTEIN, J.Polymer Sci., 20 (1956), 413.

12. H. D. KEITH, F. J. PADDEN, J.Appl. Phys., 34 (1963), 2409.

13. M. AVRAMI, J. Chem. Phys., 7 (1939), 1303; 8 (1940), 212; $9(1941), 177$.

14. F.P. PRICE, Report No.66-C-256, General Electric Research and Development Centre, Schenectady, N.Y., Aug. 1966.

15. J.BOON, Kristallisatiekinetiek van Isotactisch Polystyreen, thesis, Delft, The Netherlands (1966).

16. J.ROHLEDER, H. A.STUART, Makromol. Chem., 41 (1960), 110 .

17. H. G. ZACHMANN, H.A.STUART, Makromol.Chem., 41 (1960), 131 .

18. R. BUCHDAHL, R. L. MILLER, S. NEWMAN, J. Polymer Sci., 36 (1959), 215.

19. S.HOSHINO et al., J.Polymer Sci., $A 3$ (1965), 3041.

20. I. H. HILliER, J.Polymer Sci., $A 3$ (1965), 3067.

21. F.P.PRICE, J.Polymer Sci., A3 (1965), 3079.

22. P.H.GEIL, Polymer Single Crystals, John Wiley and Sons, New York (1963).

23. H.D. KEITH, F.J. PADDEN, J. Appl. Phys. , 35 (1964), 1270.

24. J.N.HAY, J.Polymer Sci., A3 (1965), 433.

25. F. J. PADDEN, H.D. KEITH, J.Appl. Phys., 30 (1959), 1479.

26. H.D.KEITH et al., J.Appl. Phys. 30 (1959), 1485.

27. A. TURNER JONES, J.Z.AIZLEWOOD, D.R. BECHET, Makromol. Chem., 75 (1964), 134.

28. J.C.KARDOS, A.W.CHRISTIANSEN, E. BOER, J. Polymer Sci., A4 (1966), 747.

29. R.S.STEIN, J.J.KEANE, J.Polymer Sci. , 17 (1955), 21. 
30. A. E. M. KEIJZERS, J. J. VAN AARTSEN, W. PRINS, J. Appl. Phys., 36 (1965), 2874.

31. B. VON FALKAI, H.A.STUART, Kolloid-Z., 162 (1959), 138.

32. B. VON FALKAI, Makromol. Chem., 41 (1960), 86.

33. P. H.GEIL, Chem. Eng. News, Aug. $161965,72$.

34. F. J. PADDEN, H. D. KEITH, J.Appl. Phys., 37 (1966), 4013.

35. F. KHOURY, J.D. BARNES, Bull.Am. Phys. Soc , 11 (1966), 248.

36. H. D. KEITH, F. J. PADDEN, J. Polymer Sci. , 39 (1959), 101.

37. H.E. BUCHLEY, Crystal Growth, John Wiley and Sons, New York (1951).

38. C.PICOT, G. WEILL, H. BENOIT, as yet unpublished manuscript, C.R. M. , Strasbourg.

39. L. BAXTER, J. Opt. Soc. Am. , 46 (1956), 435.

40. P.DEBYE, A. M. BUECHE, J.Appl. Phys., 20 (1949), 518.

41. M. GOLDSTEIN, E.R. MICHALIK, J.Appl. Phys., 26 (1955), 1450 . 
In this thesis an investigation is reported into the usefulness of the light scattering technique as a means for obtaining information regarding the supermolecular ordering in crystalline polymers. On the basis of physically acceptable considerations a model has been formulated, for which theoretical light scattering calculations have been carried out. In this model the imperfect spherulitic aggregates of crystallites are considered to consist of perfect spherulites, in which are present a number of crystallites, the orientations of which are distance-correlated only ("random orientation correlation").

The calculations have revealed that a separation into a perfectly spherulitic and a random orientation- part can be effectuated through measurement of four different components of the scattering (the $V_{\mathrm{v}}, H_{\mathrm{h}}, V_{\mathrm{h}}$ and $K_{\mathrm{d}}$ components are used). Scattering experiments on isotactic polystyrene and isotactic polypropylene show that this separation can be achieved in practice too (see below).

A special light scattering photometer has been developed, enabling the quantitative measurement of the whole spatial scattering envelope with a high angular resolution down to $30^{\prime}$ deviation from the primary beam.

By means of relatively simple light scattering measurements information about the primary - spherulitic - crystallization process can be obtained. Such experiments performed on isotactic polystyrene have yielded radial growth rates of the spherulites of 0.044 and $0.16 \mathrm{\mu} / \mathrm{min}$ at $140^{\circ}$ and $160^{\circ} \mathrm{C}$ respectively. The total numbers of spherulites (nuclei) have been found to be $1.1 \cdot 10^{11}, 0.8 \cdot 10^{9}$ and $1.7 \cdot 10^{7} \mathrm{~cm}^{-3}$ at nucleation temperatures of $20^{\circ}, 98^{\circ}$ and $140^{\circ} \mathrm{C}$ respectively. The time dependency of the crystallization data suggests a constant number of nuclei during the crystallization or, at least, the formation of the greater part of the total number of nuclei within a relatively small time interval at the beginning of the crystallization.

More accurate quantitative measurements of the scattering and a more complex evaluation of the data are needed in order to obtain information about the morphology of crystalline polymers. Such light scattering measurements performed on isotactic polystyrene have yielded the mean radius of the spherulites, a density fluctuation correlation distance $(a)$, two orientation correlation distances ( $b$ and $c$ ), the mean refractive index fluctuation of the sample, and the mean birefringences of the perfectly spherulitic and of the non-spherulitic crystalline material within the spherulites. The radius of the spherulites and the correlation distances $a$ and $c$ seem to be interrelated. The correlation distance $b$, which is a constant (about $0.44 \mu$ ) independent of the spherulite size, appears to have its origin in the spherulitically irregular arrangement at the centre of the spherulites 
and $c$ originates from the irregularly disposed crystallites over the whole spherulite. The birefringence of the perfectly spherulitic as well as that of the non-spherulitic crystallites decreases with increasing spherulite size. This shows that the crystallinity within the spherulites diminishes from centre to surface.

Three isotactic polypropylene samples, quenched from the melt to $98^{\circ}, 0^{\circ}$ and $-95^{\circ} \mathrm{C}$ respectively, have also been extensively investigated. Here again, light scattering has revealed three correlation distances $a, b$ and $c$. The meaning of these correlation distances is the same as in the case of polystyrene $(b$ equals here about $0.39 \mu)$. From the small values of the mean refractive index fluctuation of the sample and the mean birefringence of the non-spherulitic crystallites for the deeply quenched sample $\left(-95^{\circ} \mathrm{C}\right)$ it follows that the crystallinity of the non-spherulitic part decreases with deeper quenching. The birefringences of the perfectly spherulitic parts of the various samples are about the same. It is concluded that the primary crystallization is mainly spherulitic and the secondary crystallization, which is suppressed in the case of a deep quench, is non-spherulitic. The secondary crystallization process thus leads only to new crystallites, but does not increase the degree of perfection of already existing spherulitic crystallites. Since the secondary crystallites are formed in a slower process, they have a more regular crystal structure than the primary crystallites; this has been conformed by X-ray diagrams. 


\section{SA MEN VAT T ING}

In dit proefschrift is nagegaan of de lichtverstrooiing een bruikbare techniek is om informatie over de supermoleculaire ordening in kristallijne polymeren te verkrijgen. Theoretische berekeningen van de lichtverstrooiing zijn uitgevoerd aan een fysisch aanvaardbaar model. In dit model wordt aangenomen dat de niet ideaal sferulitische kristalliet-aggregaten in polymeren bestaan uit ideale sferulieten met daarin aanwezig een aantal niet-sferulitisch gerangschikte kristallieten; de oriëntaties van deze kristallieten vertonen een bolsymmetrische correlatie ("random orientation correlation").

De berekeningen tonen aan dat voor dit model de totale verstrooiïng gescheiden kan worden in een ideaal sferulitisch en een "random orientation"-gedeelte, als vier verschillende componenten van de verstrooïing gemeten worden (b. v. de $V_{\mathrm{v}}, H_{\mathrm{h}}$, $V_{\mathrm{h}}$ en $K_{\mathrm{d}}$ componenten). Lichtverstrooïngsmetingen aan isotactisch polystyreen en isotactisch polypropeen laten zien dat deze scheiding ook in de praktijk tot stand kan worden gebracht.

Een lichtverstrooiingsapparaat met groot scheidend vermogen is ontwikkeld speciaal met het doel om het hele ruimtelijke verstrooiïngspatroon kwantitatief en tot zeer kleine hoeken (30') te kunnen meten.

Met behulp van betrekkelijk eenvoudige verstroolïngsmetingen kunnen inlichtingen over het primaire - sferulitische - kristallisatieproces worden verkregen. Uit dergelijke experimenten aan isotactisch polystyreen zijn radiële groeisnelheden van de sferulieten bepaald van 0,044 en $0,16 \mu / \mathrm{min}$ bij resp. $140^{\circ}$ en $160^{\circ} \mathrm{C}$. Het totale aantal sferulieten (kiemen) blijkt $1,1 \cdot 10^{11}, 0,8 \cdot 10^{9}$ en $1,7 \cdot 10^{7} \mathrm{~cm}^{-3}$ te zijn voor kiemvormingstemperaturen van resp. $20^{\circ}, 98^{\circ}$ en $140^{\circ} \mathrm{C}$. Het verloop van de kristallisatie met de tijd wijst op een constant aantal kiemen gedurende de kristallisatie of, in ieder geval, op de vorming van het grootste gedeelte van het totale aantal kiemen in een betrekkelijk kort tijdsbestek aan het begin van de kristallisatie.

Nauwkeuriger, kwantitatief meten van de verstrooiïng en een meer complexe verwerking van de meetresultaten zijn vereist ter verkrijging van inlichtingen over de morfologie van kristallijne polymeren. Dergelijke verstrooiïngsexperimenten aan isotactisch polystyreen geven de gemiddelde straal van de sferulieten, een correlatieafstand (a) voor de dichtheidsfluctuatie, twee oriëntatie-correlatieafstanden $(b$ en $c)$, de gemiddelde brekingsindex-fluctuatie van het preparaat, en de gemiddelde dubbele brekingen van het ideaal sferulitische en het niet-sferulitische kristallijne materiaal in de sferulieten. De straal van de sferulieten en de correlatieafstanden $a$ en $c$ lijken met elkaar in verband te staan. De correlatieafstand $b$, een constante (ca. $0,44 \mu$ ) die onafhankelijk van de afmeting van de sferulieten is, wordt in verband gebracht met het sferulitisch onregelmatig ge- 
rangschikte centrum van de sferuliet, en $c$ met de onregelmatig gerangschikte kristallieten over de hele sferuliet. De dubbele breking van zowel de ideaal sferulitische als de niet-sferulitische kristallieten neemt af met toenemende sferulietgrootte. Dit toont aan dat de kristalliniteit in de sferuliet afneemt van het centrum uit naar buiten.

Aan drie polypropeenpreparaten, afgeschrikt uit de smelt naar resp. $98^{\circ}, 0^{\circ}$ en $-95^{\circ} \mathrm{C}$, zijn ook uitgebreide verstrooiingsmetingen verricht. Ook hier levert de lichtverstrooiïng drie correlatieafstanden $a, b$ en $c$ op. De betekenis van deze correlatieafstanden is dezelfde als in het geval van polystyreen (hier is $b \approx 0,39$ $\mu$ ). Uit de kleine waarden van de gemiddelde brekingsindex-fluctuatie van het preparaat en de gemiddelde dubbele breking van niet-sferulitische kristallieten voor het diep afgeschrikte preparaat $\left(-95^{\circ} \mathrm{C}\right)$ volgt, dat de kristalliniteit van het niet-sferulitische gedeelte $\mathrm{k}$ leiner is naarmate het preparaat dieper is afgeschrikt. De dubbele breking van het ideaal sferulitische gedeelte is voor alle preparaten ongeveer even groot. De conclusie is, dat de primaire kristallisatie voornamelijk sferulitisch is en de secundaire kristallisatie, die onderdrukt wordt in het geval van een lage afschriktemperatuur, niet-sferulitisch. De graad van perfectie van de reeds bestaande sferulitische kristallieten wordt dus niet beïnvloed door de secundaire kristallisatie; alleen nieuwe kristallieten ontstaan tengevolge van dit proces. Daar het secundaire kristallisatieproces langzamer is, zullen de secundaire kristallieten een regelmatiger kristalstructuur hebben dan de primaire kristallieten; Röntgen-opnamen laten dit duidelijk zien. 
Op verzoek van de Senaat van de Technische Hogeschool volgt hier een kort levensbericht van de schrijver.

Anthony Egidius Maria Keijzers werd op 5 oktober 1937 te Deurne geboren. Hij genoot lager onderwijs aan de St. Willibrordusschool te Deurne. Van 1950 tot 1956 bezocht hij het Gymnasium Augustinianum te Eindhoven en behaalde het einddiploma gymnasium- $\beta$. Daarna studeerde hij scheikunde aan de Technische Hogeschool te Delft en legde achtereenvolgens af in 1958 het propaedeutisch examen, in 1962 het kandidaatsexamen met lof en in 1964 het ingenieursexamen met lof.

Van 1963 tot 1964 was hij als assistent en daarna als wetenschappelijk medewerker verbonden aan de afdeling Fysische Chemie van de Technische Hogeschool te Delft, waar hem de gelegenheid werd gegeven aan het in dit proefschrift beschreven onderzoek te werken. 
De door Stein en medewerkers bij lichtverstrooïingsberekeningen gebruikte vector $O$, aangevende de richting van polarisatie van het licht dat door een Polaroid filter wordt doorgelaten, is niet juist.

R.S.Stein, M.B.Rhodes, J.Appl.Phys., 31 (1960), 1873.

Dit proefschrift, Appendix I.

II

De veronderstelling van Wallach, dat de assen van het "klaverblad-vier" verstrooïingspatroon van sferulieten te verdraaien zouden zijn door draaiing van het preparaat, getuigt van weinig inzicht in de theorie van lichtverstrooiing door sferulieten.

M.L.Wallach, J.Polymer Sci., C13 (1966), 90.

\section{III}

Verkorting van de werkweek betekent niet noodzakelijk een verlenging van de werkelijke vrije tijd.

\section{IV}

De methode van Stein c.s. om maximale gevoeligheid te verkrijgen bij hun apparaat voor het meten van dynamische dubbele breking is omslachtig en kan zeer vereenvoudigd worden door op de juiste wijze gebruik te maken van een $\frac{1}{4} \lambda$-plaatje en een verdraaibare analysator.

R.S.Stein, S.Onogi, D.A.Keedy, J.Polymer Sci., 57 (1962), 801.

$\mathrm{V}$

Metingen van dynamische dubbele breking met het apparaat van Stein c.s. kunnen veel nauwkeuriger geschieden als afgestapt wordt van de eis dat de verandering in de intensiteit van het doorgelaten licht recht evenredig moet zijn met de dynamische dubbele breking.

R.S.Stein, S. Onogi, D.A.Keedy, J.Polymer Sci., 57 (1962), 801.

\section{VI}

Op grond van theoretische berekeningen lijkt de bewering van Peterlin en Meinel, dat de lichtverstrooïng door éénkristal-suspensies een minimum vertoont als de brekingsindex van de suspensievloeistof gelijk is aan één van de karakteristieke brekingsindices van de dubbelbrekende éénkristallen, zeer twijfelachtig.

A.Peterlin, G.Meinel, J.Appl. Phys., 35 (1964), 3221. 
De beschrijving van de lichtverstrooiïng door afgeschrikt polypropeen zonder rekening te houden met de verstrooiing door sferulieten, zoals gegeven door Keijzers, van Aartsen en Prins, was succesvol tengevolge van een gelukkige keuze van preparaat.

A.E. M.Keijzers, J.J. van Aartsen, W.Prins, J.Appl.Phys., 36 (1965), 2874.

Dit proefschrift, Hoofdstuk VII.

\section{VIII}

Aan de manier van verwerking van lichtverstrooiïngsmetingen, toegepast door Debye en Bueche, teneinde de dichtheidscorrelatie-functie te verkrijgen, kleven ernstige theoretische bezwaren, die niet onderkend blijken te zijn door Wilkes.

P.Debye, A.M.Bueche, J.Appl.Phys. , 20 (1949), 518.

G.L. Wilkes, Ph.D. Thesis, State University of Forestry, Syracuse N.Y., U.S.A.

IX

Gezien de huidige fabricagetechnieken van schoenen gaat het argument, dat leren zolen gezonder zouden zijn dan zolen van ander materiaal, in het algemeen niet op.

Slagzin "Leren Zolen, Gezonder Zolen" e.d. van Ledercentrum Nederland (voorheen Stichting Zoolleer Informatie).

$\mathrm{X}$

Het systeem van heffing van wegenbelasting in Nederland is onbillijk en nodeloos kostbaar. 
Tekeningen en foto's: A. J. Dekker. 